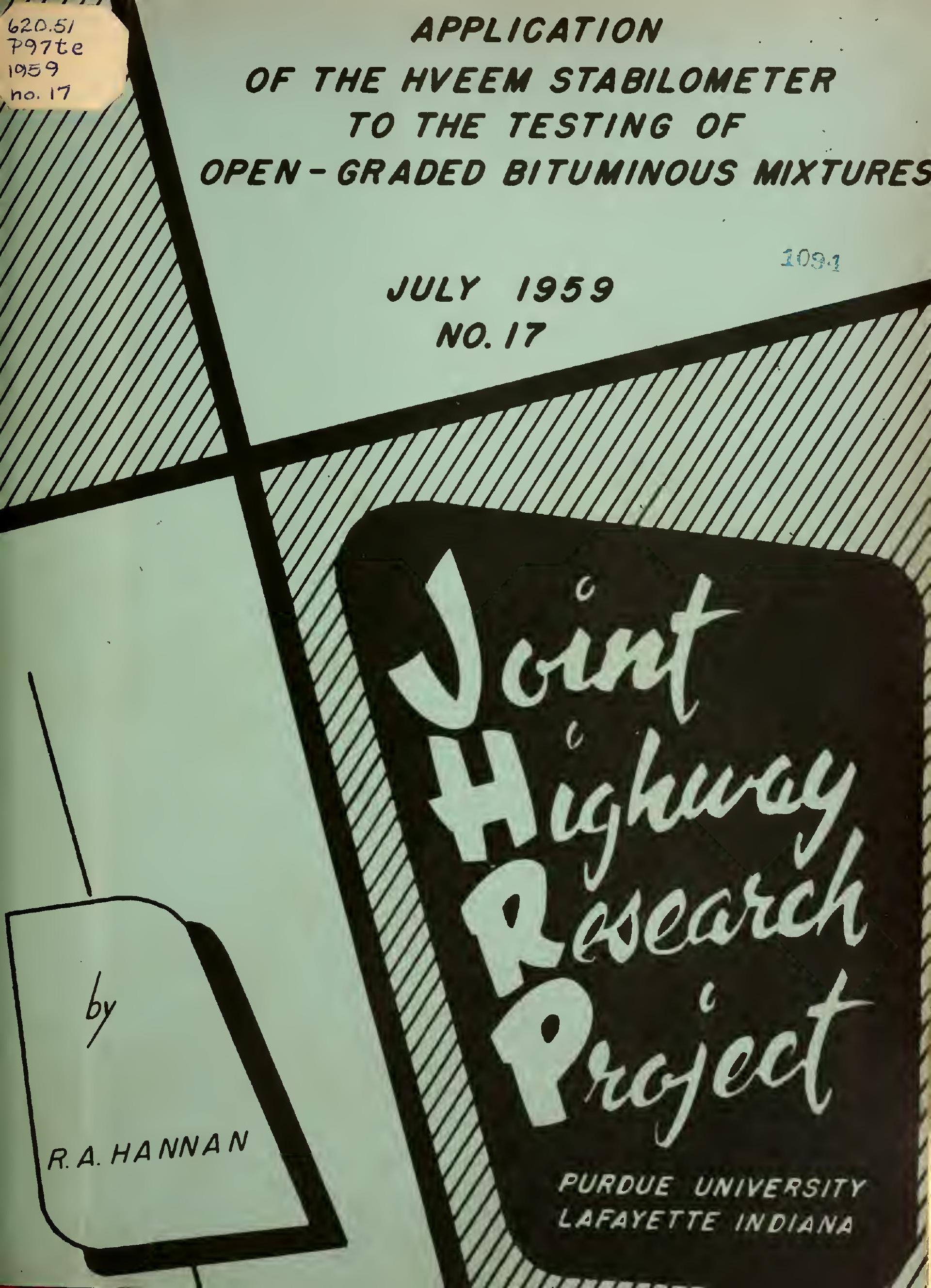



APPLICATION OF THE HVEEM STABTLOHETER TO THE TESTIIG OF OPEN-GRADED BITUMIINOUS ILIXIURES

TO:

FPOLI:
K. B. Woods, Director

Joint Highrey Research Project

H. Is Iifichael, Assistant Director Joint llightry Rosearch Project
JuIJ 1, 1959

File: $2-4-17$

Project: c-36-60

Attached is a final roport entitled, "Application of the Bveem Stabilometer to the Testing of Operi-Graded Bituminous ifixtures," by R. A. llannan, Graduate Assistant on our gtaff. MIr. Hannar utillzed this research reported as a portion of the requirements for the ISCE. The research ves performed under the direction of Professor H. H. Gootz.

lir. Hannan while performing the major portion of ihis research raceited a fellotship from the llational Sand and Gravel Association. Ho was employod by the Project for only the last few months of the research. Laboratory facilities, extra labor and some supplics vore also furnished by the Project.

The report is presonted for the record.

Respectfully subnitted,

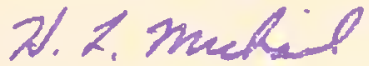

H. Is lifichael, Secretary

\section{HLis gt}

Attachrent

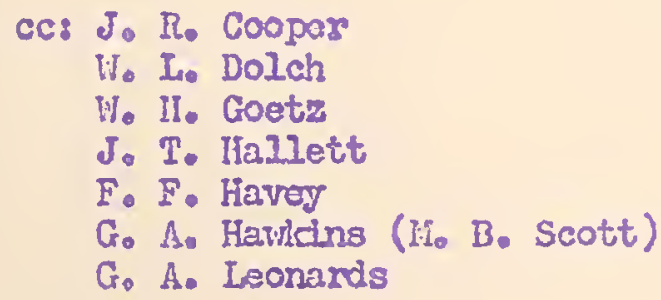

J. F. McInughlin

R. D. Hites

R. E. Mills

C. E. Vogelgesang

J. L. Vhling

J. E. Wilson

E. J. Yode? 
Digitized by the Internet Archive in 2011 with funding from

LYRASIS members and Sloan Foundation; Indiana Department of Transportation 
Final Report

APPLICATION OF THE HVEEM STABILOMETER

TO THE TESTING OF OPEN-GRADED BITUMINOUS MIXTURES

\section{By}

R. A. Hannan, Graduate Assistant

Joint Highway Research Project

File: $2-4-17$

Project: C-36-6Q

Purdue University

Lafayette, Indiana 


\section{ACKNOWLEDGMENTS}

Th18 study was conducted at Purdue University under a fellowship financed by the National Sand and Gravel Association. The author wishes to express his appreciation to this organlzation and to Mr. Stanton Walker, its Director of Engineering, for their valusble assistance.

The writer will always be indebted to Professor William H. Goetz, Research Engineer of the Joint Highway Research Project and Professor of Highway Engineering at Purdue University. 'It was Professor Goetz' constant guidance and support that made the completion of this study possible.

Special thanks are also due the Jolnt Highway Research Project, Purdue University, for financing the final portion of the study and providing the laboratory facilities, equipment, materlals, and parttime student help needed for the project. 


\section{TABLE OF CONTENTS}

Page

LIST OF TABLES. . . . . . . . . . . . . . . . . . y v

LIST OF FIGURES . . . . . . . . . . . . . . . . . . vil

ABSTRACT. . . . . . . . . . . . . . . . . IX

INTRODUCTION. . . . . . . . . . . . . . . . . 1

REV IEW OF LITERATURE . . . . . . . . . . . . . . 4

Operation of the Hveem Stabilometer . . . . . . . . . 4

Effect of Alr on Test Results... . . . . . . . . . . 5

Interpretation of Test Results. . . . . . . . . . . . 8

The Stab1lometer Specimen... . . . . . . . . . 10

PURPOSE AND SCOPE OF THE INTESTIGATION. . . . . . . . . 13

MATERIALS . . . . . . . . . . . . . . . 15

Mineral Aggregate .. . . . . . . . . . . . 15

Bituminous Material . . . . . . . . . . . . 15

PROCEDURE . . . . . . . . . . . . . . . . . . 17

Fabrication of Test Specimens . . . . . . . . . . . 17

Hveem Stabllometer Tests. . . . . . . . . . . . . . . 23

Evaluation of the Displacement Measurement . . . . . . 23

Influence of Vertical Stress and Specimen Deformation
on Hreem Stability. . . . . . . . . . . 29

Dats Reduction................ 30

RESULTS . . . . . . . . . . . . . . . . . . 33

Evaluation of the Displacement Measurement. . . . . . . 34

Hreem Stab1lity vs. Stabilometer Displacement. . . . . . 34

M1xture A . . . . . . . . . . . . . . . 34

Mixture B....................... 36

Mixture C................... 39 
TABLE OF CONTENTS ( continued)

Page

Stabilometer Displacement vs. Reciprocal of

Transmitted Pressure ........... 39

Mixture A ................ 41

Mixture B................. 41

Mixture C............... 45

Comparison of Measured and Theoretical Relationships. 45

Influence of Vertical Stress and Specimen Deformation

on Hveem Stability. . . . . . . . . . . . 48

Per Cent Strain versus Deviator Stress ........ 48

Mixture A . . . . . . . . . . . 49

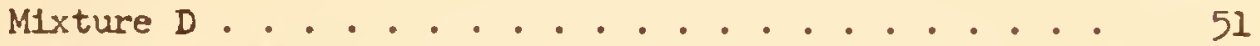

Stabilometer D1splacement versus Per Cent Strain at a

$5,000-1 b$. Load. . . . . . . . . . . . 51

Comparison of Results for Specimens with Coated and

Unaltered Ends. . . . . . . . . . . 53

SUMMARY OF RESULTS AND CONCLUSTONS .............. 56

SUGGESTIONS FOR FURTHER RESEARCH ................ 59

BIBLIOGRAPHY ......................... 61

APPENDIX A, APPARATUS AND DETAILED PROCEDURES. ...... 63

Preparation of Aggregate. . . . . . . . . 63

Preparation of Test Specimens ........... 64

Mixtures A and B................. 65

Mixture C. ............... . . 67

Mixture D. . . . . . . . . . . . 68

Hveem Stabliometer Tests. . . . . . . . . 70

APPENDIX B, DATA ........................ 73

APPENDIX C, STATISTICAL COMPARISON OF MEAN STABILITY VALUES

FOR SPECIMENS OF MIXTURE D, WITH AND WITHOUT COATED ENDS. . 


\section{LIST OF TABLES}

Table

Page

1. Physical Propert1es of Aggregates . . . . . . . 15

2. Physical Properties of Asphalt Cement. . . . . . . 16

3. Sieve Analyses for Aggregate Mixtures......... 18

4. Asphalt Contents for Various Aggregate Gradations. . 20

5. Stab1lometer Test Results, Mixture A,

In1tial Displecement $=2.00$, Unaltered Specimens . . 74

6. Stabilometer Test Results, Mixture A,

Inftial Displacement $=2.00$, Drilled Specimens.. .75

7. Stabilometer Test Results, Mixture A,

Initial Displacement $=1.00$, Coated Specimens. . . . 77

8. Stabilometer Test Results, Mxture A,

Init1al Displacement $=2.00$, Coated Specimens. ... 79

9. Stabilometer Test Results, Mixture A,

In1tial Displacement $=3.00$, Coated Specimens. . . .

10. Stabllometer Test Results, Mixture A,

Initial Displacement $=4.00$, Coated Specimens.....

11. Stabiloneter Test Results, Mixture A,

Initial Displacement $=5.00$, Coated Specimens. . . . 82

12. Stabllometer Test Results, Mixture B,

Initial Displacement $=1.00$, Coated Specimens.....

13. Stab1lometer Test Results, Mixture B,

InItial Displacement $=2.00$, Coated Specimens.....

14. Stabilometer Test Results, Mixture B,

Initial Displacement $=3.00$, Costed Specimens.....

15. Stab1lometer Test Results, Mixture B,

Initial Displacement $=4.00$, Coated Specimens..... 


\section{LIST OF TABLES (continued)}

Table

Page

16. Stabilometer Test Results, Mixture B,

Initisl Displacement $=5.00$, Costed Specimens. ... 87

17. Stabilometer Test Results, Mixture C,

Initial Displacement $=1.00$, Coated Specimens. . .

18. Stabilometer Test Results, Mixture C,

Initial Displacement $=2.00$, Coated Specimens. . .

19. Stabilometer Test Results, Mixture C,

Initial Displacement $=3.00$, Coated Specimens. . . 90

20. Stabilometer Test Results, Mixture C,

Initial Displacement $=4.00$, Coated Specimens....

21. Stabilometer Test Results, M1xture C,

Initial Displacement $=5.00$, Coated Specimens. . . 92

22. Stabilometer Test Results, Mixture D,

Initial Displacement $=2.00$, Coated Lateral Surfaces.

23. Stabilometer Test Results, Mixture $D$,

Intial Displacement $=2.00$, Coated Ends and

Lateral Surfaces . . . . . . . . . . . . 


\section{LIST OF FIGURES}

Figure

Page

1. Diagramatic Sketch of the Hveem Stabilometer. . .

2. Gradation Curves for Gradings A, B, C, D. .....

3. Mechanical Kneading Compactor . . . . . . .

4. Vibratory Compaction Apparatus. . . . . . . .

5. Typical Test Specimens .............

6. Hveem Stabilometer Test with Strain Measurements. .

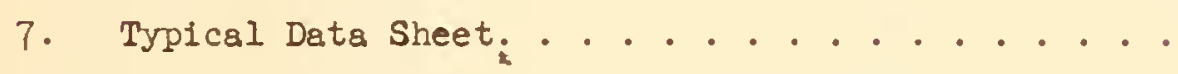

8. Hveem Stability vs. Fins I Displacement; Mixture A, Initial Displacement $=2.00$, Coated, Unsltered, Drilled Specimens.

9. Hveem Stab1lity vs. Final Displacement; Mixture A, Costed Specimens . . . . . . . .

10. Hveem Stability vs. Final Displacement;

M1xture B, Coated Specimens ...........

11. Hveem Stability vs. Final Displacement;

Mixture C, Costed Specimens ............

12. Reciprocal of Lateral Pressure vs. Final

Displacement; Mixture A, Initial Displacement

= 2.00, Costed, Unaltered Drilled Specimens ... .

13. Reciprocal of Lateral Pressure vs. Final

Displacement; Mixture A, Costed Specimens .....

14. Reciprocal of Lateral Pressure vs. Finsl

Displacement; Mixture B, Coated Specimens ....

15. Reciprocal of Lateral Pressure vs. Final

Displacement; Mixture C, Coated Specimens . . . . 


\section{LIST OF FIGURES (continued)}

Figure

16. Reciprocal of Lateral Pressure vs. Final

Displacement; Measured and Theoretical Curves. . . 47

17. Deviator Stress vs. Percent Strain;

Mixture A, Costed Specimens... . . . . . . 50

18. Deviator Stress vs. Percent Strain; Mixture D, Coated Lateral Surfaces, Coated Lateral Surfaces and Ends. . . . . . . . . . . . . . 52

19. Percent Strain vs. Final Displacement; Mixture A, Initial Displacement $=2.00$, Coated, Drilled, Unaltered Specimens ............ . . 54

20. Percent Strain vs. Final Displacement; Mixture A, Coated Specimens. . . . . . . . . . . 55 


\section{ABSTRACT}

Hannan, Robert A., M.S.C.E., Purdue University, August, 1959. APPLICATION OF THE HVEEM STABILOMETER TO THE TESTING OF OPEN-GRADED BITUMINOUS MIXTURES. Major Professor, William H. Goetz.

This laboratory investigation was conducted with the purpose of determining the applicability of the Hveem Stabilameter to the testing of open-graded bituminous mixtures.

The study was divided into two major sections. The first of these investigated the validity of the stabilometer displacement messurement when applied to open-graded specimens having large surface alr volds. The second portion of the study had two specific purposes: (I) to Investigate the stress-strain characteristics of open-graded mixtures tested in the Hveem Stabilometer and (2) to determine whether surface volds on the ends of Stabilometer test specimens influenced Hveem stability values.

To check the validity of the displacement measurement, Stabilometer tests were conducted over a wide range of displacement values for duplicate specimens molded from three different mixtures. Displacement readings were varied by altering the surfsces of test specimens and by adjusting the quantity of air inside the stabilometer oil chamber.

In studying the stress-strain characteristics of open-graded mixes, Stabilometer values and specimen deformation readings were obtained for two mixtures. The first of these open-type mixes was 
well-graded, but the second was essentially "one-sized" in gradation.

Results of this investigation showed that the finsl displacement value, when substituted into the Hveem stability equation, did not compensate for the varlations in lateral pressure caused by large changes (one or more turns) in the final displacement messurement.

Stress-strsin relationships for the well-graded, open-type mixture Indicsted that the quantity of strain permitted a Stabilometer test specimen conformed closely with the amount of strain developed st the maximum shearing strength of a rational triaxial test specimen subjected to confining pressures similar to those present in a Stabilometer test.

Strain measurements recorded for Stabilometer specimens of the one-sized mixture used in this study were much lower than those obtained at the peak value of shearing resistance for triaxisl test specimens of the same mixture and for similar confining pressures.

Surface air volds on the ends of Stabilometer test specimens had a small effect on test results. When these volds were f1lled, Hveem stability values were not $s$ gafficantly higher, but the reproducibility of test results was greatly improved by costing test speclmens.

To improve the consistency of Stabilometer test results obtained from open-graded mixtures, certain modifications in the testing technique were suggested. These changes involved the filling of alr volds on the surface of test specimens and the admittance of an increased amount of air in the Stabllometer oll chamber during the callbration of the testing apparatus. 


\section{INTRODUCTION}

The stability of a bituminous pavement may be defined as the pavement's ablify to resist lateral deformation when subjected to normal traffic loads. Several laboratory tests are currently used for messuring the stability of bituminous paving mixtures. Among these, the Hveem stabilometer test is rapidly growing in popularity. Originated by Francis $\mathbb{N}$. Eveem of the Calffornia Division of Highways, this test has now been adopted by several other agencies, including the Indians State Highway Department.

Under Hveem's method of mix design, the Stabilometer is used in conjunction with the Hveem Cohesiometer. The Stabilometer is primarily a measure of that part of the specimen's resistance which is due to the friction developed between aggregate particles. The Cohesiometer test accounts for the $\mathrm{mix}$ 's tensile strength, or cohesion. Although the Cohesiometer is employed, the Stabilometer does measure the total shearing resistance of the specimen. The short test specimen used in the Stabilometer tends to exaggerate the frictional component of the mix's strength, and the Coheslometer is added merely to obtain an indication of the specimen's cohesive resistance (9)*.

The Stabilometer has distinct advantages over other stability tests. It is quick and easy to mun, and may be used for fleld control purposes as well as for the laboratory design of bituminous mixes. 
The Stabilometer also affords the specimen a lateral confinement almilar to that provided the losded portion of an actual pavement. The main criticism of the test is that it presents an emplrical rather than s rationsl approsch to the design of mixtures. Th1s is true of all current design procedures, however, and unt1l more is les rned sbout the subject, the Stabilometer will continue to play an important role in the field of pavement design.

In this report, any well-graded mixture containing materis down to, and passing, the No. 200 mesh sleve is consldered to be "dense-graded." A mixture contalning no materlal finer than the No. 200 mesh is "open-graded." Despite the avallability of a vast amount of dsta correlating Stabilometer results with fleld performance, very little work has been done with open-graded mlxtures. Concerning this, The Asphalt Institute (21) states, "To date, the Aveem Method has been used principsily for the design of dense paving mixtures."

For several yesrs, the Indisna State Highway Department has had considerable success paving primary rosds with open-graded mixtures of bituminous concrete. In fact, many of these pavements have performed more satisfactorily than those made with dense mixtures. In order to obtain a more thorough analysis of open-graded mixtures, hovever, 8 laboratory test procedure is needed which will provide a reslistic stability messurement for this type of m1x. The purpose of this study, then, was to determine what modiflcations, if sny, are necesssry should the stabllometer be used to test open-graded mixes. Although time did not permit an extensive correlation between fleld performance and Stabllometer results for these mixes, it is felt that the study 
did bring out ifmitations in the present test procedure which until now, have not been given proper consideration. 


\section{REVIEW OF LITERATURE}

The preparstion of thls study necessitated the revlew of seversl technical papers desling with the design of bltuminous mixtures. When written, each of these had a valid contribution to make on the subject. Much of this work, however, does not directly pertsin to the phase of mix design encompassed by this report. Therefore, this review will include only that subject matter which is essentisl to 8 bssic understanding of the following topics:

1. Operations of the Hveem Stabilometer.

2. Effect of Alr on Test Results

3. Interpretation of Test Results

4. The Stsbilometer Specimen

\section{Operation of the Hveem Stabllometer}

Since Its inception by Hveem several yesrs ago, the Stabllometer has undergone many revisions. As a result, the test methods utilized by some agencles $(9,10)$ differ from the procedure sdvocated by Hreem. Moreover, Hveem's method of test for solls $(5,16,20)$ is quite unlike the test he uses for bituminous mixtures. All methods, however, have the same bssic spprosch, and the technique discussed here will be that currently specified for the testing of bituminous mixtures by Hveem snd the Californis Division of Highways $(6,20,21)$. A detalled description of Hveem's method is included in the portion of this 
report entitled "Procedure."

The Stabilometer test is essentially a "closed" system triaxial compression test based upon the "... conclusion that the ability to resist lateral displacement is a characteristic of stable biturinous pavements" (6). As shown in Figure 1, a cylindrical specimen is confined laterally by a rigld cell. The boundary between the confinting mixture and the specimen consists of a flexible rubber diaphragm. When loaded axially, the specimen is deformed outwards against the diaphragm, causing a reduction in the volume occupled by the confining fluids. As a result of this volume reduction, a pressure is crested in the system that provides the specimen with the lateral support characteristic of all triaxisl tests. The effects of this latersl confinement have been widely discussed in the literature $(3,4,6,12,13,14)$.

The magnitude of the transmitted pressure in the stabilometer can be interpreted $88 \mathrm{sn}$ inverse messure of the specimen's stability (6). For any given vertical load, a weak apecimen will give higher lateral pressures than a strong one because of the weak mixture's greater tendency to deform. Uaing this observation as the basis for his test, Hreem records the lateral pressure transmitted under a 400 psi vertical load to measure the stability of a bituminous mixture.

\section{Effect of Air on Test Results}

Since the transmitted lateral pressure depends upon the volume reduction of the confinlng fluids, air and oll, in the stabilometer system, the differing compressibilities of these fluids must be taken Into considerstion. For the temperature and pressure conditions of 


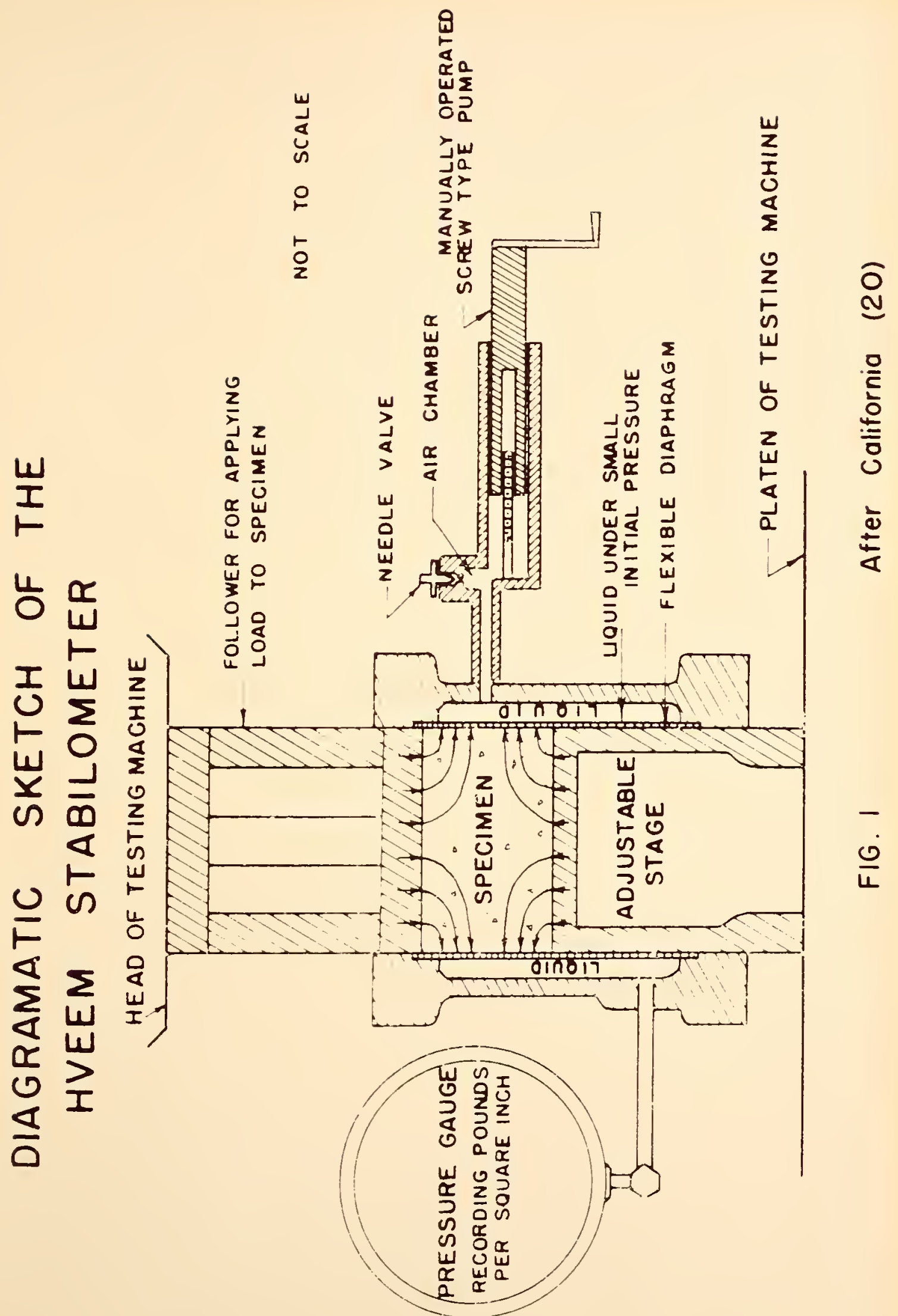


this test, the compressibility of oll is negligible. Air, however, is easily compressed and relatively large changes in volume can occur without appreclable changes in pressure. From this observation, sny volume reduction in the confining medium is evidently a reduction in the volume occupied by the air. Also, small increases in the $81 \mathrm{r}$ content of the system will permit grester specimen deformations without compenssting increases in lateral pressure.

Because of the critical influence of air content on test results, Hveem attempts to control this variable with a "displacement" messurement $(6,16)$. At the start of each test, the amount of alr inside the Stabilometer cell is calibrated using s dummy metsl specimen and the displacement pump shown in Figure 1. The correct sir content is indicated when two revolutions of the displacement pump will increase the lateral pressure reading from 5 to $100 \mathrm{psi}$. This messurement is termed the "Initial displacement" and actually messures the volume reduction created in the system when the lateral pressure is increased from 5 psi to $100 \mathrm{psi}$. An infial displacement of two turns was adopted by Hveem because the significance of test results was impaired when lower displacement values were used (6).

In addition to the air inside the Stabilometer cell, the air between the rubber diaphragn and the specimen will cause variations in the lateral pressure $(6,10,16)$, since during a test "... the specimen becomes in effect an integral part of the Stabilometer system..." (6). Recognizing this influence of the specimen's surface sir voids, Hveem incorporates a "total displacement" measurement. This reading, taken at the end of every test with the biturinous specimen 
held in place by a 1000-pound vertical load, accounts for the air in the surface voids of the specimen as well as the air inside the Stabilometer cell. On this subject, Hveem and Davis (6) stated:

While in a sense the displacement value is a correction for the test specimen itself, fundamentslly it is a correction for the entire Stabilometer system as air volds anywhere in the system will have the same effect on the instrument reading.

To the author's knowledge, Bveem's method of correcting for surface air volds is currently the only one in use. In 1947, McCarty (10) of the Texas Highway Department proposed a method of correction based on empirical relationships between Stabilometer gage pressure, finsl displacement, and the volume of specimen surface volds. This procedure did not gain general acceptance, however, and a later publication by McCarty (9) outlined Texas' Standard Method of Test which is essentially the same as the one used by Hreem.

\section{Interpretation of Test Results}

For the purpose of reporting test results, Bveem employs the following empirical formuls $(6,8,10,20,21)$ :

$$
S=\frac{22.2}{\frac{P_{h} D_{2}}{P_{v}-P_{b}}+0.222}
$$

where: $S=$ Hveem stability

$P_{v}=$ vertical pressure $=400$ psi

$P_{h}=$ lateral pressure corresponding to $P_{v}=400 \mathrm{ps} 1$

$D_{2}=$ total displacement on specimen

As implied above, the stability of a bituminous mixture tested 
In the Stabllometer is based upon the lateral pressure transmitted under a vertical pressure of $400 \mathrm{ps} 1$. Th1s vertical load lo sosumed to be "... ressombly representat1ve of the stresses developed by pneumatic tired truck traffic (recognizing the increase of static load due to so-called impact)"(18). Hveem and Davis (6) stated that the selection of this load is an attempt to account for the cumulative effects of traffic that occur with time. Since $100 \mathrm{psi} 18$ the usual maximum tire pressure developed on highways, McCarty (9) surmised that Hveem's cholce of the 400 psi tire pressure was made to introduce a safety factor of four with respect to static load.

The total displacement on the specimen 18 added to the stability equation such that an increase in displacement will lower the computed stability value. This, of course, is an sttempt to compensate for the decrease in lateral pressure which accompanies increased air contents. The equation established by Hveem for reporting the stability of bituminous mixtures is based solely on correlation data. An srbitrary stabillty scale was selected in which a value of 0 represents a liquid with no resistance and where 100 is a rigid solid that will not deform under load $(5,16,18)$. Experience has shown that bituminous mixes with stability numbers lower than 30 or 35 generally give unsatisfactory fleld performance $(6,18,20,21)$.

The avallable literature does not clearly describe Hveem's technique in establiahing the hyperbolic equation that 18 now used for computing the stabilities of bituminous mixes. McCarty (9) points out that even though the equations for solls and asphaltic mixtures differ, both can be reduced to the following relationship: 


$$
R(\text { or } S)=100\left(\frac{P_{v}-P_{h}}{P_{v}-P_{h}\left(1-\frac{D}{D_{0}}\right)}\right)
$$

where: $D=$ measured displacement

$D_{0}=0.222$ for bituminous mixes and 2.5 for 80118

In analyzing this equation, McCarty states:

The parameters $D$ and $D_{0}$ are functions of specimen deformation, called displacements, $D_{0}$ being a base value so chosen in relation to observed average values of $D$ as to make the index range correspond with the strength range for typical road materials in place.

Monfsmith (11) states that Hveem's stability equation was originalIy a linear relationshipbetween lateral pressure and stability, and that the present hyperbolic relationship is purely an srbitrary selection made to increase the range of stability values between good and poor mixes. With the original Iinear relationship, a large portion of the stability scale was occupied by unrealistic mixes of either very high or very low strength.

\section{The Stabliometer Specimen}

The test specimen used in the Stabilometer is a cylinder $2-1 / 2$ inches high and 4 inches in diameter. According to Hveem and Davis, "... the height of the specimen was selected to correspond to the typical thickness of bituminous surfacing commonly used in highway work..." (6). Although the size of the specimen does facilitate the testing of cored pavement sections, the low helght to diameter ratio makes a theoretical analysis of test results difficult. Triaxial-test studies conducted by Smith (17) Indicate that a helght to diameter 
ratio greater than 2.0 is desirable for the determination of cobesion, $C$, and angle of internsl friction, $\phi$. This ratio for a Stabllometer specimen is well below that flgure.

Also on the subject of specimen helght, McCarty (9) states:

Thus, while it is not correct to base the design of comparatively thick base courses on results from a Hveem Stabilometer test on a small Hveem specimen without applying a helght correction derived experimentally from theory, if possible, for the relatively great difference In structural strength, neither is it correct to apply uncorrected results from the test on a tall specimen in the design of thin bituminous-surface courses.

The preparation of realistic test specimens is essential to the correlation of laboratory and field properties of bituminous mixtures (6). Hveem 's method of fabricating Stabilometer specimens employs the mechanical compactor developed by the Triaxial Institute. This compactor was designed to mold a laboratory specimen possessing the density and stability corresponding to a pavement after one year of service $(7,22)$. In describlng the action of a kneading compactor, Endersby (4) states:

The material is fed into a rotating mold and kneaded into place by a tampling foot of the general shape of a slice of ple with rounded corners.

This foot descends with a rather slow motion in order to avoid impact and has a short "dwelling perlod" at the bottom of the descent in order to overcome viscosity. It operates under a constant load, the low polnt of the descent being automatically raised as the material rises in the mold. The specimen 18 flalshed off by a smoothing load when completed.

Although Californla uses the kneading compactor, it should be noted that Stabilometer specimens can be prepared by other means. For example, the Texas Hlghway Department has adopted a Gyratory Shear Method which also attempts to simulate fleld densities and stabilities 
$(9,15)$. The advantages and disadvantages of various compaction procedures is beyond the scope of this paper, however, snd will not be presented here. 


\section{PURPOSE AND SCOPE OF THE INVESTIGATION}

The overall purpose of this study was to determine the applicab1lity of the Bveem Stabilometer to the testing of open-graded bituminous mixtures. To attack this problem, the lnvestigation was divided into two major sections:

1. Because of the deficlency of fine material in open-graded mixtures, Stabilometer specimens made from this kind of mix will ususlly have surface air voids which are greater in both size and number than the volds present in dense-graded specimens. Consequently, Stabilometer tests on open-graded specimens will result in high displacement numbers whlch tend to vary widely from specimen to specimen. Because of this situation, the major portion of this study was designed to check the validity of the displacement measurement when applied to open-graded mixes.

2. The second part of this study was twofold in purpose:

a. As the void ratio of a granular mixture is increased, more strain is required to develop the mix's maximum shearing resistance. Since the Stabilometer limits the amount of strain which a specimen can undergo, one purpose was to investigate the stress-strain characteristics of open-graded specimens tested in the Hveem Stabilometer.

b. The final portion of this project was a short check to see if the size or the number of volds on the ends of the stabilometer specimen have an effect on test results. Although these rolds do not 
influence the displecement number, they do reduce the effective area over whtch the axlal load is applied and would appear to cause a greater unit stress in the vertical direction. 


\section{MATERIALS}

The materials used in this study were asphalt cenent, crushed limestone, uncrushed gravel and natural sand. A detalled description of these materials is presented in the following discussion.

\section{Mineral Aggregate}

Aggregates for the project were secured from two comercial plants. The crushed limestone was provided by the Obio and Indiana Stone Company of Greencastle, Indiana, and the uncrushed gravel and natural sand were obtained from the Western Indlana Sand and Gravel Company of Lafayette, Indlana. Table 1 shows the specific gravity and absorption values for each of these aggregates.

\section{TABLE 1}

Physical Properties of Aggregates

Aggregate

Crushed Limestone Uncrushed Gravel Natural Sand
Bulk Sp Gr

2.60

2.61

2.57
Apparent Sp Gr \& Absorption

2.75

2.68
1.13

2.00

1.56

\section{Bituminous Material}

The binder material in each of the four mixtures was a 60-70 penetration grade asphalt cement. This material was furnished by the Texas Company of Port Neches, Texas, and possessed the physical properties shown in Table 2 . 


\section{TABLE 2}

Physical Properties of Asphalt Cement

\section{Test}

Penetration - $1 / 100 \mathrm{~cm}$

$\left(77^{\circ} \mathrm{F}, 100 \mathrm{gm}, 5 \mathrm{sec}\right)$

Specific Gravity

$\left(77^{\circ} \mathrm{F} / 77^{\circ} \mathrm{F}\right)$

Ductility - cm

$\left(77^{\circ} \mathrm{F}, 5 \mathrm{~cm} / \mathrm{sec}\right)$

Solubility in $\mathrm{CCl}_{4}-\%$

\section{Results}

66

1.031

$200+$

99.92 


\section{PROCEDURE}

In collecting data for this investigation, the utilization of a large amount of laboratory apparatus and equipment led to a variety of techniques, some of whlch became quite involved. With this in mind, the writer feels that a detalled discussion of these procedures in this section would only tend to cloud their overall objectives. Hence, the technlques discussed here include only those needed to provide an understanding of the general approach to the problem. Appendix $A$, entitled "Apparatus and Detailed Procedures" has been added to supplement this information.

The procedures outlined in this section are grouped as follows:

1. Fabrication of Test Specimens

2. Hveem Stabilometer Tests

3. Data Reduction

\section{Fabrication of Teat Specimens}

Hveem Stabilometer specimens of four different aggregate gradations were formed in this study. For the sake of convenience, these mixtures have been denoted as A, B, C, and D. Each grading is tabulated in Table 3, and is graphically illustrated in Figure 2. The asphalt contents, by weight of mix, are listed in Table 4.

Grading A was an open-graded mixture in that it included no mineral aggregate finer than the No. 200 mesh sieve. It consisted of uncrushed 
TABLE 3

Sleve Anelyses for Aggregate Mixtures

(Percent by Weight)

\begin{tabular}{|l|c|c|c|c|c|}
\hline \multicolumn{2}{|c|}{ Sieve Size } & \multicolumn{4}{|c|}{ Percent Between } \\
\hline Passing & Retained & A & B & C & D \\
\hline-- & $3 / 4 "$ & 0 & 0 & 0 & 0 \\
$3 / 4 "$ & $1 / 2 "$ & 17.5 & 25 & 0 & 29.2 \\
$1 / 2 "$ & $3 / 8 "$ & 21.4 & 25 & 0 & 35.4 \\
$3 / 8 "$ & $\# 4$ & 21.4 & 6.5 & 16 & 35.4 \\
$\# 4$ & $\# 8$ & 4.6 & 27.5 & 18 & 0 \\
$\# 8$ & $\# 16$ & 10.5 & 3 & 14 & 0 \\
$\# 16$ & $\# 30$ & 10.4 & 5 & 12 & 0 \\
$\# 30$ & $\# 50$ & 10.3 & 5 & 14 & 0 \\
$\# 50$ & $\# 100$ & 3.6 & 2 & 10 & 0 \\
$\# 100$ & $\# 200$ & 0.3 & 1 & 8 & 0 \\
$\# 200$ & -12 & 0 & 0 & 8 & 0 \\
& & & & & \\
\hline
\end{tabular}




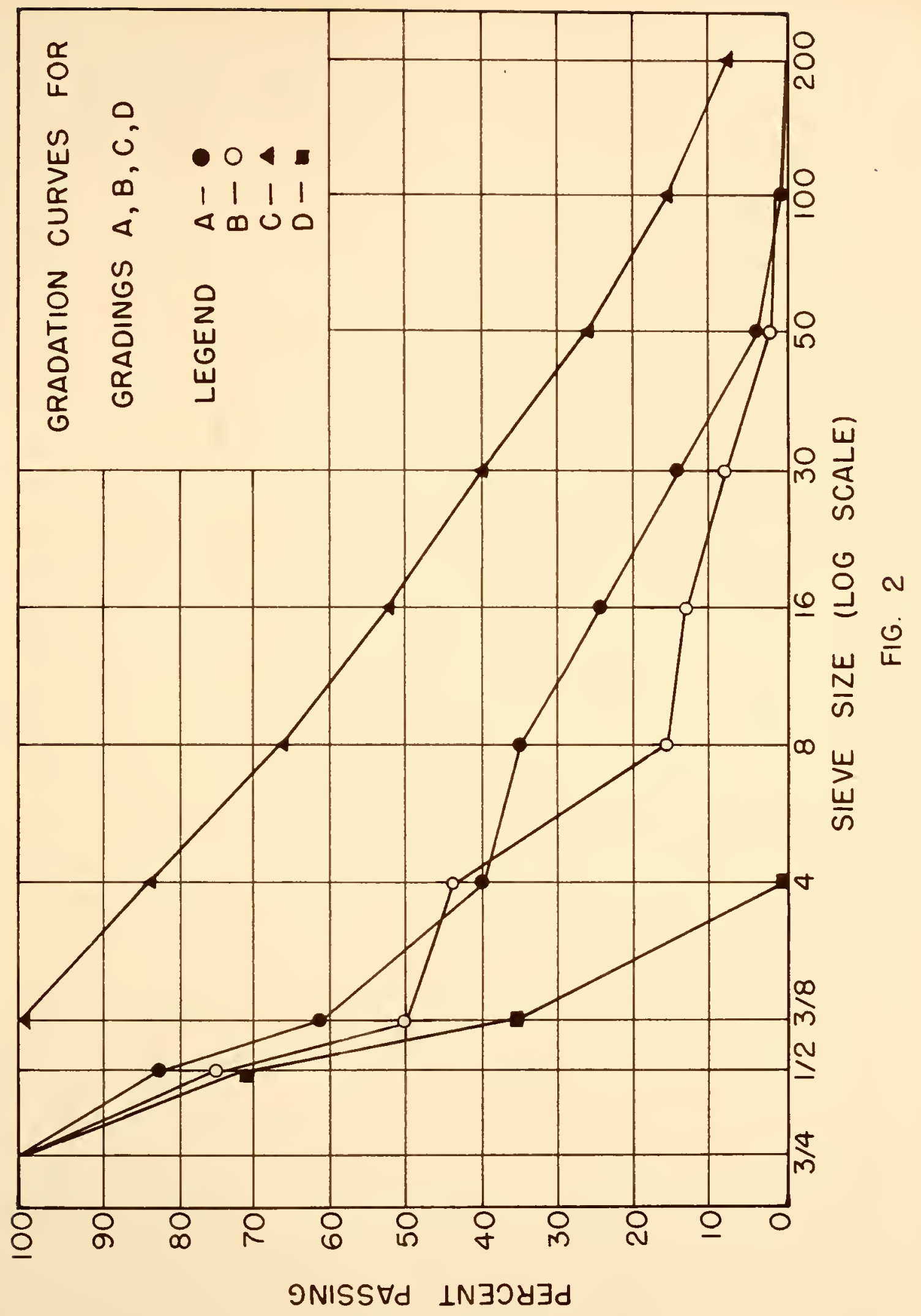


TABLE 4

Asphalt Contents for Various Aggregate Gradations

\begin{tabular}{|c|c|}
\hline Aggregate Gradation & $\begin{array}{c}\text { Aspholt Content Percent of } \\
\text { Total Weight of Mix }\end{array}$ \\
\hline A & 5.0 \\
B & 5.0 \\
C & 5.0 \\
D & 4.0 \\
\hline
\end{tabular}


gravel and natural sand, and was combined with $5 \%$ asphalt, by weight of mix. This mix also was used in the triaxial studies by Oppenlander (12), and by Oppenlander and Goetz $(13,14)$. Stabilometer specimens made from this mixture were molded by a double-plunger method of compection. After mixing the asphalt and aggregate in the desired proportions, a mix was placed in a heated mold in two equal layers. Each layer was rodded 40 times with a 5/8-inch diameter steel rod. The rodded mix was then subjected to a 2170 psi static load for a perlod of a minute. During the application of the static load, both the upper and lower loading pistons were free to move vertically 80 as to produce equal compactive efforts at each end of the specimen. After reaching room temperature, the specimens were extruded from the molds and readied for testing.

Grading B, another open-graded mixture, combined crushed limestone and natural sand with $5 \%$ asphalt. This gradation meets the specifications for Indiana's Type A, cosrse-textured surface mix (19). The method of compaction used here was identical to that used for mixture A.

Grading C was a very dense mixture selected from the U. S. Army, Corps of Engineers Specifications (2) for surface courses constructed with a 3/8-inch maximum size aggregate. Spectmens made from this mix consisted entirely of crushed limestone mixed with $5 \%$ asphalt cement. A newly-acquired mechanical kneading compactor (Figure 3) was used to form these speclmens and except for a few minor changes brought out in Appendix A, the procedure followed was that recomended by Callfornia (20)

Grading D was the "one-sized" mix used in the work by Oppenlander (12), and Oppenlander and Goetz (13, 14). For this Investigation, 


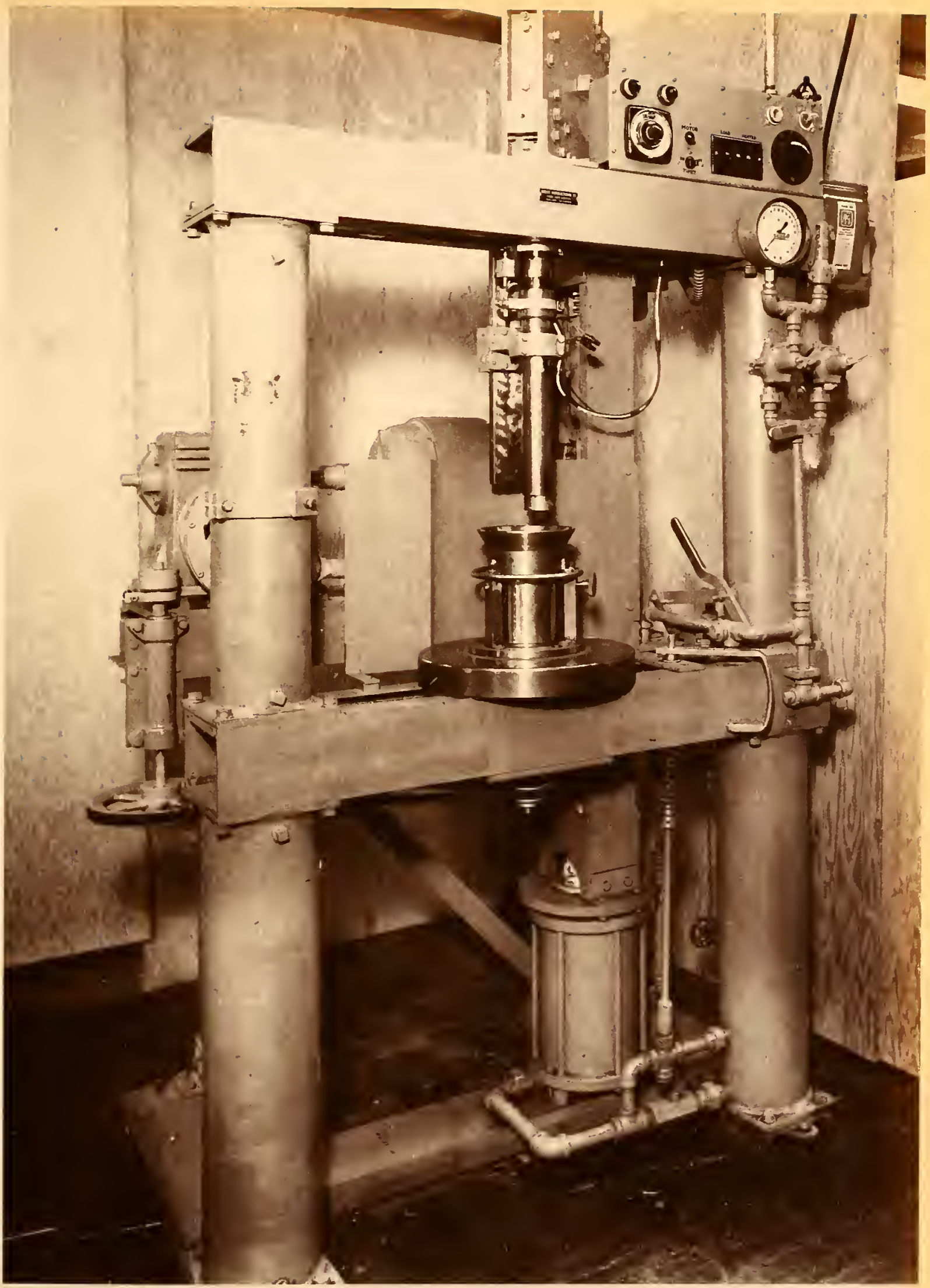

FIG. 3 MECHANICAL KNEADING COMPACTOR 
uncrushed gravel was mixed with $4 \%$ asphalt. Because of the lack of fine aggregate in this gradation, attempts to compact the mixture with the kneading compactor resulted in excessive aggregate fracture. For this reason, a combined vibratory-double plunger method of compaction was adopted. Under this procedure, the materisl was placed in the mold in two layers and rodded 40 times per layer with a 5/8-inch steel rod. The rodded mix was then placed in the compaction frame pictured in Figure 4. After applying a vertical seating load of 600 pounds, the vibrator was started and the losd raised to 12,600 pounds. Th1s load was held constant for one minute. Because of the nature of a specinen made from grading $D$, it was necessary to provide confinement for the molded speclmen in order to avold pre-test slumping.

\section{Eveem Stabilometer Tests}

As stated earlier, this investigation can be divided into two major divisions. The rirst part was set up to check the validity of the Aveem Stabilometer displacement measurement when obtained from specimens hoving surface air volds of considerable size and number. In this, the major portion of the study, Stabilometer tests were conducted on specimens molded from mixtures A, B, and C. The second section of the project was later added to investigate the influence of specimen deformation and effective vertical stress on the Hreem Stab1lity number. The discussion of the procedures used to conduct Stab1lometer tests in this study is subdivided into these two major divisions.

Evaluation of the D1splacement Measurement The displacement measurement 1s, in reality, an approximate 


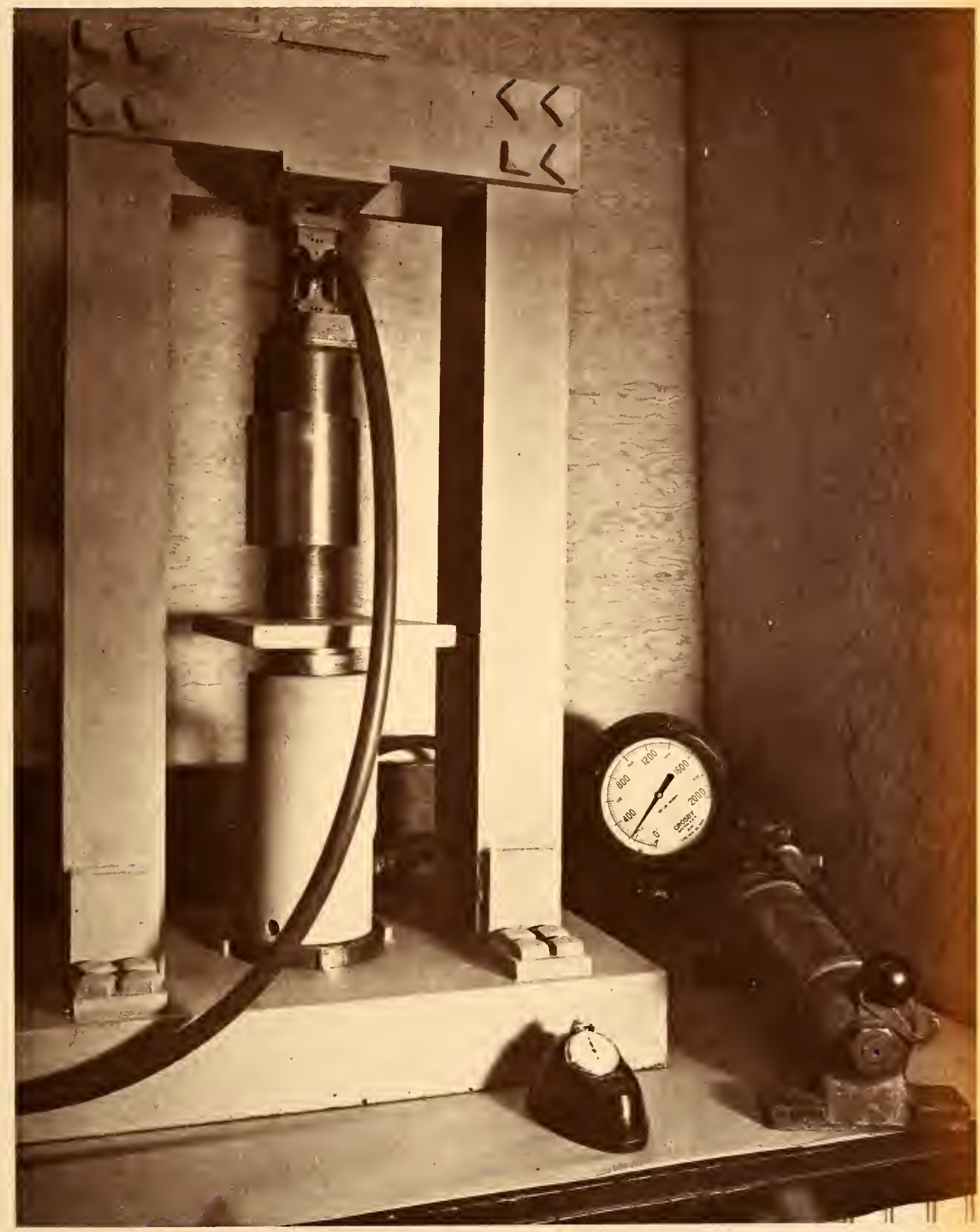

FIG. 4 VIBRATORY COMPACTION APPARATUS 
correction for the air which is compressed in the system of a Stab11ometer test. To determine the validity of this measurement for spec1mens with large air volds, then, the most loglcal approsch to the problem was to tert specimens of equal strength in the Stabllometer at a varlety of alr contents. If these tests gave Hveem Stabillty values of equal magnitude, the use of the displacement value would be ascertained correct for specimens with large surface volds.

In investigating the displacement number, two methods were used to vary the amount of air present in the system of the different Stabilometer tests. The first procedure was to control the surface characteristics of each specimen in one of the following three ways:

1. Alr volds on the lateral surface of the specimen were filled by costing the surface with a paste made from plaster of paris, portland cement, and water.

2. Holes were drilled on the surface of the specimen to introduce additional air into the system.

3. The surface was left unsltered so that the volds present during the test were those actually formed during the compaction of the specimen.

The specimens shown in Figure 5 typify those used in this phsse of the investigation.

The possibility of a reduction in the strength of a specimen due to the drilling of simulated surface volds limited the range of air contents which could be obtained by this method. As a result, this procedure was used only for a few specimens made from mixture $A$, and a second method was devised for controlling the air in the system of a 

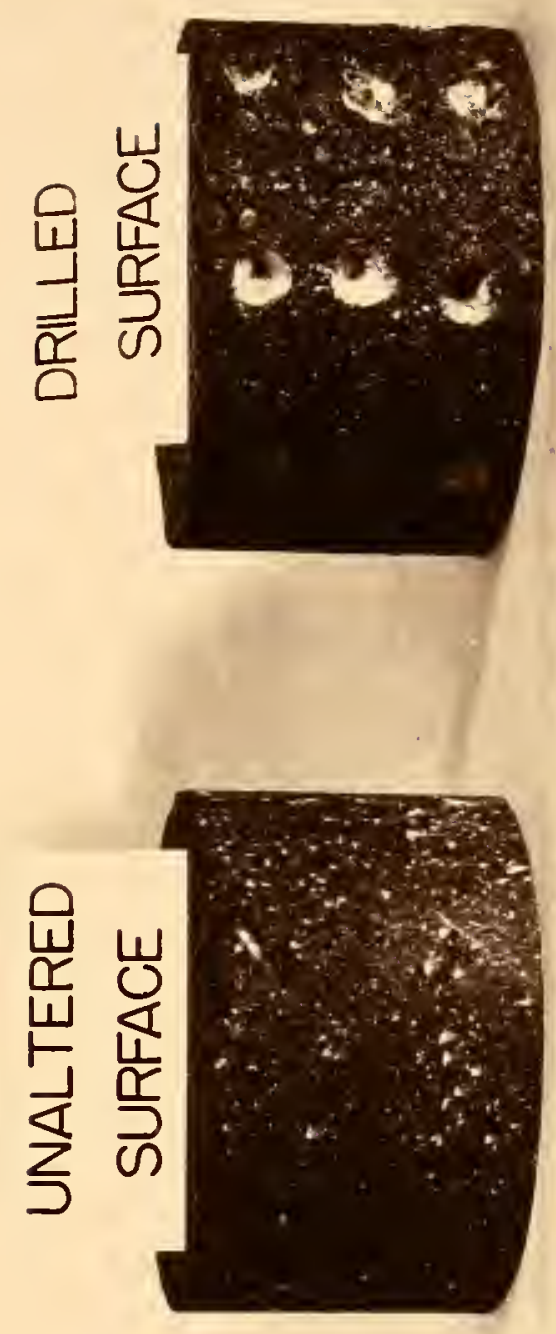

$n$
$\sum$
$\sum$
$u$
$w$
$n$
$\infty$

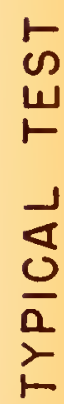

n

븐

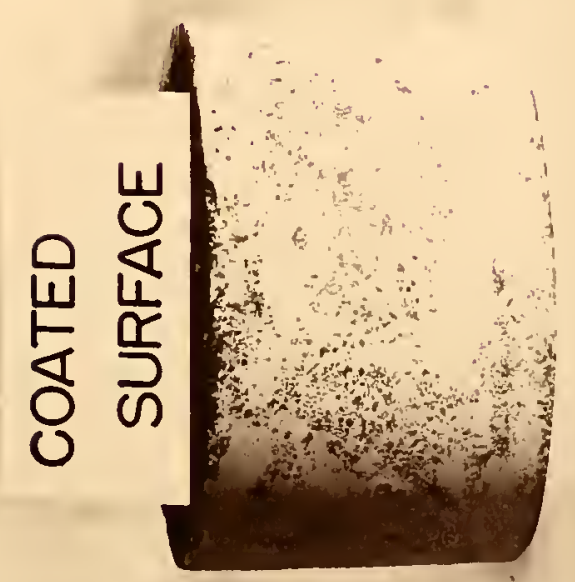


Stabllometer test. Under this second technique, all specimens were costed with the plaster-cement-water mixture and the air content was adjusted lnside the Stabilometer oll chamber rather than on the surface of the specimen. This procedure permitted a wider range of air contents and much better control over the displacement values than was possible with the original approach.

To vary the amount of air inside the oll chamber of the stabilometer, the instrument was calibrated at initial displacement readings of 1.00 , $2.00,3.00,4.00$, and 5.00. Several Bveem Stabllometer tests were then conducted at each of these displacements for mixtures $A, B$, and C.

To provlde better control over test conditions, all tests were performed at room temperature, rather than at the $140^{\circ} \mathrm{F}$ temperature specifled by Ireem. Also, because deformation measurements were recorded during tests on mixture A, \& 10,000 pound proving ring and a deflection dial were added to the apparatus. Stabllometer gage pressures and deformation readings were then taken at vertical load increments of 250 pounds. For tests on mixtures B and C, deformation values were not included in the test procedure, and lateral pressure readings were taken at vert1cal loads of $500,1000,2000,3000,4000,5000$, and 6000 pounds. In this instance, the proving ring was not used, but vertical loods were measured directly from the testing machine's calibrated beam.

F1gure 6 shows the complete assembly for a Hveem Stabilometer test in whlch deformation readings were taken. 


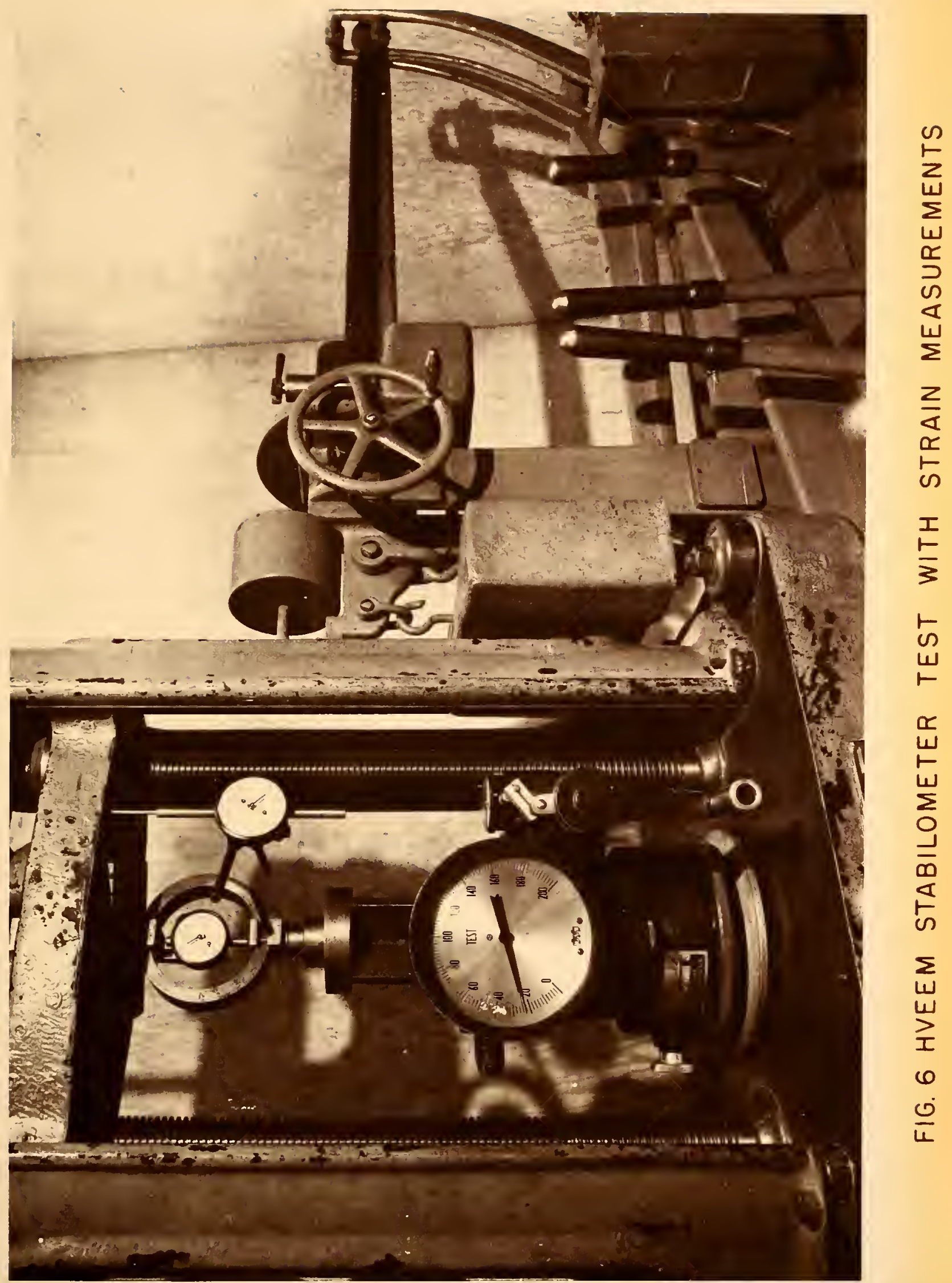


Influence of Vertical Stress and

Specimen Deformation on Bveem Stability

The second portion of the 1nvest1gation was approached w1th two objectives in mind. First, 1t was desired to investigate the stressstrain characteristica of Stabilometer test specimens. The second objective was designed to tell whether the presence of large volds on the ends of the test specimen caused a signtficant decrease in measured strength due to the reduced effective area over which the vertfcal load was applied.

Although strain values were already available for mixture $A$, it was felt that this information should be supplemented with data from specimens representing a more extreme type of open mix. Therefore, grading D, which is essentially a "one-sized" mixture, was added to the study. Since specimens made from mixture D contained a very large number of volds, this gradation also was used to determine the effect of surface volds on vertical stress.

It was earlier stated that the finsl displacement values for specimens of gradings A, B, and C were controlled by costing the specimens with a mixture of cement, plaster, and water. For grading D, this procedure was abandoned because of the additionsl strength provided the specimens when the mixture hardened. Instead, the volds were filled with a relatively stiff paste formed with water and limestone mineral filler. This method did not permit as good a control over the displacement as did the process of coating specimens with cement, but results were consldered more representative of the mixture's strength. 
Specimens of grading $D$ were tested in the Stabilometer in two series. One group had the entire surface of the specimen coated with mineral filler paste, and the second series was tested with only the lateral surface volds filled with paste. The purpose of this procedure was to determine whether surface air voids on the ends of the test specimen had an important effect on test results.

For all Stabilometer tests conducted on this mixture an initial displacement of 2.00 turns was used, specimens were tested at room temperatures, and deformation values were recorded.

\section{Data Reduction}

Floure 7 shows a dats sheet typical of those used for the Hveem Stabllometer tests in which deformation messurements were recorded. The deformation dial and lateral stress readings were entered into their respective columns at the time of testing.

The column headed "Corrected Deformstion" was added to the data sbeet to account for the errors in deformation readings due to the deflection of the proving ring with the application of the vertical load. This value was obtained by subtracting the load dial reading from the deformation dial reading. The strain was then computed by dividing the corrected deformation by the inftial specimen height.

As the vertical losiding of the test specimen progressed, the cross-sectionsl area of the specimen became greater. For this reason, computations for the vertical stress on a specimen required a correction for the surface area over whtch the load was applied. The method of computing the loaded area was based on the assumptions that the specimen did not undergo any volume change and that it remained cylindrical 
DATA SHEET

\section{Hveem Stabilometer Tests}

Test №. $2-A-5$

Initial $\mathrm{D}_{2} 2.00$

Specimen Ht. 2.484
Date Molded \&/15/58 Surface Coated

Date Tested 8/18/58 Final $D_{2} 2.25$

Test Temp. $77^{\circ} \mathrm{F}$ Stability 26.1

\begin{tabular}{|c|c|c|c|c|c|c|c|c|}
\hline $\begin{array}{l}\text { Load } \\
\text { Dial }\end{array}$ & $\begin{array}{l}\text { Vert. } \\
\text { Load }\end{array}$ & $\begin{array}{c}\text { Deform. } \\
\text { Dial }\end{array}$ & $\begin{array}{l}\text { Corr. } \\
\text { Deforn. }\end{array}$ & $\begin{array}{c}\% \\
\text { Strain }\end{array}$ & $\begin{array}{l}\text { Corr. } \\
\text { Ares }\end{array}$ & $\begin{array}{l}\text { Vert. } \\
\text { Stress }\end{array}$ & $\begin{array}{l}\text { Horiz. } \\
\text { Stress }\end{array}$ & $P_{\mathrm{v}}-\mathrm{P}_{\mathrm{h}}$ \\
\hline \hline 0 & 0 & 0 & 0 & 0 & 12.57 & 0 & 5.0 & -5 \\
\hline 12 & 250 & 22 & 21 & 0.85 & 12.68 & 19.7 & 7.0 & 12.7 \\
\hline 24 & 500 & 26 & 24 & 0.97 & 12.69 & 39.4 & 8.5 & 30.9 \\
\hline 36 & 750 & 31 & 27 & 1.09 & 12.71 & 59.0 & 11.0 & 48.0 \\
\hline 49 & 1000 & 37 & 32 & 1.29 & 12.73 & 78.6 & 14.0 & 14.2 \\
\hline 62 & 1250 & 42 & 36 & 1.45 & 12.75 & 98.0 & 17.0 & 81.0 \\
\hline 72 & 1500 & 47 & 40 & 1.61 & 12.78 & 117.4 & 20.0 & 97.4 \\
\hline 86 & 1750 & 52 & 43 & 1.73 & 12.79 & 136.8 & 24.0 & 112.8 \\
\hline 97 & 2000 & 56 & 46 & 1.85 & 12.81 & 156.1 & 28.0 & 128.1 \\
\hline 110 & 2250 & 60 & 49 & 1.97 & 12.82 & 175.5 & 32.0 & 143.5 \\
\hline 123 & 2500 & 64 & 52 & 2.09 & 12.84 & 194.7 & 36.5 & 158.2 \\
\hline 134 & 2750 & 68 & 54 & 2.17 & 12.85 & 214.0 & 41.0 & 173.0 \\
\hline 147 & 3000 & 72 & 57 & 2.30 & 12.87 & 233.1 & 46.0 & 187.1 \\
\hline 159 & 3250 & 75 & 59 & 2.38 & 12.88 & 252.3 & 50.5 & 201.8 \\
\hline 171 & 3500 & 78 & 61 & 2.46 & 12.89 & 271.5 & 55.0 & 216.5 \\
\hline 188 & 3750 & 82 & 64 & 2.58 & 12.90 & 290.7 & 60.0 & 230.7 \\
\hline 198 & 4000 & 85 & 65 & 2.62 & 12.91 & 309.8 & 66.0 & 243.8 \\
\hline 210 & 4250 & 88 & 67 & 2.70 & 12.92 & 329.0 & 70.5 & 258.5 \\
\hline 222 & 4500 & 90 & 68 & 274 & 12.92 & 348.3 & 16.5 & 271.8 \\
\hline 234 & 4750 & 93 & 70 & 2.82 & 12.93 & 367.4 & 82.0 & 285.4 \\
\hline 248 & 5000 & 96 & 71 & 2.86 & 12.94 & 386.4 & 87.5 & 298.9 \\
\hline 259 & 5250 & 99 & 73 & 2.94 & 12.95 & 405.4 & 930 & 312.4 \\
\hline 271 & 5500 & 102 & 75 & 3.02 & 12.96 & 424.4 & 98.0 & 326.4 \\
\hline 283 & 5750 & 105 & 77 & 3.10 & 12.97 & 443.3 & 105.0 & 338.3 \\
\hline 296 & 6000 & 108 & 78 & 3.14 & 12.97 & 462.6 & 111.0 & 351.6 \\
\hline & & & & & & & & \\
\hline
\end{tabular}

FIG. 7. TYPICAL DATA SHEET. 
throughout the test. Using these assumptions, then, the cross-sectional area at any point in the test was found by dividing the inftial ares of the specimen by a quantity equal to one minus the strain at the point in question. The vertical stress was computed as the vertical load divided by the corresponding corrected area. The difference between the vertical stress and the Stabilometer gage pressure was entered in the final column of the data sheet.

For each test, the Hveem stabllity number was computed from the final displacement number and the latersl pressure corresponding to a 5000 pound vertical losd.

To present the results of this study, a number of graphs were drawn. Straight line relstionships were obtalned by the method of least squares (1). For non-linesr plots, curves were drawn through average test values. 
RESULTS

The results of this investigation are presented in accordance with the following outline:

I. Evaluation of the displacement measurement.

A. Hreem stability vs. Stabllometer displacement.

1. Mixture A

2. Mixture $B$

3. Mixture C

B. Stabllometer displacement vs. reciprocal of transmitted pressure.

1. Mixture A

2. Mixture B

3. Mixture C

4. Comparison of measured and theoretical relationships.

II. Influence of vertical stress and specimen deformation on Hveem stability.

A. Per cent strain vs. deviator stress.

B. Stabilometer displacement vs. per cent strain at a 5000-1b. load.

III. Comparison of results for specimens with costed and unaltered ends.

All data which are graphically depicted in this section are also tabulated in Appendix B. 


\section{Evaluation of the Displacement Measurement}

In evaluating the validity of the displacement measurement for open-graded specimens, tests were conducted on duplicate specimens of the same mixture over a wide range of Stabilometer air contents. This was done for mixtures $A, B$, and C. Using the data from these tests, two methods of analysis were used to evsluate the displacement value. Each of these is discussed in this section.

Eveem Stability v8. Stabilometer D1splacement

For esch of mixtures A, B, and C, a graph was plotted with the computed Hveem stability as the ordinate and the final displacement as the abscissa. If the displacement measurement was a true correction for alr in the Stabilometer test system, this graph should have formed a horlzontal line for each mixture tested. The relationships obtained for mixtures $A, B$, and $C$ are reported individually in the following discussion.

Mixture A. Two methods were used to vary the final displacement measurements for tests on specimens made from mixture A. Under the first method, all tests were conducted at an inftial displacement of 2.00 turns, and the specimen surfaces were elther coated, drilled, or left unaltered. F1gure 8 shows the relationship between Hveem stability and final displacement for each of these tests. As the final displacement values were increased, the computed Aveem stability numbers did not remain constant, but decreased appreciably.

Although the slope of the line in Figure 8 suggests on inconsistency in the displacement measurement, the variation in stability 


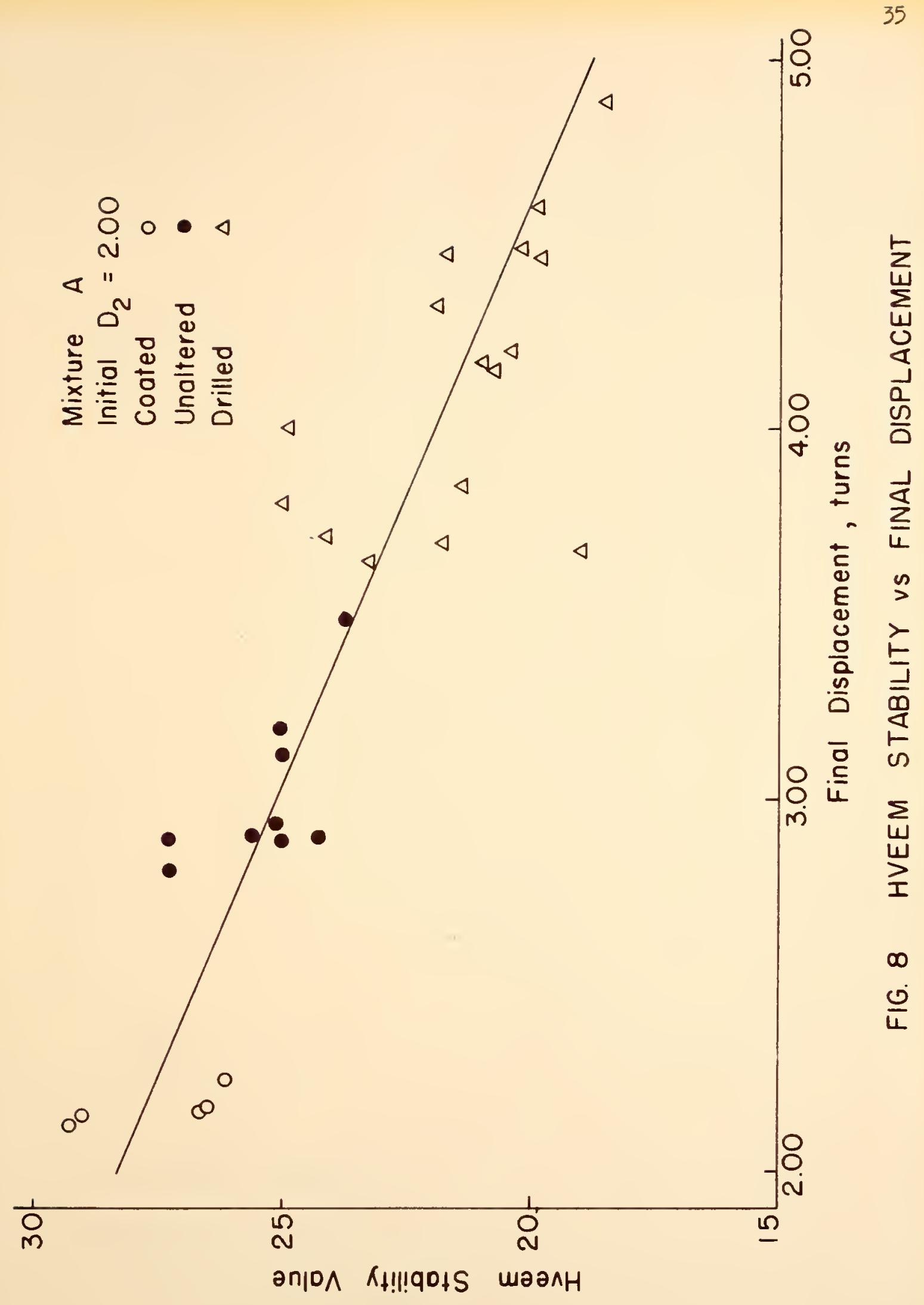


with increased air content might also be attributed to actusl chenges in the strength of specimens caused by the drilling and costing of lateral surfaces. For this reason, and also to obtain a greater range of displacement values, a second method was used to vary the amount of air in the test system. Under this procedure, only costed specimens were tested, and alr was adjusted inside the Stabilometer oil chamber to give infial displacement values ranging from 1.00 to 5.00 turns. Figure 9 show the relationship between Hveem stability and final displacement for coated specimens of mixture A. Here, as in Figure 8, increased displacement values resulted in reduced stability numbers. At high values of displacement, however, computed stability numbers were higher for the coated apecimens of Figure 9 then for the drilled specimens of Figure 8. This difference probably resulted from actual variations in strength due to the drilling and coating techniques. The variable of true atrength was eliminated for the relationship show in Figure 9, since only costed test specimens were used. Hence, the observed decrease in stability for these specimens must have been due to the increased air content of the system as indicated by the displacement messurement.

Mixture B. Stabilometer tests on costed apecimens made from mixture $B$ were conducted at infial displacements of $1.00,2.00,3.00$, 4.00 , and 5.00 turns. Figure 1018 a plot of final displacement vs. Eveem stability for specimens of mixture B. Test results for this mixture were quite erratic, but there was a dowaward trend in the value of stability number when displacement values were increased. The erratic 


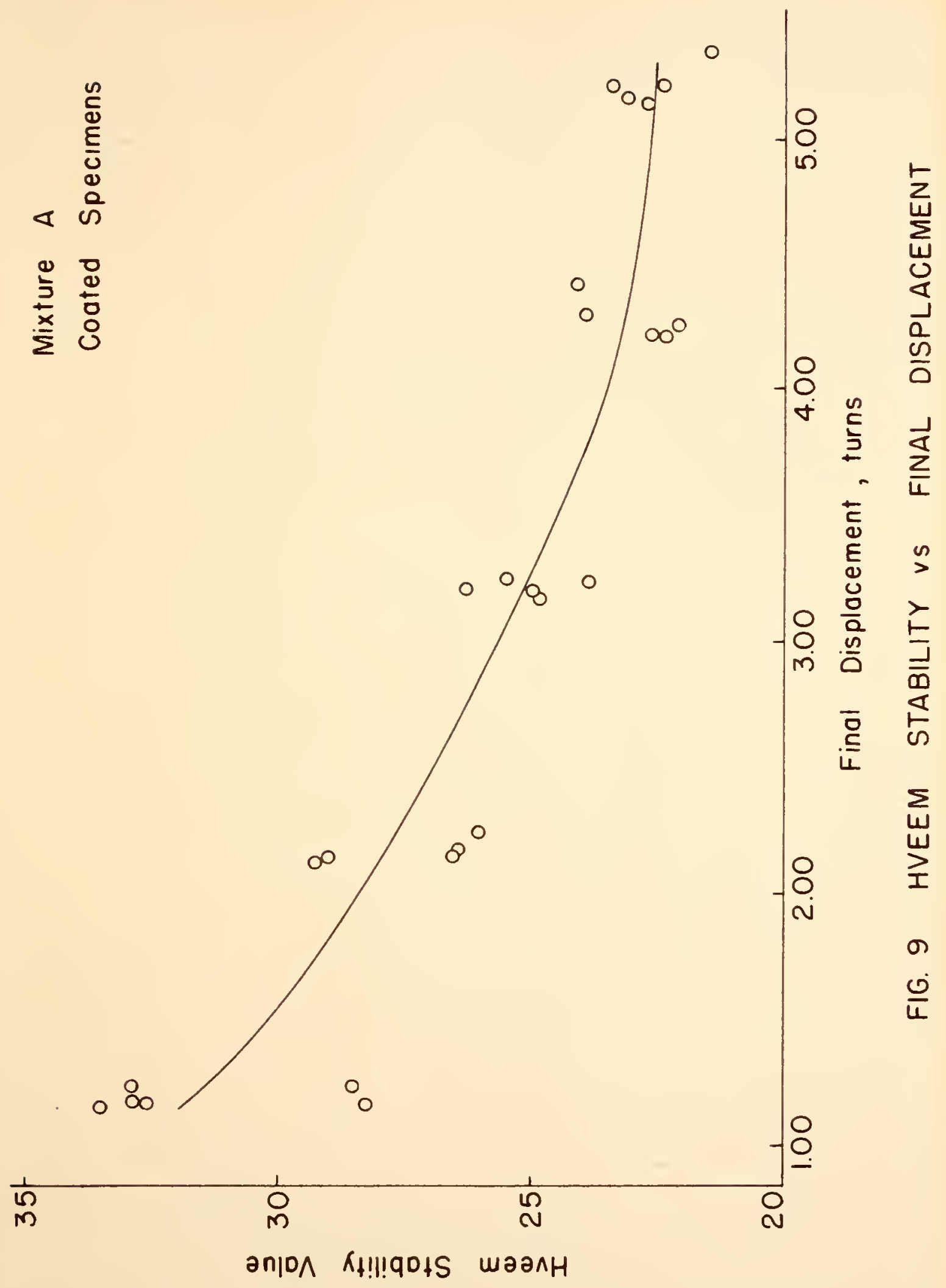



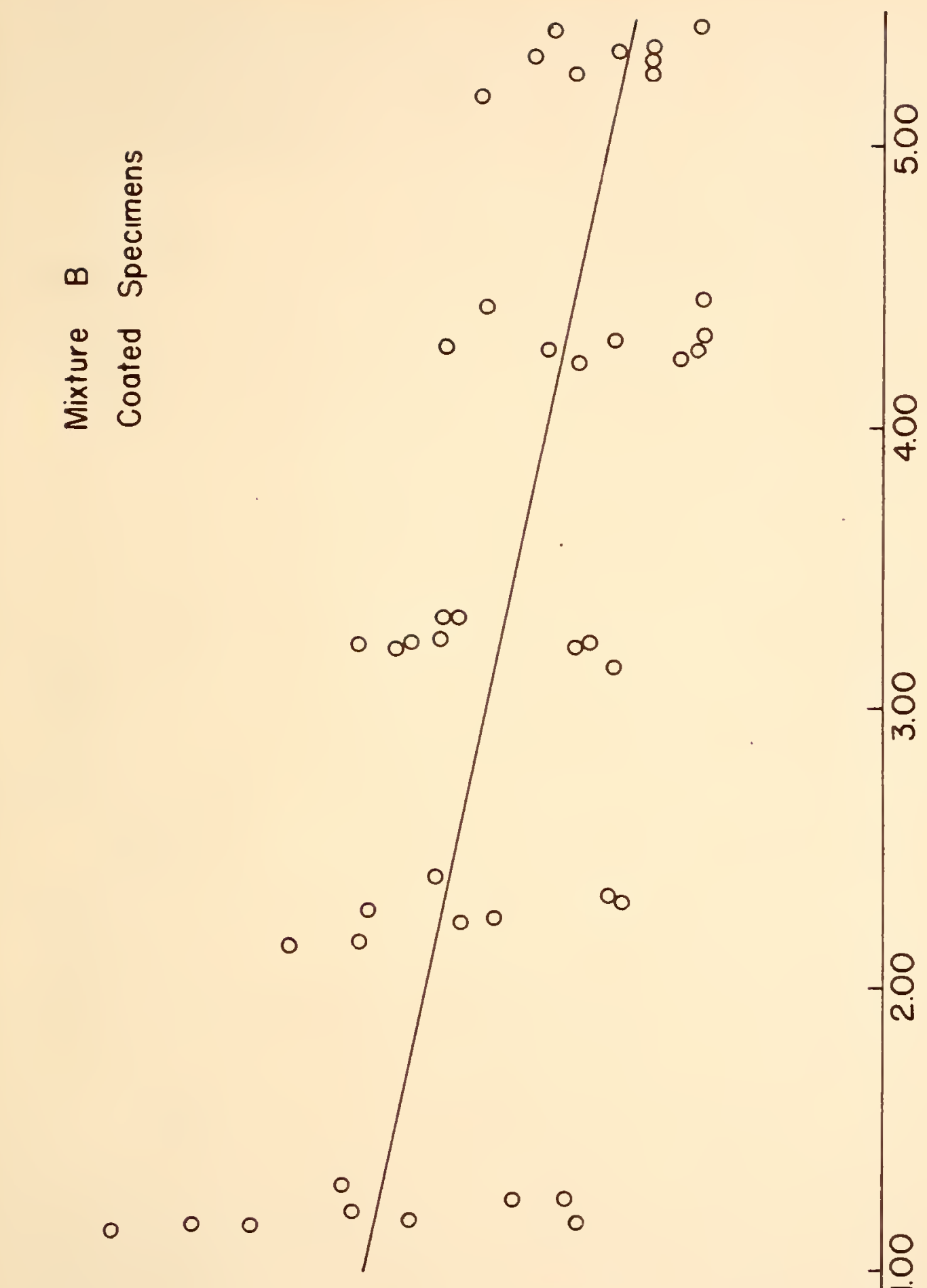

है

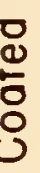


results obtained from specimens of mixture B can probably be attributed to the segregation and arching effects of the large, angular pieces of crushed limestone contained in this $\mathrm{mix}$.

Mixture C. Figure 11 illustrates the relationship between Hveen stability and final displacement for specimens of mixture C. The dense gradation of these specimens, coupled with the fact that they were molded in the mechantcal kneading compactor, resulted in much higher values of stabllity than those which were obtained from mixtures A and $B$. Also, the slope of the curve of finsl displscement vs. stablifty differed for mixture C. Stabilometer tests on m1xtures A and B indicated a steady decrease in messured stability when $81 \mathrm{r}$ in the test system was incressed. Stability numbers for mixture $C$ were highest at displscement values of 2.00 and 3.00 turns, but then decreased as more air was added or removed from the system.

As seen in Figure 1l, the reproducib1lity of test results wss better at higher alr contents than at lower ones. For tests with initial displacement values of 1.00 and 2.00 turns, the transmitted lateral pressures were very erratic, probably because of the limited strain afforded the specimens.

Stab1lometer D1splacement vs. Reciprocal of Transmltted Pressure

Hveem's empirical stability equation is a byperbolic relationship in which stability is expressed ss a function of a constant (5,000 lbs.) vertical load and the finsl displacement messurement. By substituting stablilty numbers into this formula, the plot of lateral presaure versus 


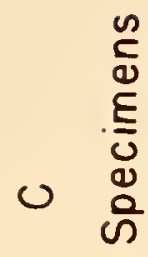

$\begin{array}{ll}0 & 0 \\ \frac{1}{3} & 0 \\ \frac{1}{x} & 0 \\ & 0\end{array}$

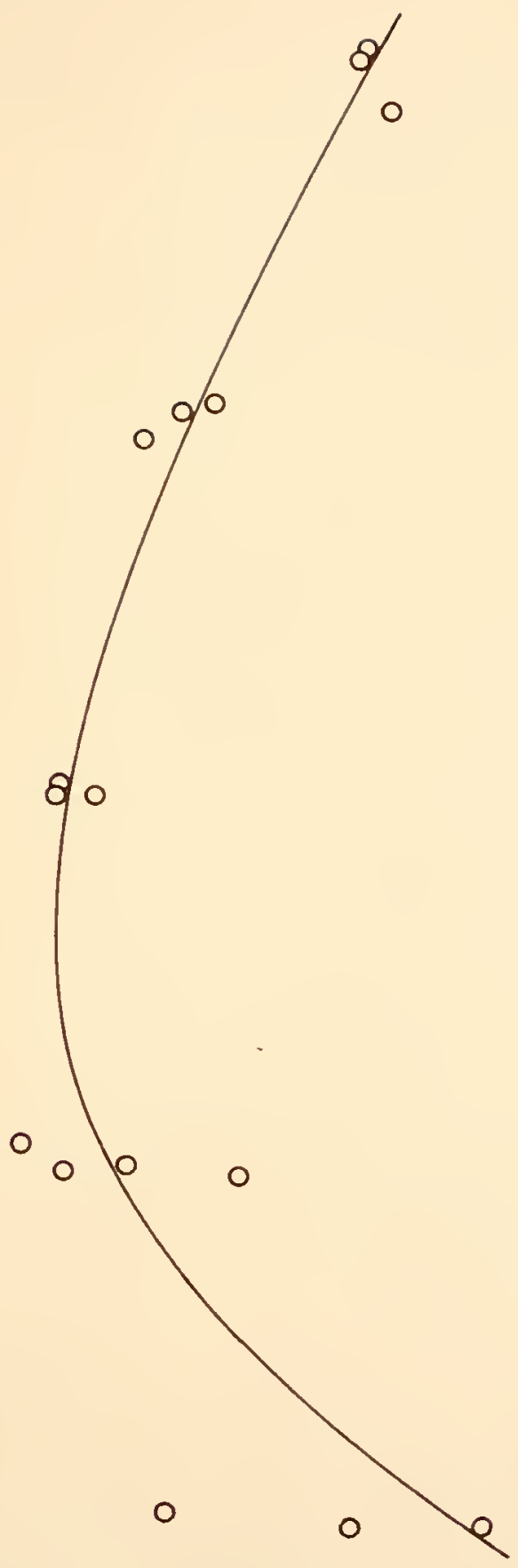

$-10$

$\frac{5}{4}$
$\sum_{u}^{u}$
$\frac{1}{1}$
$\frac{1}{0}$
$\frac{0}{0}$

$-\int_{0}^{2}$

$\stackrel{5}{5} \frac{1}{2}$

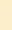

E s

ह $>$

$-10$

웅

긍

吕 $\frac{\pi}{\infty}$

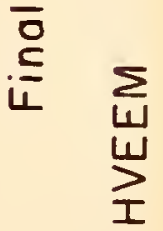

$-10$

- 응

-

$\frac{0}{4}$

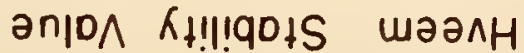


displacement results in s family of hyperbolas. As a further simplification, the graph of final displacement versus the reciprocal of lateral pressure gives a family of stralght lines for a range of hypothetical stab1l1ty numbers.

In order for the final displacement measurement to be a true correction for air in the Stabilameter test system, the graph of displacement versus the reciprocal of lateral pressure for any given mixture should conform to the IInear relationshlps obtained by substituting hypothetical values into the stability equation.

In this section of the study, the relationships between displacement and the reciprocal of lateral pressure for mixtures $A, B$, and $C$ are graphed and compared to the theoretical curves.

Mixture A. Flgure 12 shows the results obtained by testing costed, unaltered, snd drilled specimens at an inftial displacement of 2.00 turns. Because of the wide scatter in the points which represent tests on drilled specimens, as well as the strength reduction experienced by specimens when drilled, no attempt was made to fit a curve to these data. There appears to be a non-linear trend in the relationship, however, and the reproducibility of test results was very much improved when the surfaces of specimens were costed.

In Figure 13, the graph of the reciprocal of latersl pressure versus finsl displacement is plotted for tests on coated specimens of mixture A. A linear relationshlp was Indicated by the data obtained from these specimens.

Mixture B. Figure 14 graphs the reciprocal of lateral pressure 


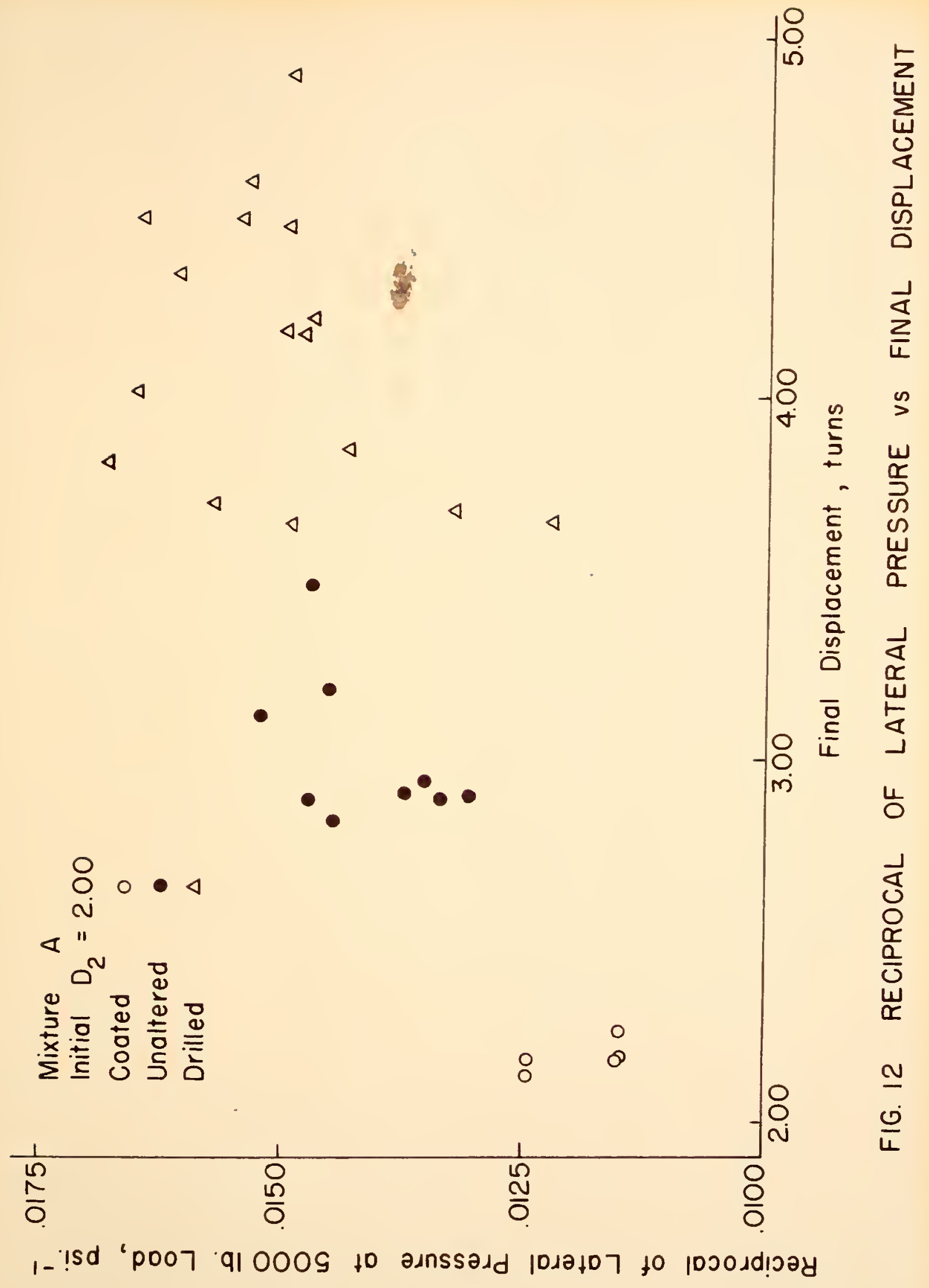




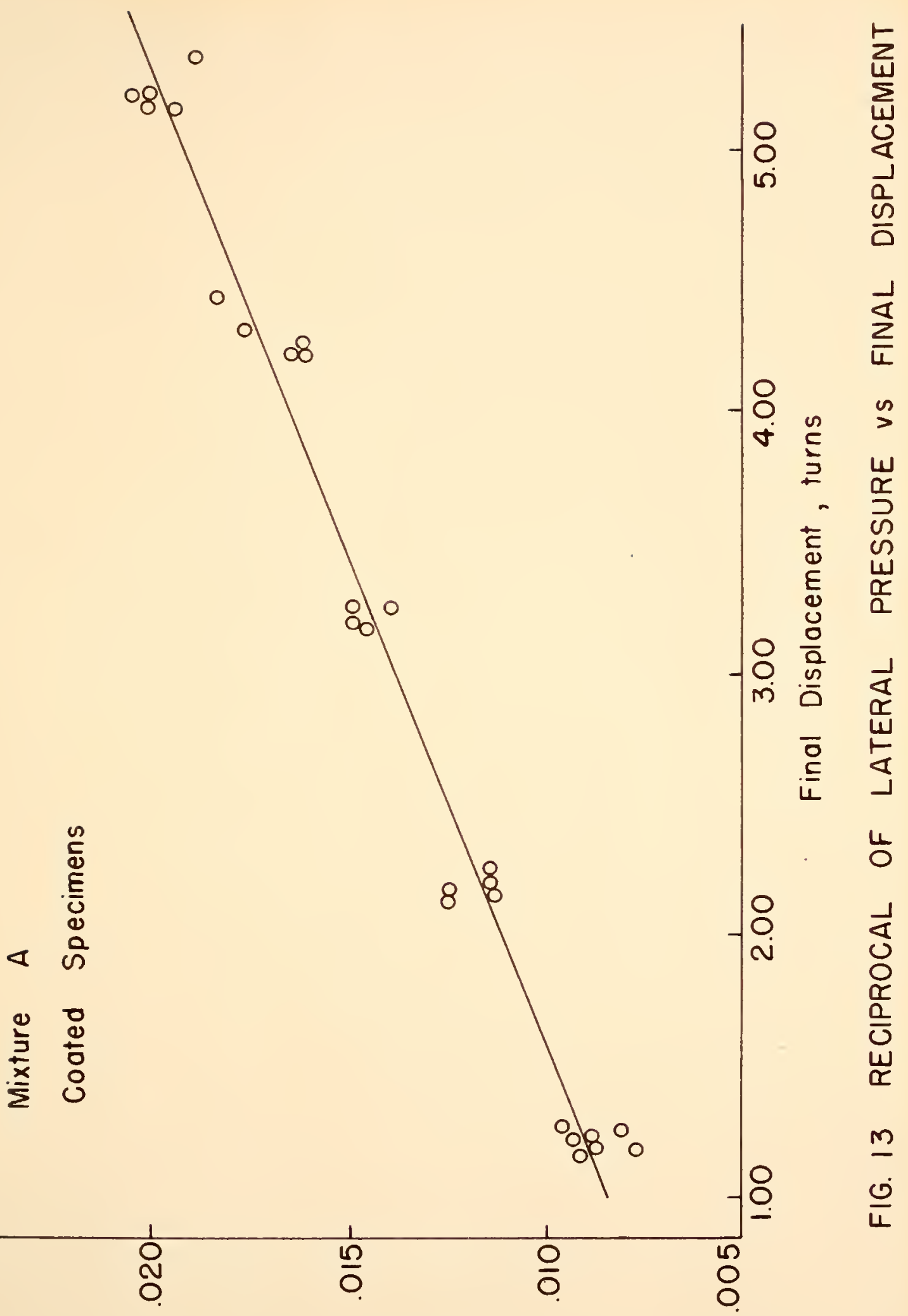

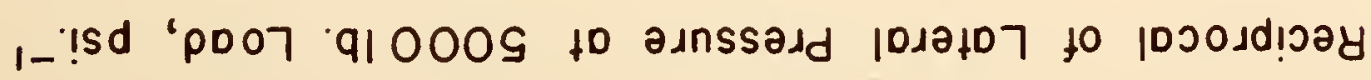




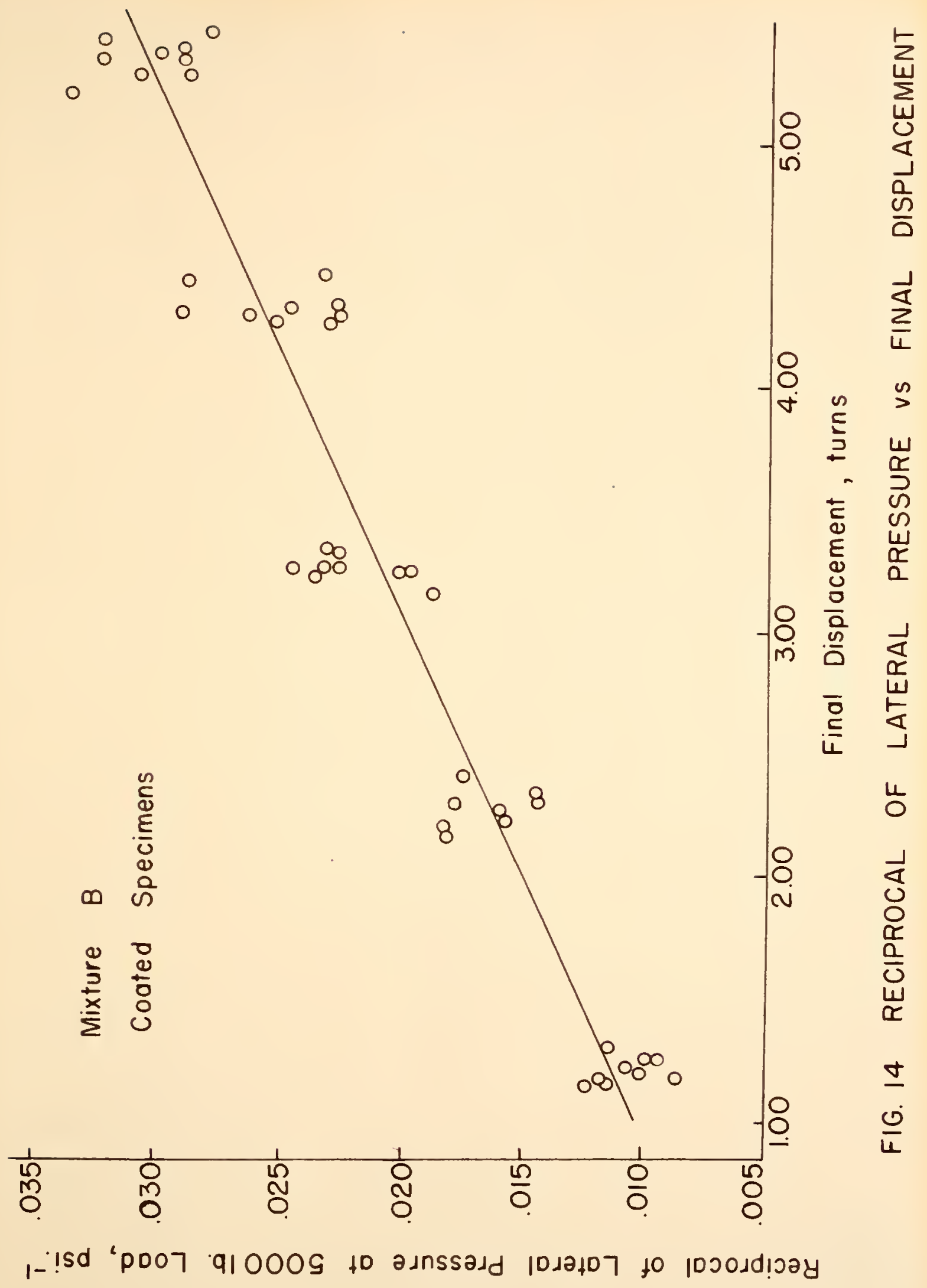


against the final displacement measurement for coated specimens of mixture B. Results were somewhat erratic, but the curve appears to be IInear.

Mixture C. In Figure 15, the graph of the reciprocal of lateral pressure versus final displacement is plotted for mixture C. A non-linear relationship was obtained from these data rather than the expected straight line.

Comparison of Measured and Theoretical Relationships. The dashed lines shown in Figure 16 represent the relstionships between the reclprocal of latersl pressure and values of final displacement which were computed by substituting hypothetical stability values into the Hveem equation. The solid lines, marked A, B, and C, correspond to the curves shown in Figures 13, 14, and 15.

The slopes of the lines corresponding to mixtures A and B sre slightly lower than those which represent the stability equation, resulting in smaller values of stability st high values of displacement. Although the curve representing mixture $C$ is not a straight line, it conforms well with the theoretical curve of seventy per cent stability between displacement values of 2.00 and 3.00 turns. Above and below these displacement values, the stabllity drops off substantially, however.

The deviation from the straight line for mixture $C$ may be due to the extremely low lateral pressure developed by specimens tested at high values of displacement. For inftial displacements of 4.00 and 5.00 turns, the average lateral pressures were only 10.3 and $9.2 \mathrm{psi}$. Each test was started at a 5 psi lateral pressure, and the validity of measurements 


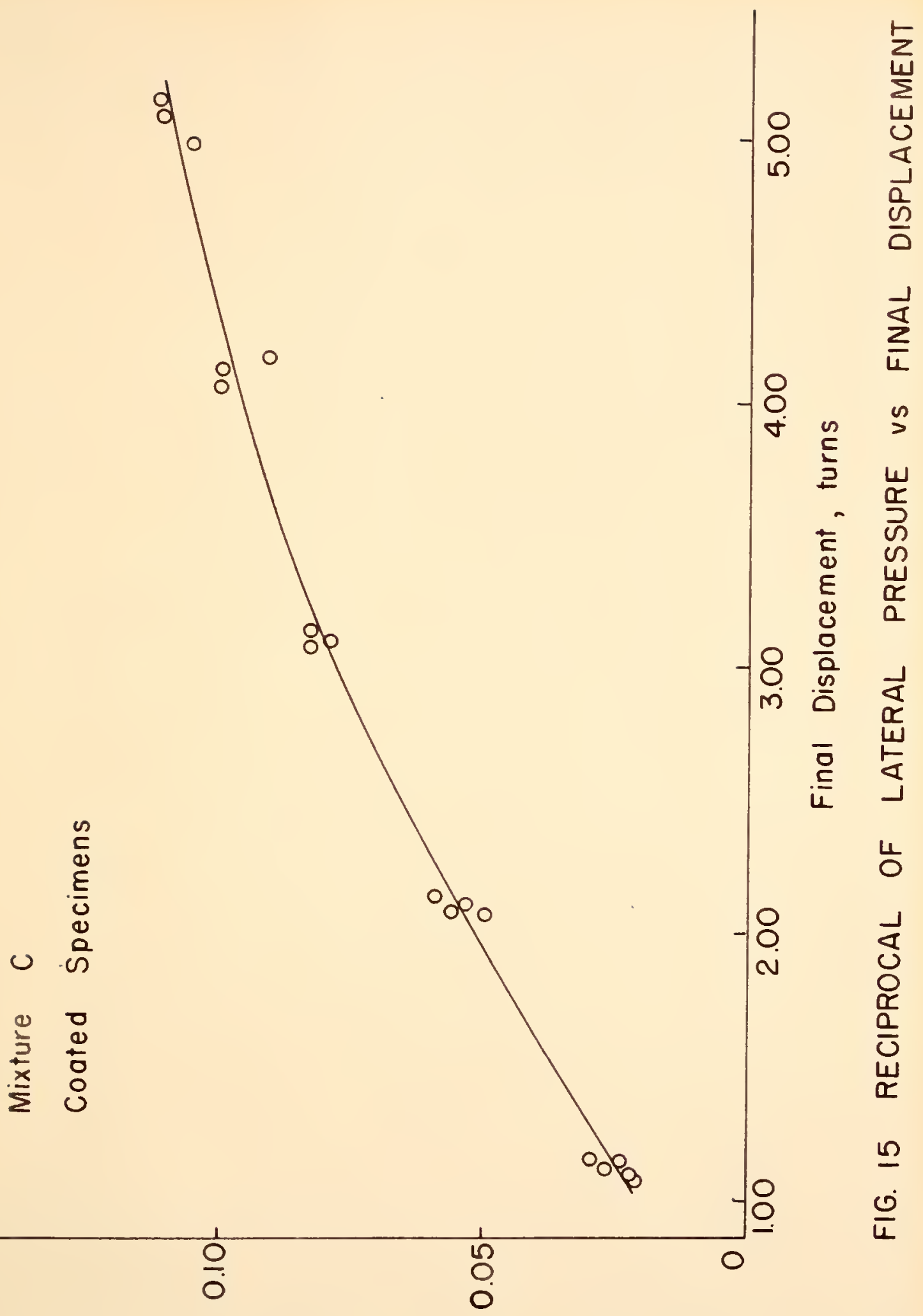

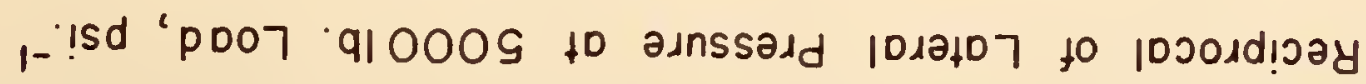




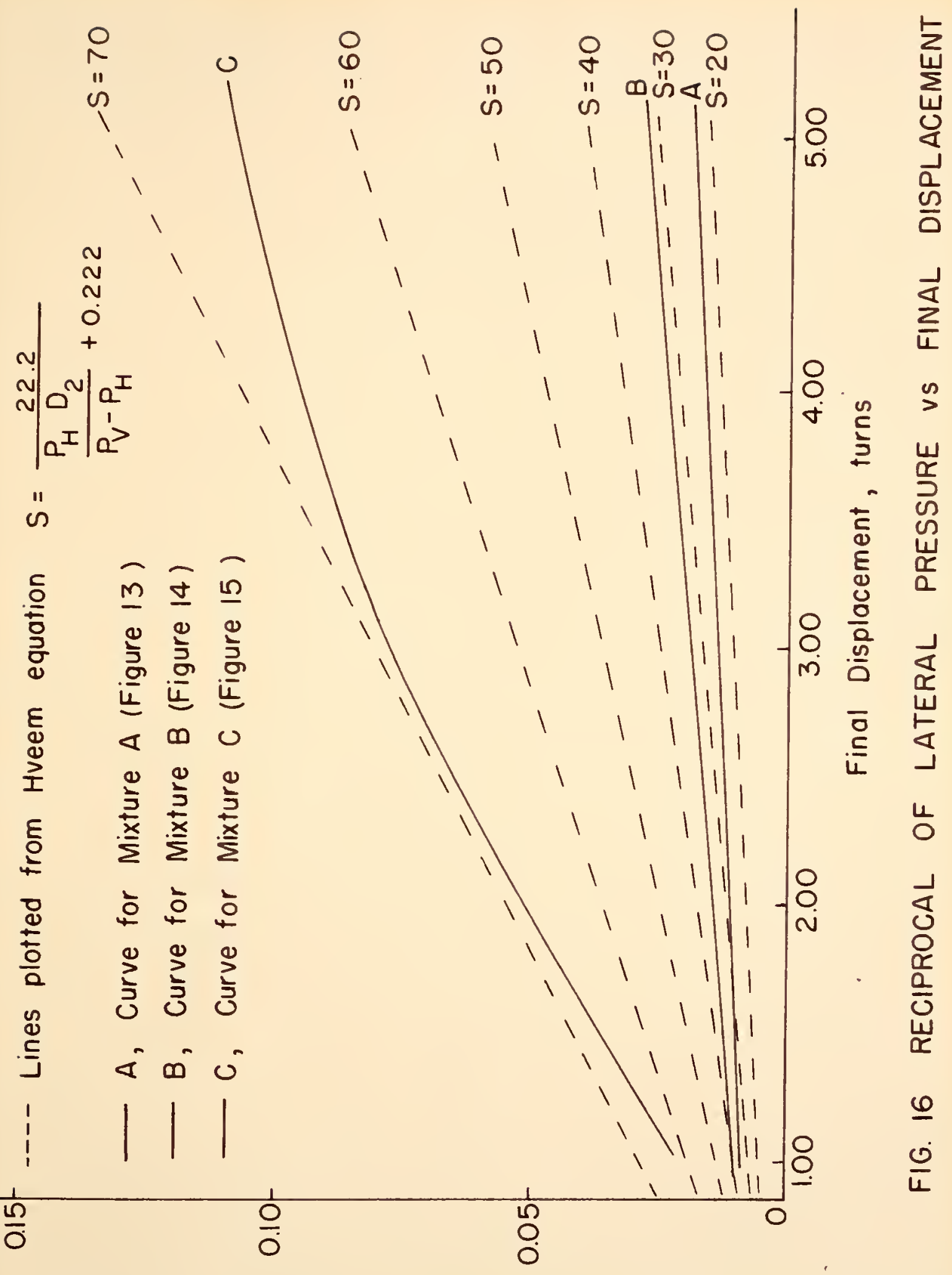

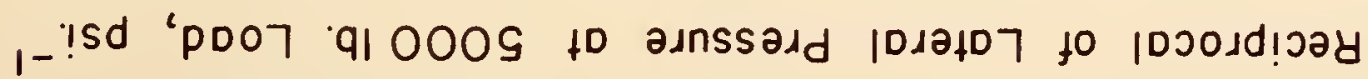


at such low pressures is questionable because of the lack of sensitivity of the Stabilometer pressure gauge.

\section{Influence of Vert1cal Stress and Specimen}

Deformation on ㅂeem Stability

Triaxial compression test results for open-graded bituminous mixtures have been reported by Oppenlander (12) and by Oppenlander and Goetz $(13,14)$. These results showed that, for very open-graded mixtures, the shearing stress developed by the specimen increased as the amount of strain and the confining pressure were increased.

Since the Hveem stability number 18 based on the amount of strain experlenced by a specimen under a 5,000-pound vertical load, the stressstra1n characterlstics of open-graded mixes, as exhibited by the stabilometer test, are of considerable interest. These characteristics are discussed in this section.

\section{Per Cent Stra1n versus Devistor Stress}

The triaxisl compression test results reported by Oppenlander and Goetz were obtalned from mixes Identical to those designated as mixtures $A$ and $D$ in this study. The stress-strain values for these triaxlal tests can be expected to differ from those obtalned with the Stabilometer, because the triaxial tests were conducted at constant confining pressures and on taller test specimens. Ideally, the deformations permitted in the Stabilometer test should be compared with those occurring under the actual field condition. Since fleld data are not avallable, the triaxial data are used here to obtain a rather general indication of 
what quantity of strain should be permitted the Stabllometer test specimen if its resistance is to be fully mobilized.

Mixture A. Figure 17 illustrates the relationshlp between per cent strain and deviator stress for coated Stabilometer specimens of mixture A tested at inftial displacement values of $1.00,2.00,3.00,4.00$, and 5.00 turns. It is evident from the shape of the curves that a large portion of the strain occurs during the inftial stages of the test when the air in the system is belng compressed and the confining pressure is low. As the confining pressure builds up, however, the slope of the curve incresses rapidly. Also, higher values of displacement result in greater amounts of deformation and higher deviator stress values for a given vertical losd.

The points labeled A and B on Flgure 17 represent triaxial test results obtalned by Oppenlander and Goetz. Point A shows the strain ( 1.7 per cent) which occurred at the peak devlator stress (149 ps1) for tests conducted at a $30 \mathrm{ps} 1$ confining pressure. Polnt B locstes the point of maximum deviator stress ( $326 \mathrm{psi)}$ at a value of 4.2 per cent strain for a confluing pressure of $90 \mathrm{psi}$. A third confining pressure of 150 ps 1 gave a peak deviator stress of 510 psi at a 5.4 per cent strain. The locations of points $A$ and $B$ conform quite well with the five curves obtained from Stabilometer measurements. The range of strain values for the Stabilometer tests on this well-graded mixture was approximately the same range required to develop the maximum shearing resistances of trlaxial specimens tested at conflaing pressures between 30 and 90 ps 1. 


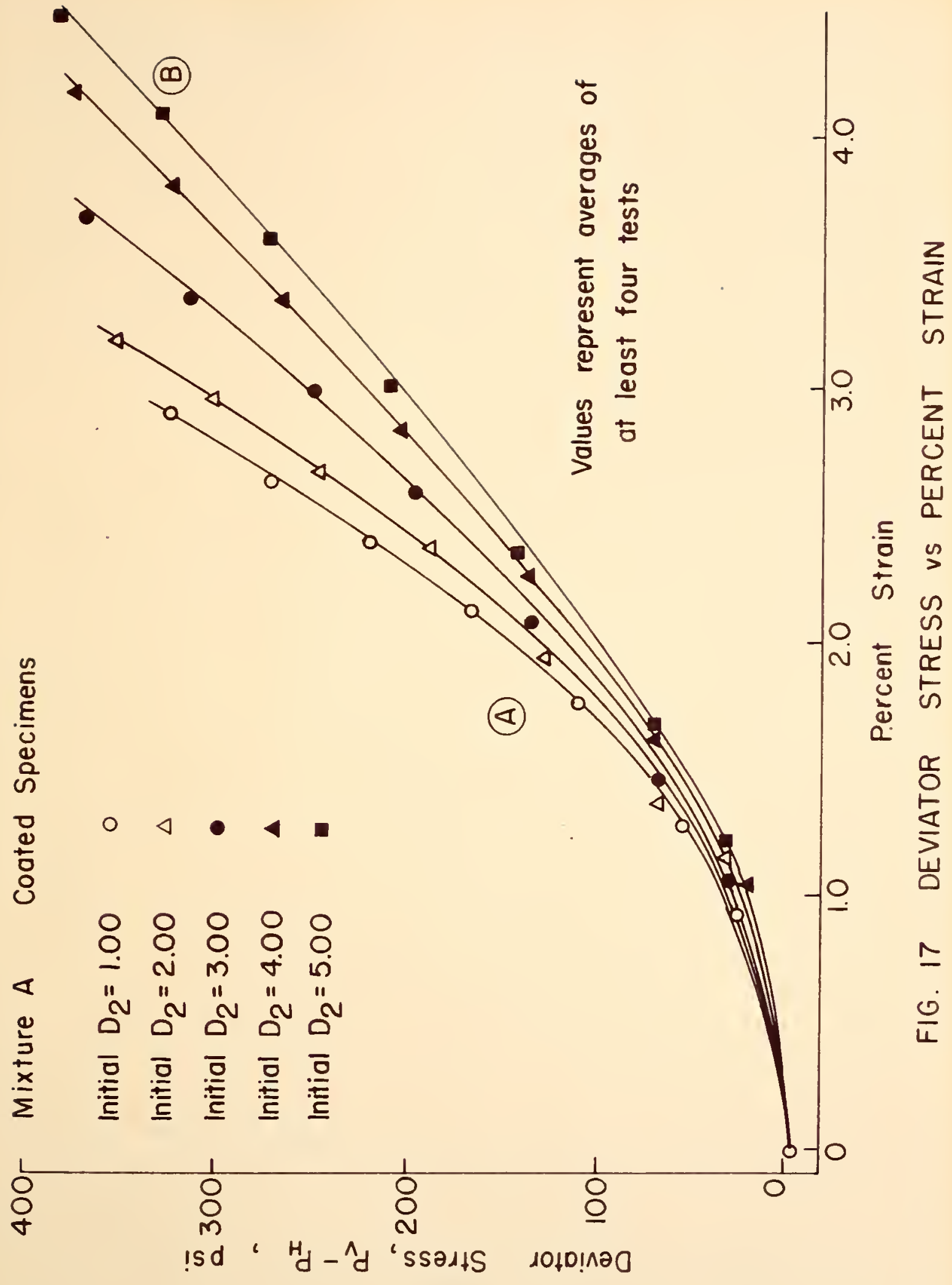


Mixture D. Figure 18 shows the relationship between per cent strain and deviator stress for Stabllometer tests on the "one-sized" mixture D. One curve represents tests on specimens which had their ends and latersl surfaces costed. The other represents those which had only the lateral surfaces costed. Although infial stabilometer displacement values were set at 2.00 turns for all tests, it was not possible to fill all the voids on the specimens. Hence, final displacement values were in the range of 3.00 turns.

The maximum strain values for stabilometer tests on mixture D were slightly greater than 5 per cent. For the triaxial tests reported by Oppenlander and Goetz, however, specimens made from this same mixture required more than 15 per cent strain to develop their peak shearing resistances. It is fairly safe to assume, then, that the limited strain conditions in the Stabilometer test do not permit full mobilization of the shear strength of specimens of mixture D. Sufficient information is not available to determine whether the strain sfforded this type of specimen by the Stabilometer is compatible with the strain occurring in an actual pavement.

\section{Stabilometer Displacement versus Per cent}

Strain at a 5,000-1b. Load

Since the Hveem stability number is computed fram the lateral pressure transmitted at a 5,000-pound axial load, it was desired to determine how the stabilometer displacement measurement affected the per cent strain occurring under this load.

Figure i3 shows the relationship between final displacement and 


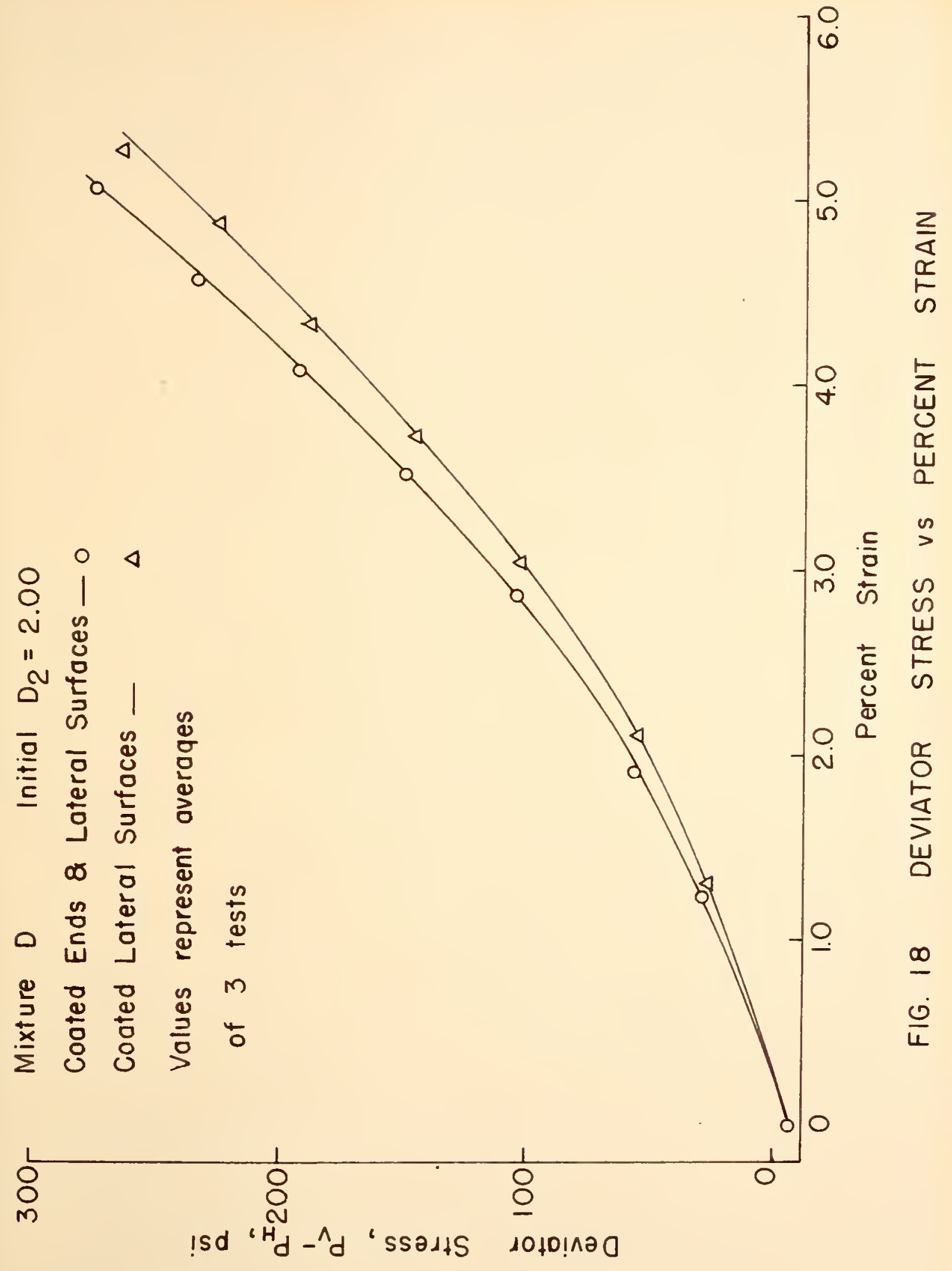


the per cent strain at a 5,000-pound vertical load for Stabilometer tests on drilled, coated, and unaltered specimens of mixture A. Figure 20 shows this relationship for costed specimens of mixture A. In both cases, increased air in the test system resulted in increased specimen deformation at a losd of 5,000 pounds.

\section{Compar1son of Results for Specimens with}

\section{Coated and Unsltered Ends}

Surface volds on the ends of Stabilometer test specimens reduce the effective area over which the axial load is applied. This reduced ares would appear to give a higher vertical unit stress for a given vertical load. As a result, it is possible that the stability number will be reduced for a specimen having large volds on 1 ts ends.

To investigate this aspect of the Stabilometer test, two groups of specimens were fabricated from mixture D. For each group, the lateral surfaces of all specinens were costed with a stiff paste of Ilmestone mineral filler and water. The ends of one group were unaltered, but the second set had the ends coated, as well as the lateral surface. Appendix C shows the statistical computstions used in comparing the mean stability numbers for the two types of specimens tested in this section. The results of this comparison indicated that, at a 5 percent level of algnificance, Hveem stability numbers were higher for specimens with costed ends than for those with unsitered ends. It should be pointed out, however, that the difference in mean stability numbers for these two types of specimens was relatively small $\left(\bar{x}_{1}-\bar{x}_{2}=1.0\right)$, if compared to the variations in stability values obtained from mixtures $A, B$, and C. 


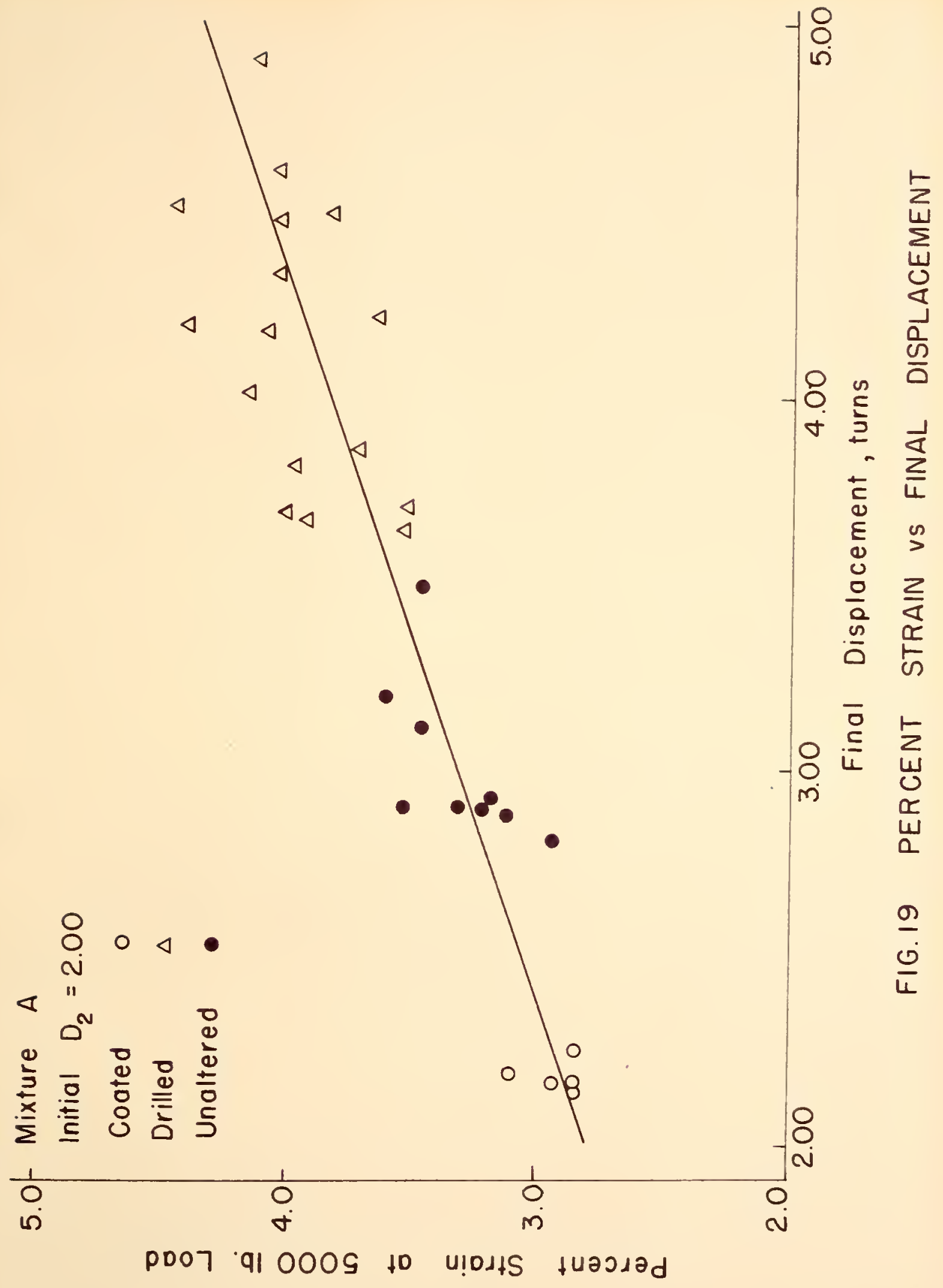




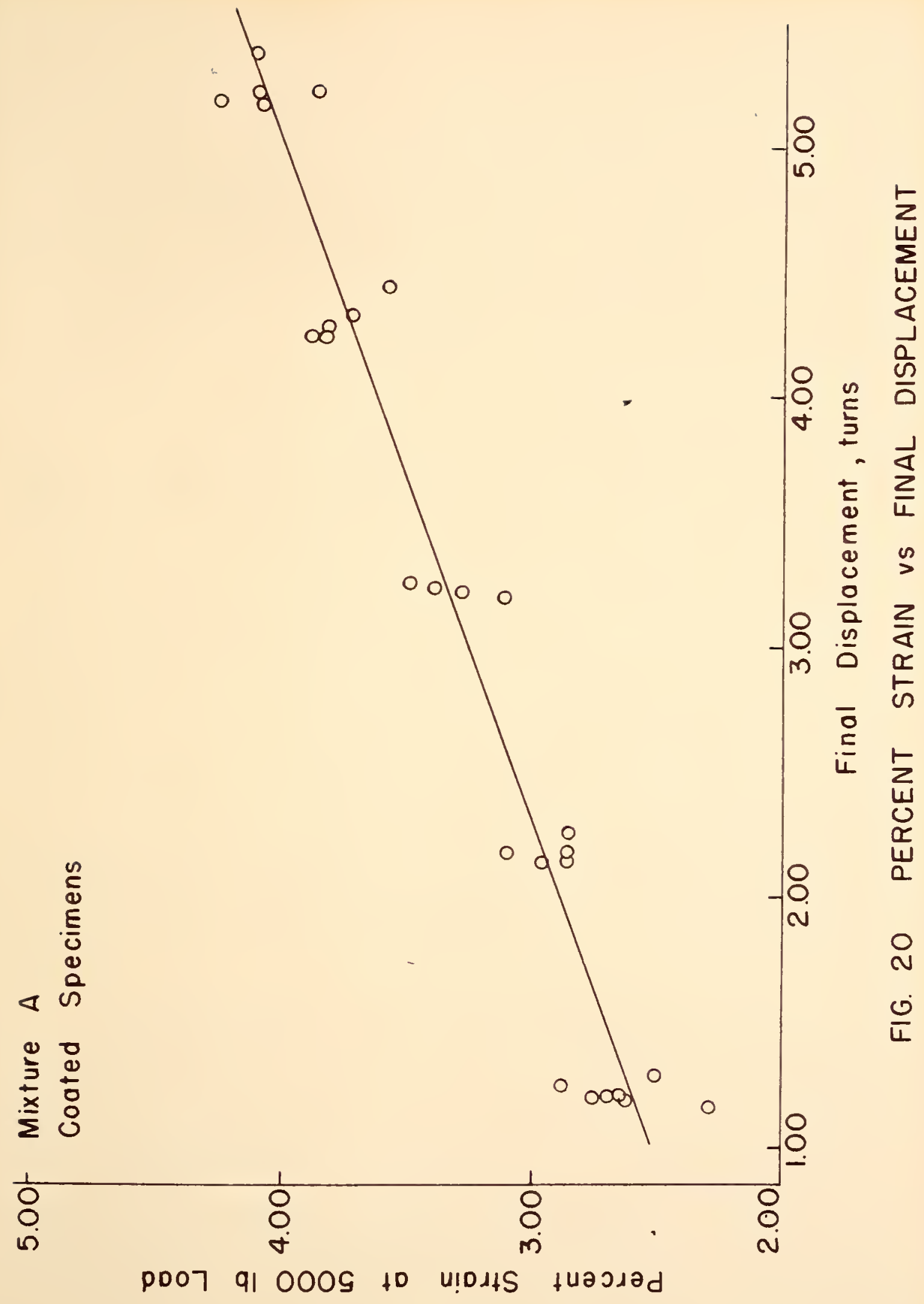




\section{SUMMARI OF RESULTS AND CONCLUSIONS}

The conclusions stated here are based solely on test results obtained from the bituminous mixtures incorporated in this study. Before the Hveem Stabllometer test can be applied to the testing of open-graded mixtures with a high degree of confidence, these results should be supplemented with field performance data.

1. As the smount of air in the stabilometer test system was incressed, the magnitude of the laterally transmitted pressure was reduced. Stability numbers, as computed from Hveem's equation, remained fairly constant when displacement values did not differ widely (one or less turns of displacement pump) from specimen to specimen. However, when displacement values were increased appreciably, computed Hveem stability numbers were generally reduced.

2. The reproducibility of test results was improved when the Stabilometer was calibrated at displacement values above 2.00 turns and when air voids on the lateral surfaces of specimens were filled prior to testing.

3. The presence of air voids on the ends of test specimens resulted in stability numbers which were not significantly lower but much more erratic than those obtained when these volds were filled. These effects on the stability value for specimens with surface voids on their ends were attributed to the reduced effective area over which the vertical load was applied. 
4. During the early stages of a Stabilometer test, a1r in the system required a relatively large reduction in volume in order to undergo small increases in pressure. As a result, a major portion of the strain experienced by a Stabilometer test specimen was developed at this time. Also, lncressed quantities of alr in the test system, as measured by the displacement value, resulted in greater specimen deformations.

5. Stabllometer tests on the open-graded mixture A gave straln $/$ measurements very near to those required to develop the mix's maximum shearlng resistance in a rational triaxial compression test of the same mixture conducted at confining pressures simflar to those which occur in a Stabilometer test.

6. Stralns experlenced by Stabilometer test specimens of the "one-sized" mixture D were much lower than those needed to furly mobllize the shearing strength of rationsl triaxial specimens made from this mixture and exposed to simliar confinfing stresses. Hence, the signiflcance of Stabilometer test results secured from one-sized mixes is questionable and further Investigation is desirable.

7. Certain minor modifications in the Stabilometer testing technlque appear justified when 1 is to be applied to the testing of open-graded mixtures.

a. Test specimens capable of ylelding final displacement measurements of more than 3.00 turns should have the lateral surface volds filled with a non-cementing mixture such as mineral filler and water. Th1s costing process w11l 1mprove the reproducibility of results and help to minimize inadequacies in the displacement measurement. Large 
volds on the ends of test spectmens should be filled to insure a unform transmission of vertical stress to the specimen's aggregate framework.

b. Tests on specimens having coated lateral surfaces should be conducted at an inftial stabilometer displacement value of 3.00 turns. This modification 18 made to improve reproduciblitty of results and to permit more specimen deformation than that which would occur if coated specimens were tested at an Initial displacement measurement of 2.00 turns. 


\section{SUGGESTIONS FOR FURTHER RESEARCH}

Although this study was designed to investigate the applicability of the Hveem Stab1lometer Test to open-graded bituminous mixtures, time did not permst an extensive correlation between the performance of these mixes in the field and their stability values as measured by the Stabilometer. Instead, a correlation study of this sort is suggested as a topic for further research. The fallure criteria for the Stabilometer test are based on California's highway performance data. This profect would give an indication of the stabllity values needed for satisfactory pavement performance in Indiana.

A second possibility for further study is to investigate the effect of aggregate size on Stabilometer test results. There is good reason to believe that specimens containing aggregate particles greater than $1 / 2$ inch in size will not give representative stability values because of the relatively small dimensions of the specimen.

The mechanical kneading compactor, which is used to mold Stabilometer specimens, provldes another topic for additional research. Using the current compaction procedure, this machine will produce excessive aggregate fracture in very open-graded mixtures, and for this reason does not simulate the true fleld compaction of such a mix. By varying the pressure and number of load applications of the tamping foot, the kneading compactor could conceivably be used to fabricate specimens from a wide range of bituminous mixes. 
Another research subject which would be of future value to the field of bituminous $\mathrm{mix}$ design is a correlation between the Hveem stability number and the parameters $\phi$ and $C$ as measured by the rational triaxial compression test. This study would involve the testing of a varlety of mixes, both open and dense, and could help to clear up a number of the problems which have prevented the formulation of a purely rational method of $\mathrm{mlx}$ design. 
BIBLIOGRAPHY 


\section{BIBLIOGRAPHY}

1. Bennett, C. A., and Frankl1n, N. L., Stat1st1cal Anslyais in Chemistry and the Chemical Industry, John W1ley and Sons, Inc., New York, 1954 .

2. Corps of Englneers, Airfleld Paving Deslgn, Flexible Pavements, Englneerlag Manual for Miltary Construction, Part XII, Chapter 2, July, 1951.

3. Endersby, V. A., "The Analyt1c Mechanical Testing of Bituminous Mixes," Proceedings, The Assoclation of Asphalt Paring Technologisti, Vol. 11, 1940.

4. Endersby, V.A., "The History and Theory of Trlaxial Testing, and the Preparation of Realist1c Test Specimens - A Report of the Triaxial Institute," Triaxial Testing of Solls and Bituminous Mixtures, American Society for Testing Materials, Special Technical Publication No. 106, 1951.

5. Hveem, F. N., and Carmany, R. M., "The Factors Underlying the Rational Design of Pavements," Proceedings, Highway Research Bosid, Vol. 28, 1948.

6. Hveem, F. N., and Davis, H. E., "Some Concepts Concerning Trlaxlal Compression Testing of Asphalt1c Paving Mixtures and Subgrade Materials," Triaxial Testing of Solls and Bituminous Mixtures, American Society for Testing Materials, Special Techntcal Publication No. 16, 1951.

7. Hveem, F. N., and Vallerga, B. A., "Density Versus Stability," Proceedings, The Association of Asphalt Paving Technologista, Vol. 21, 1952.

8. McCarty, L. E., "Applications of the Mohr Circle and Stress Trlangle Diagrams to Test Data Taken with the Hveem Stabllometer," Proceedings, H1ghway Research Board, Vol. 26, 1946.

9. McCarty, L. E., "Correlation between Stability and Certain Physical Properties of Bltuminous Materials," Proceedings, Highway Research Board, Vol. 33, 1954.

10.. McCarty, L. E., "Further Methods for the Analys1s of Data Taken in the Hveem Stabllity Test," Proceedings, Highway Research Bos rd, Vol. 27, 1947. 
11. Monismth, C. L., Personal Comunication.

12. Oppenlander, J. C., "Trlaxial Test1ng of Bituminous Mixtures at High Confining Pressures," A Thesis submitted to Purdue University for the degree of Master of Sclence in Civll Engineering, June, 1957.

13. Oppenlander, J. C., and Goetz, W. H., "Trlaxial Testing of B1tuminous Mixtures at High Confining Pressures," Proceedings, Highway Research Board, Vol. 37, 1958.

14. Oppenlander, J. C., and Goetz, W. H., 'Trlaxial Testing of OpenType Bituminous Mixtures," Proceedings, The Associstion of Asphalt Paving Technologists, Vol. 27, 1958.

15. Ortolant, L., and Sandberg, H. A., "The Gyratory-Shear Method of Molding Aaphaltic Concrete Test Specimens; Its Development and Correlation with Field Compaction Methods. A Texas Bighway Department Standard Procedure," Proceedings, The Association of Asphalt Paving Technologists, Vol. 21, 1952.

16. Pickering, 甘. P., "Developments in the Use of the Stabilometer in the Evaluation of Subgrade and Base Course Materials," Solls and Bases, The Institute of Transportation and Traffic EnglneerIng, University of California.

17. Smith, V. R., "Application of the Triaxial Test to Bituminous Mixtures--California Research Corporation Method," Triaxial Testing of Solis and Bituminous Mixtures, American Soclety for Testing Materials, Special Technical Publication No. 106, 1951.

18. Stanton, T. E., and Eveem, F. N., "Role of the Laboratory in the Preliminary Investigation and Control of Materials for Low Cost Bituminous Pavements," Proceedings, Highway Research Bosrd, Vol. 14, Part II, 1934.

19. State Highway Department of Indiana, Standard Specifications for Rosd and Bridge Construction and Mintenance, 1957.

20. State of California, Depertment of Public Works, Division of Highways, Materials Manusl of Testing and Control Procedures, Vol. I.

21. The Asphalt Institute, Mix Des1gn Methods for Hot-Mix Asphalt Paving, Manual Series No. 2, College Park, Md., 1957.

22. Vallerga, B.।A., "The Triaxial Inst1tute and the Stabilometer," Proceedings, Highway Research Board, Vol. 34, 1955. 
APPENDIX 
APPENDD A

\section{APPARATUS AID DETAIIED PROCEDURES}


APPENDIX A

\section{APPARATUS AND DETAILED PROCEDURES}

The laboratory apparatus and detalled procedures used in this investigation are described under the following headings:

1. Preparation of Aggregste

2. Preparation of Test Specimens

3. Hveem Stabllometer Tests

\section{Preparation of Aggregate}

The apparatus used in the preparation of the mineral aggregate was as follows:

1. Gilson mechanical sieving machine.

2. Tyler "Ro-Tap" testing sleve shaker.

3. U. S. Standard Sieves, olzes $\frac{3}{4}$ 1n., $1 \frac{1}{2}$ 1n., $3 / 8$ in., nos. $4,8,16,30,50,100$, and 200 .

4. Torsion balance, capacity $4.5 \mathrm{~kg}$., accuracy $\frac{1}{4}$ gram.

In order to provide a close control over the aggregate gradation for each test specimen, the aggregate obtalned from the comercial plants was sleved 1nto the needed sieve fractions. A Gilson mechanlcal sieving machine was used to separate the cosrse aggregate into the fractions of $\frac{3}{4}$ in. to $\frac{1}{2}$ in., $\frac{1}{2}$ in. to $3 / 8$ in., and $3 / 8$ in. to \#4. A Taylor "Ro-Tap" testing sleve shaker was used to divide the fine aggregate into fractions of \#4 to \#8, \#8 to \#16, \#16 to \#30, \#30 to \#50, 
\#50 to \#100, \#100 to \#200, and passing \#200. Sleved aggregate fractions were stored in covered contalners until needed for mixing operations. At that time, the individual aggregate sizes were recombined to give the desired aggregate gradations. To form compacted test speclmens of the desired $2 \frac{1}{2}-1$ nch height, the respective aggregate batch weights for gradings A, B, C, and D were 1092 gram8, 1073 grams, 1121 grams, and 900 grams. These welghings were made on the torsion balance just prior to the preparation of the test specimen.

\section{Preparation of Test Specimens}

The following list includes all apparatus needed to prepare teat specimens in this investigation:

1. Peerless gas oven with tempersture regulator.

2. Ohaus beam balance, capac1ty $20 \mathrm{~kg}$, accuracy 1.0 grams.

3. Modffled Hobart mixer with steel paddle and flat bottomed brass bowl.

4. Steel rod, 5/8-inch diameter, 17-1nch length.

5. Steel compection molds, 4-inch diameter, 5-inch height.

6. Riehle testing machine (50,000 pound capacity) with varlable speed drlve.

7. Trlaxial Institute Mechanfcal Kneading Compactor, equipped with 4-inch diameter molds, mold holder, and insulated feeder trough.

8. Blackhawk hydraulic jack ( 50 ton capacity).

9. Steel compaction frame.

10. Cleveland pneumatic vibrator.

11. Hobart Brothers air compressor.

12. Extrusion collar (collar of Marshall mold).

13. Split mold, 4-inch diameter. 
14. Delta drill press and 3/8-1nch carbide-tipped steel drill.

15. Miscellaneous equipment. Pans, beakers, metal spoons, spatulas, thermometers, stop watch, heat-resistant gloves, paper discs, steel pistons, feeder trough blade, sandpaper, etc.

Because of the wide variations in compaction techniques, the procedure for molding Stabilometer test specimens will be discussed according to mixture type.

\section{Mixtures $A$ and $B$}

1. For each specimen to be molded, approximately 80 grams of asphalt cement was put into a $400 \mathrm{ml}$ metal beaker.

2. Metal pans containing the batched aggregate mixtures were placed on the top shelf of the oven, the temperature of which was maintained at $300 \pm 10^{\circ} \mathrm{F}$.

3. When the mineral aggregate reached the $300 \pm 10^{\prime} \mathrm{F}$ temperature, one beaker of asphalt was placed on the top shelf of the oven. At the same time, the mixing bowl, mixing paddle, steel rod, spoon, spatula, mold, and upper and lower pistons were placed on the second shelf.

4. When the asphalt reached a temperature of $275 \pm 5^{\circ} \mathrm{F}$, the mineral aggregate was placed into the mixing bowl, and the bowl and aggregate were tared on the beam balance. The required welght of asphalt was then added to the beam, and the hot asphalt was poured into the bowl until the bean became balanced.

5. The mixing paddle was removed from the oven and the paddle and bowl were connected to the mixer: The asphalt and aggregate were then mixed at the alow mixer speed for a period of two minutes.

6. While the mixing was being accomplished, the mold, spatula, 
spoon, plstons, and steel rod were removed from the oven. The lower piston was inserted into the mold where it was held in place with a steel p1n. A 4-inch diameter paper disc was placed in the bottom of the mold to prevent adhesion of the mixture to the metal piston.

7. At the end of the mixing period, the material was spooned from the bowl into the mold in two equal layers. Each layer was rodded 40 times with the steel rod.

8. A paper disc was placed on top of the mixture and the upper piston was inserted into the mold.

9. The mold was placed in the compression machine and the steel pin was removed from the mold to permit vertical movement of the lower pliston.

10. A vertical load was applied to the mixture at a rate of 0.165 inches per minute. When the load reached 27,500 pounds, the clutch was maneuvered so as to keep the load constant for one minute. At the end of this time, the load was removed and the specimen allowed to cool to room temperature.

11. To remove the cooled specimen from the mold, the specimen was extruded into the upper half of a Marshall compaction mold. This was done in the compreasion machlne at a rate of 0.84 inches per minute.

12. At this point the trestment of the test specimen wos varfed, depending on whether it was fabricated from mixture A or mixture $B$. a. The lateral surface of a specimen made from mix A was elther left unaltered, was drilled to form a number of shallow volds, or was costed with a stiff mixture of portland cement, plaster of paris and water. To provide the specimen with a smooth lateral surface, 
the mixture was allowed to harden, and the excess material was removed with sandpaper.

b. All specimens made from mixture $B$ were costed with the cement-plaster-water mixture and then sandpapered.

\section{Mixture C}

1. The electrical power switches of the knesding compactor were engaged and the compaction foot heater was started with the powerstat set at 80 .

2. Asphalt was placed in metal beskers as was done for mixtures $A$ and $B$, and the aggregate was placed on the top shelf of the oven with the temperature controlled at $300 \pm 10^{\circ} \mathrm{F}$.

3. When the aggregate's temperature reached $300 \pm 10^{\circ} \mathrm{F}$, the asphalt cement was placed on the top shelf of the oven. The mixing bowl, mlxing paddle, spoon, spatula, and steel rod were placed on the second shelf.

4. When the temperature of the asphalt became $275 \pm 5^{\circ} \mathrm{F}$, the aggregate was added to the mixing bowl, and the bowl plus aggregate were tared on the beam balance. The desired weight of asphalt was then added to the bowl.

5. The asphalt and aggregate were mixed for two minutes at the slow mixing speed. During this time the spoon, spatula, and steel rod were removed from the oven and the mold was fitted into the special mold holder. A 1/4-inch ahim was placed between the bottom of the mold and the base, and the set screw was tightened against the side of the mold. A 4-inch dlameter paper disc was placed in the bottom of the mold. 
6. After mixing operations were completed, the mix wos not subjected to the fifteen-hour curing time specifled by calffornia. Instead, the mixture was spooned directly into the mold and rodded 40 times. The mold and holder were then attached to the turntable of the compactor.

7. The compactor was started, and 20 tamps were applied to the mixture at a 250 psi pressure.

8. When the 20 tamps at $250 \mathrm{psi}$ had been applied, the pressure was increased to 500 psi and the timer set for five minutes (150 tamps). The metal shim under the mold was removed, the set screw loosened, and a paper disc placed over the speclmen.

9. When the machine stopped automstically after 150 tamps at 500 psi, the mold was removed from the holder, and the upper and lower pistons inserted in the mold.

10. The mixture was then subjected to a 12,600 pound "levelingoff" load at a rate of 0.25 inches per minute. When the 12,600 pound load was obtained, the testing machine was lumediately shut off, and the load removed.

11. The specimen was cooled to room temperature and removed from the mold by extrusion into the upper portion of a Marshall mold.

12. After extruding the specimen, its lateral surface was coated with a mixture of portland cement, plaster of paris, and water. When dry, the surface was sandpapered.

\section{Mixture D}

1. Approxlmately 60 grams of asphalt cement were placed in each of several $400 \mathrm{ml}$ metal beakers, one for each specimen to be made. 
2. The batched aggregate mixes were placed on the top shelf of the gas oven, the temperature of which was $300 \pm 10^{\circ} \mathrm{F}$.

3. When the aggregate reached $300 \pm 10^{\circ} \mathrm{F}$, the asphalt was placed on the top shelf of the oven. The mixing bowl, mixing paddle, spoon, spatula, feeder trough, and feeder trough blade were put on the second shelf.

4. When the asphalt reached a temperature of $275 \pm 5^{\circ} \mathrm{F}$, the aggregate was put in the mixing bowl and tared on the beam balance. The necessary quantity of asphalt was then poured into the bowl.

5. The bowl and paddle were attached to the mixer and mixed for a period of two minutes.

6. At the end of the mixing period, the mix was transferred from the bowl to the insulated trough and placed back on the third ahelf of the oven. The purpose of the trough, of course, was to reduce the excessive segregation which could occur in a one-sized mix of this type.

7. While the mixture and trough were in the oven, the lower piston was inserted into the mold and a paper disc was placed above the piston.

8. When the mix and trough reached a temperature of $230 \pm 5^{\circ} \mathrm{F}$, the mixture was transferred from the trough into the mold in two equal layers. Each layer was rodded 40 times.

9. A paper disc was placed on top of the rodded mix and the upper piston was added. The mold was then placed in the compaction frame, with the vibrator resting above the upper piston.

10. A vertical lood of 600 pound wa applied with the hydraulic 
jack and the vibrator was started. With the vibrator operating continuously under an 80 psi pressure, the load was held at 600 pounds for 30 seconds and then increased to 12,600 pounds at a rate of 200 pounda per second. The 12,600 pound load was held constant for one minute, after which the vibrator was stopped and the load released.

11. The specimen was left in the mold for 24 hours before belng extruded 1nto a Marshall mold. After the extrusion process, the specimen was laid on its side in one half of a 4-inch diameter split mold. Steel pistons were also placed in the mold at each end of the specimen to prevent the compected mixture from slumping.

12. Approximately two hours before testing, the specimen was removed from the split mold and costed with a stiff mixture of limestone mineral filler and water. For one group of specimens, the entire surface of the specimen was coated. For a second group, only the lateral surface was coated.

\section{Hveem Stabilometer Tests}

The equipment used to conduct Hveem Stabilometer tests in this investigation is outlined below:

1. Hveem Stabllometer test cell, follower-piston, and dumy metal specimen.

2. Riehle testing machine $(50,000$ pound capacity) with varlable speed drive.

3. 10,000 pound proving ring.

4. Dial indicator, 0.001 inch scale divisions, 2-1nch movement.

5. Dial indicator support bracket.

6. Thermometer.

7. 12-1nch scale. 
The method of conducting a Hveem Stabilometer test as used in this study can be described as follows:

1. Prior to the test, the helght of the specimen was obtalned with a dial indicator fastened to a support bracket. The helght of the specimen was determined by flrst referring the indicator dial reading to a known helght and then taking a dial reading on the actual test specimen.

2. For tests in which deformation measurements were recorded, the 10,000 pound proving ring was bolted to the upper platen of the testing machine and the deflection Indicator dial was bracketed to the machine to measure the distance travelled by the upper platen during the test.

3. The adjustable Stabilometer base was set so as to provide an effective contact height of 2.4 inches between the rubber diaphragm and the specimen.

4. The Stabilometer was calibrated with the dumy metal specimen and the desired quantity of air was admitted to the oil chamber through the needle valve. Because this quantlty of alr was varied for several tests, the initial displacement measurement ranged from 1.00 to 5.00 turns.

5. The test specimen was placed instde the Stabllometer cell whlch, in turn, was positioned in the testing machlne.

6. The testing machine was started and the speed set at 0.05 inches per minute. The Stabliometer displacement pump was turned laward to increase the lateral pressure to $5 \mathrm{ps}$. prior to the start of the test. 
7. Load was measured with a proving ring or by the welgh beam of the test machine.

a. When deformation measurements were being taken, the upper platen of the testing machine was lowered unt1l a small seating load was recorded on the proving ring indicator dial. The deflection indicator dial was then set to read zero.

b. For tests involving no deformation messurements, vertical load readings were taken with the calibrated beam of the testing machine. This beam was balanced to read zero at the start of each test with the Stabilometer reating on the lower platen.

8. The vertical load was applied and carrled to 6000 pounds. a. When strain values were desired, lateral pressure and deformation dial readings were recorded at incremental vertical loads of 250 pounds.

b. When deformations were not recorded, lateral pressure readings were taken at vertical loads of 500, 1000, 2000, 3000, 4000, 5000 , and 6000 pounds.

9. At the instant the 6000 pound load was reached, the testing machine was turned off and the load reduced to 1000 pounds. The lateral pressure was backed off with the displacement pump to a reading slightly below $5 \mathrm{psi}$, and then returned to the $5 \mathrm{ps} 1$ pressure.

10. The final displacement measurement was recorded as the number of turns of the displacement pump needed to increase the lateral pressure reading from 5 psi to 100 psi.

11. The 1000 pound lood was then removed, the room temperature recorded, and the specimen taken out of the stabllometer. 
APPENDIX B

DATA 


\section{APPENDIX B}

\section{DATA}

Stabilometer test results for specimens of mixtures A, B, C and D are tabulated in this section. Properties listed here include the following:

1. Per cent strain, $\epsilon$, st vert1cal loads of $500,1000,2000,3000$, 4000,5000 , and 6000 pounds.

2. Lateral pressure, $P_{h}$, in pounds per square inch, at vertical loads of $500,1000,2000,3000,4000,5000$, and 6000 pounds.

3. Deviator stress, $P_{v}-P_{h}$, in pounds per square inch, at vertical loads of 500, 1000, 2000, 3000, 4000,5000, and 6000 pounds.

4. Final displacement measurement, $D_{2}$, in the unit of turns.

5. Hveem stability number, $S$, as calculated from the equation

$$
S=\frac{22.2}{\frac{P_{h} D_{2}}{P_{v}-P_{h}}+0.222} \text {. }
$$




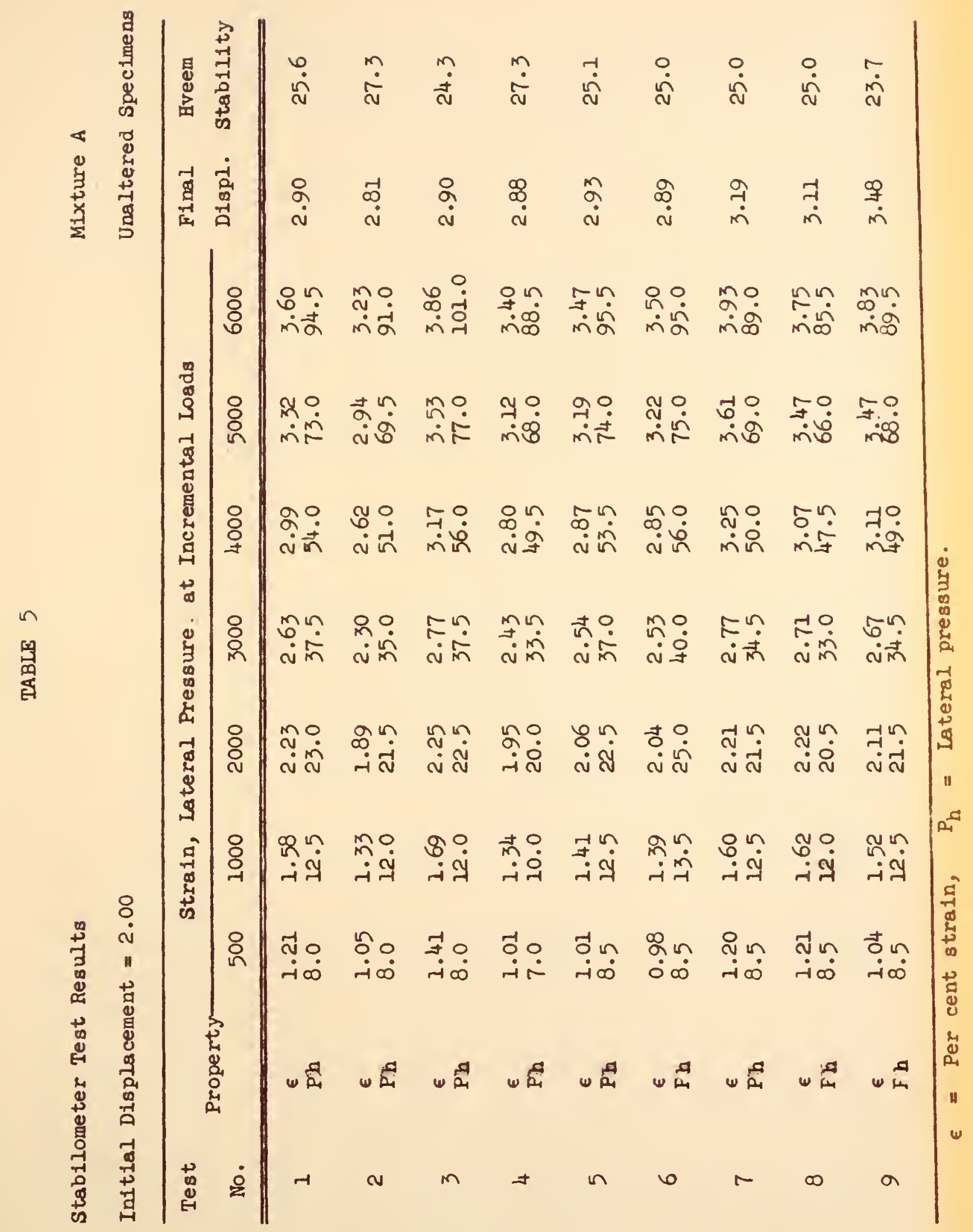




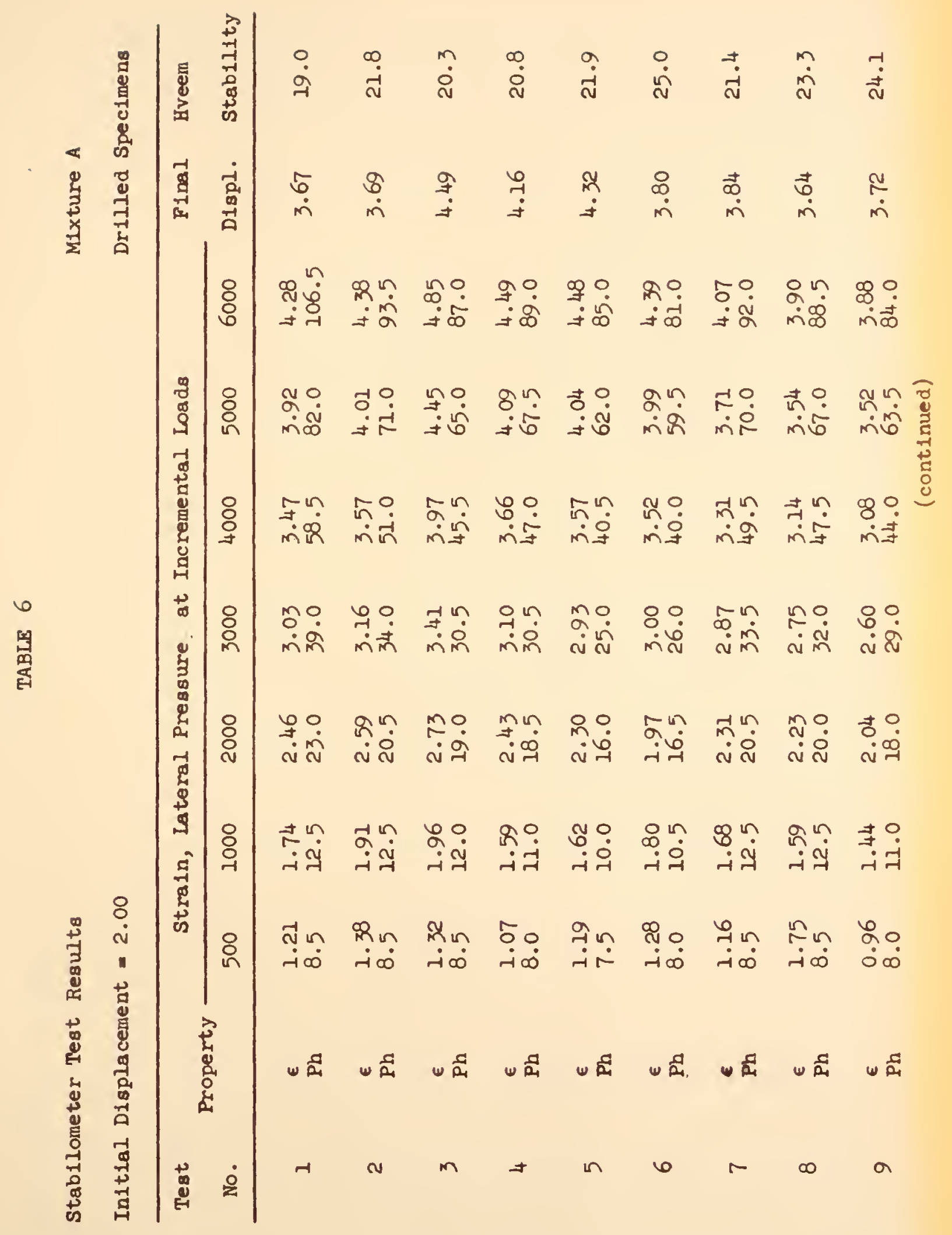




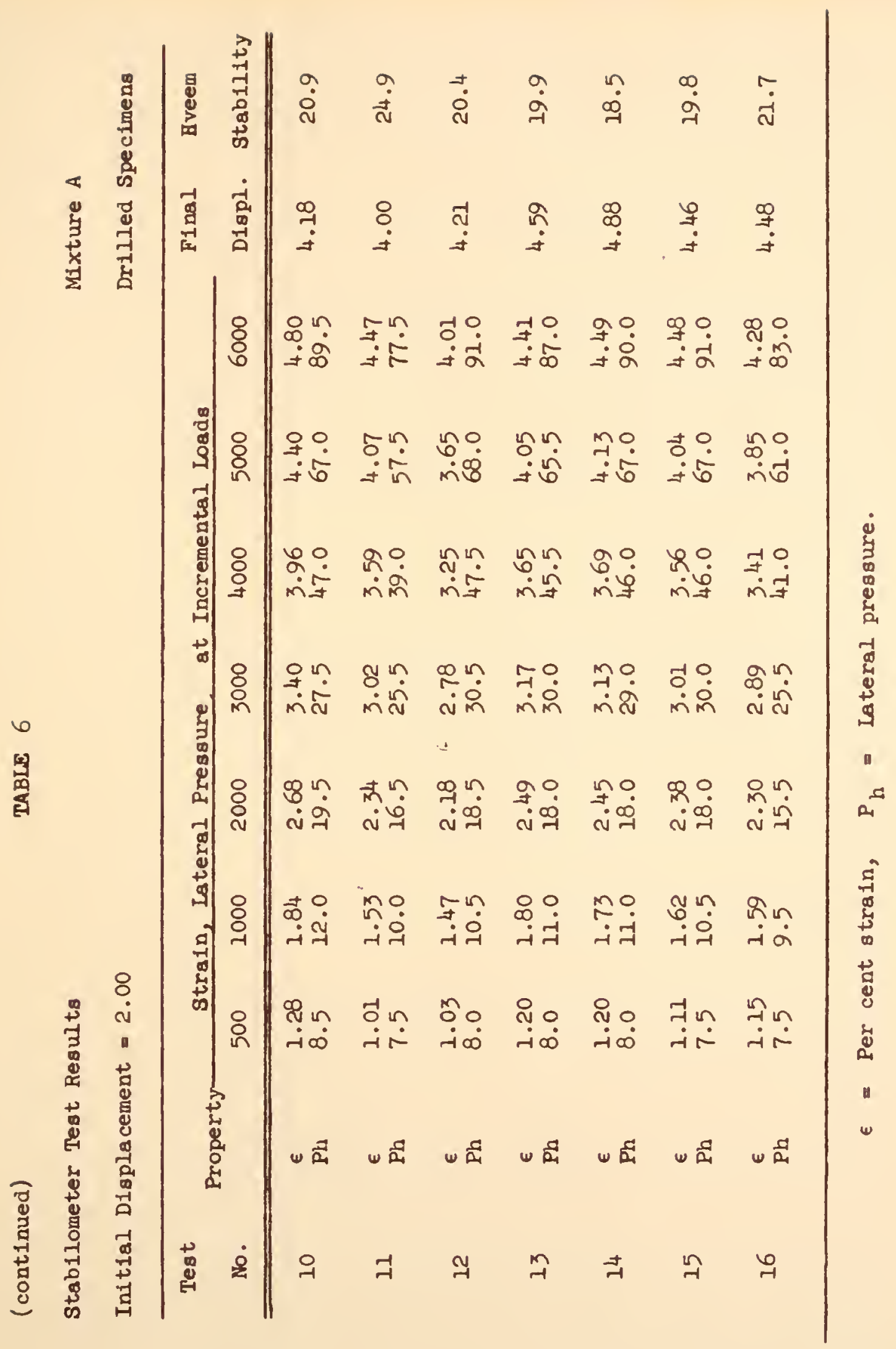




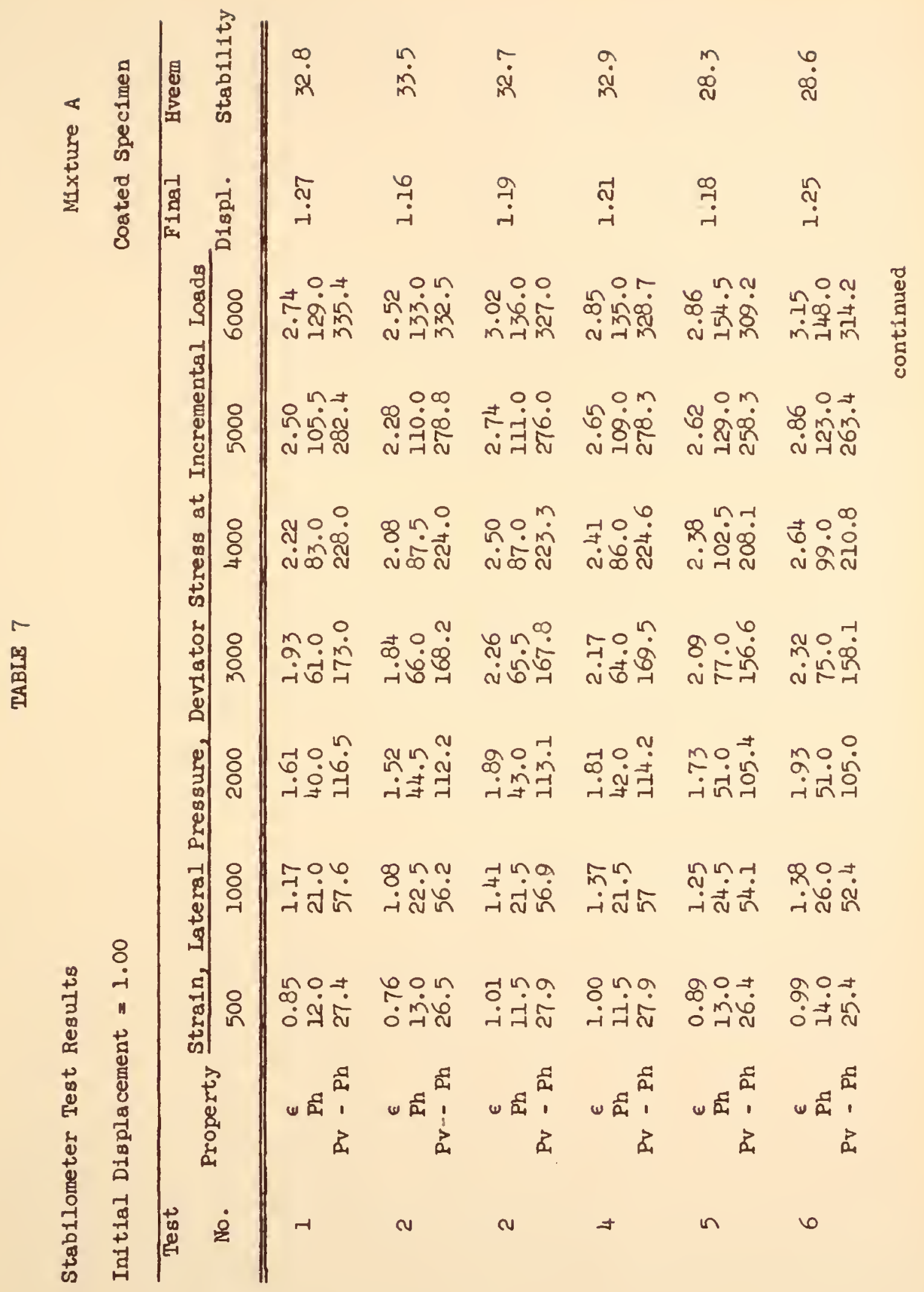




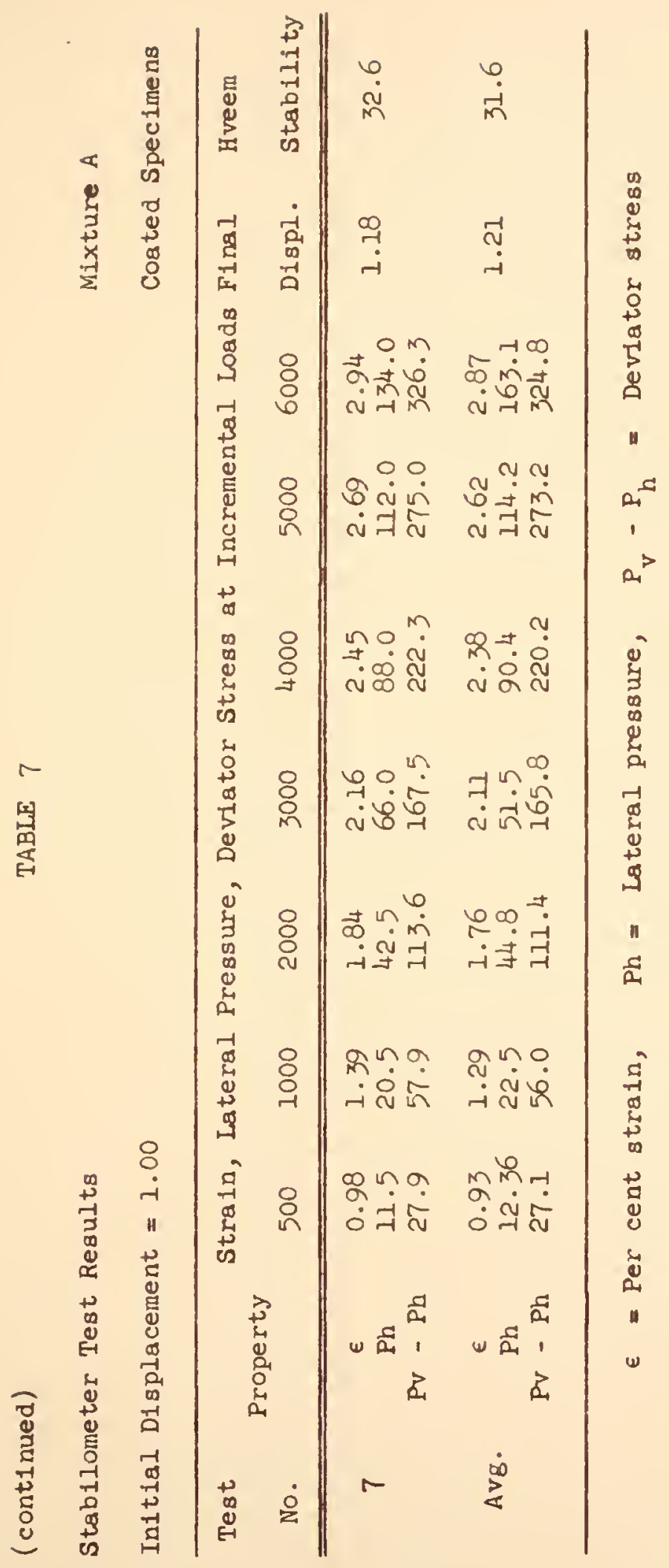




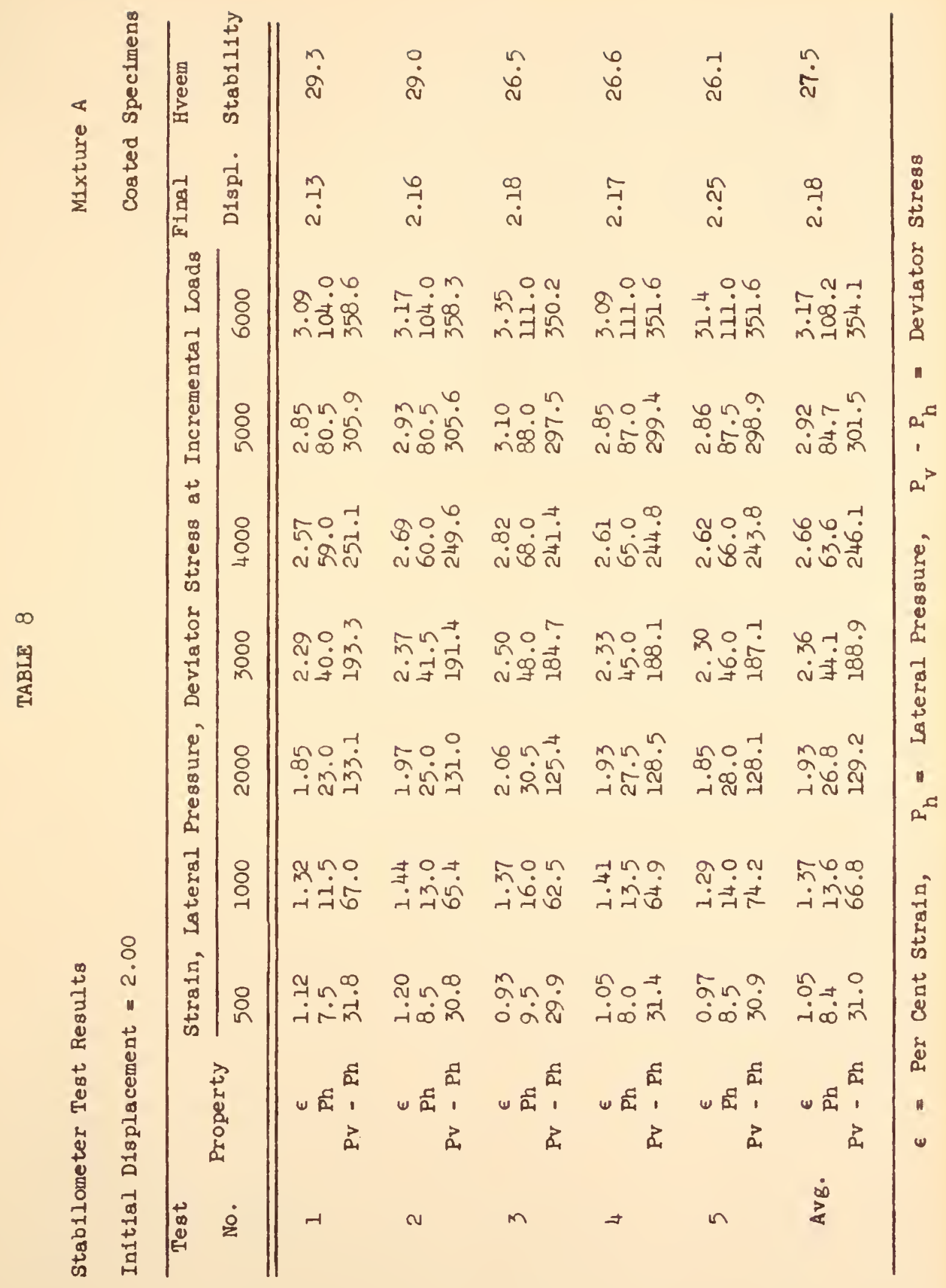




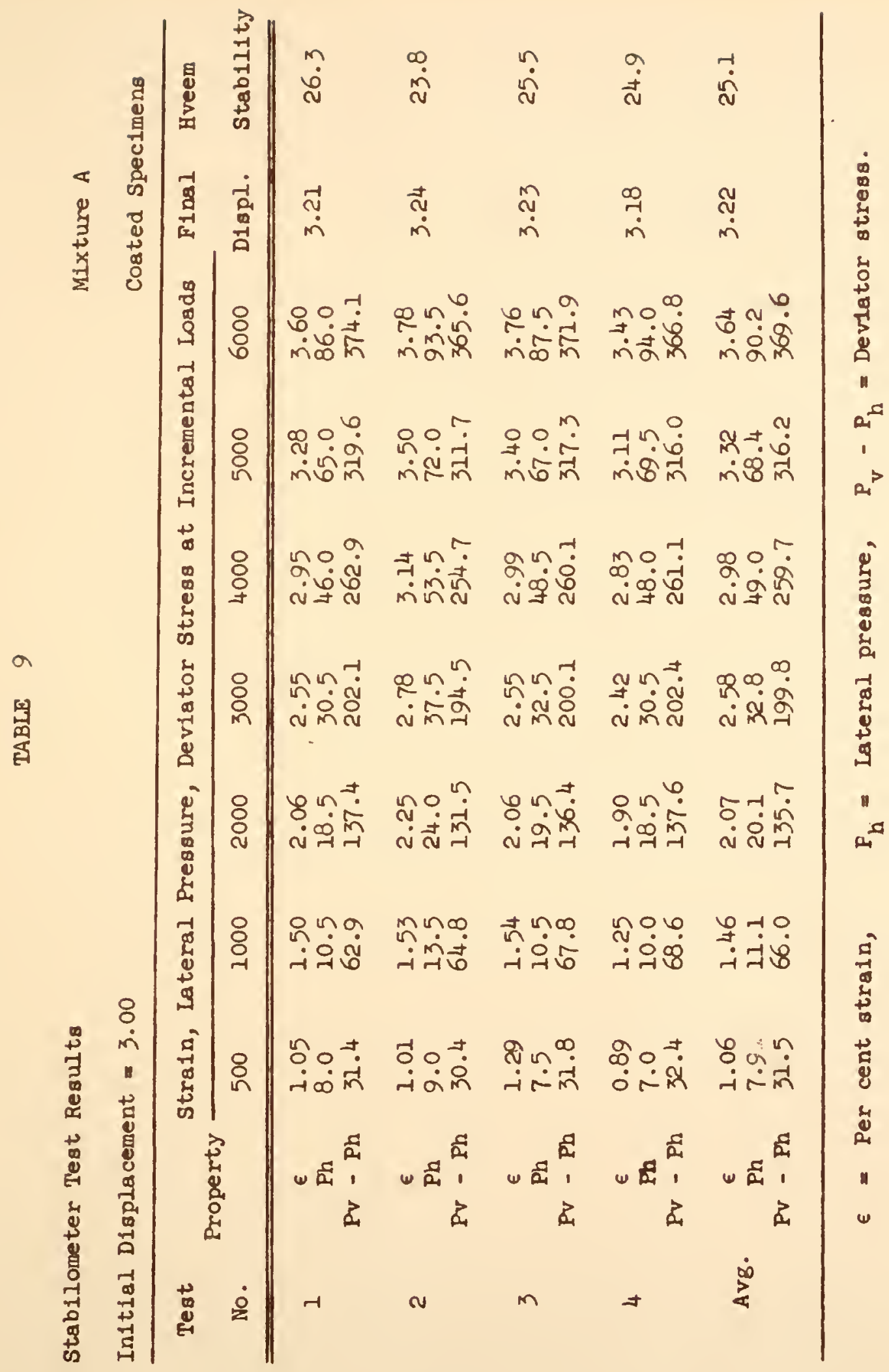




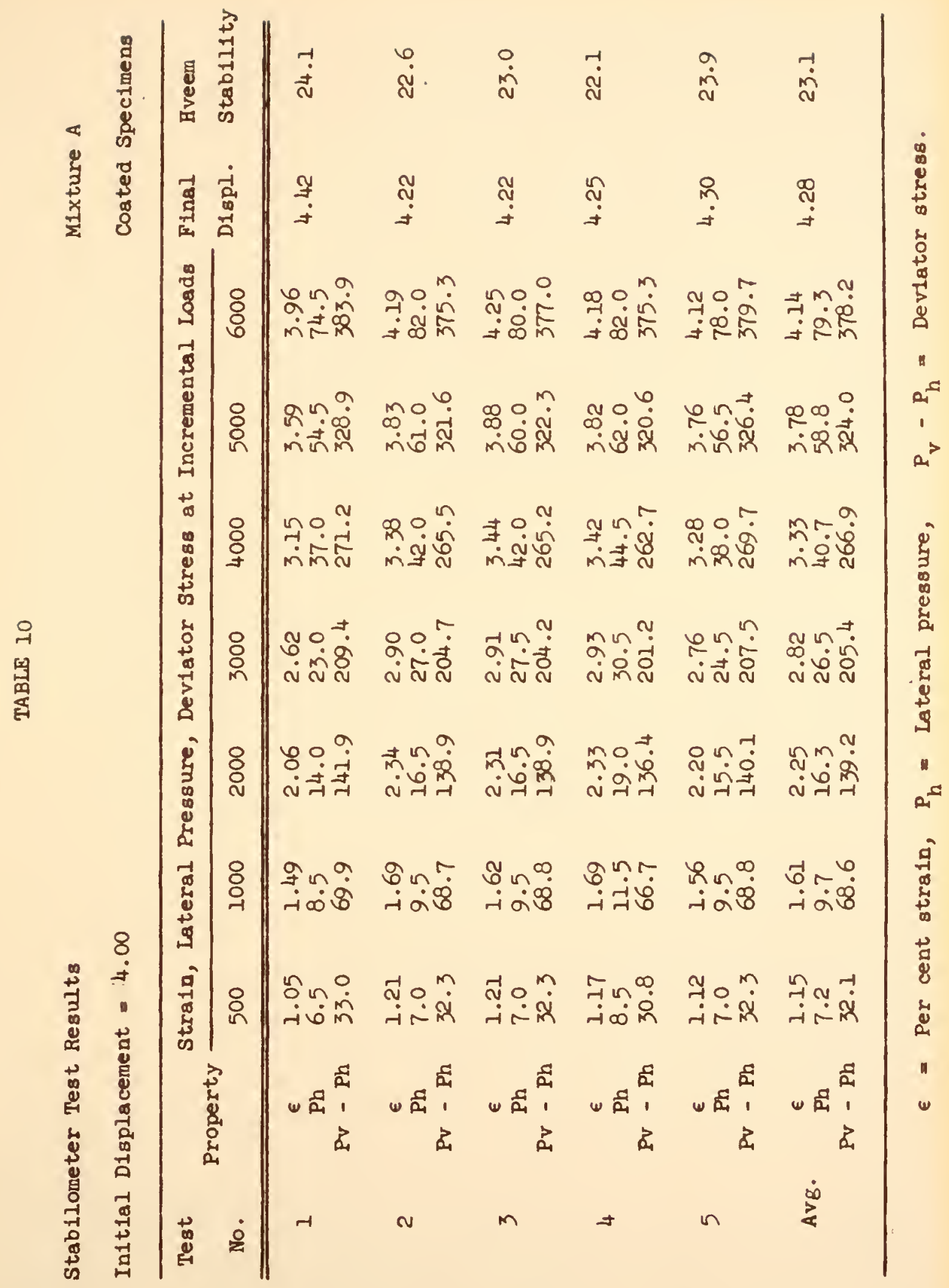




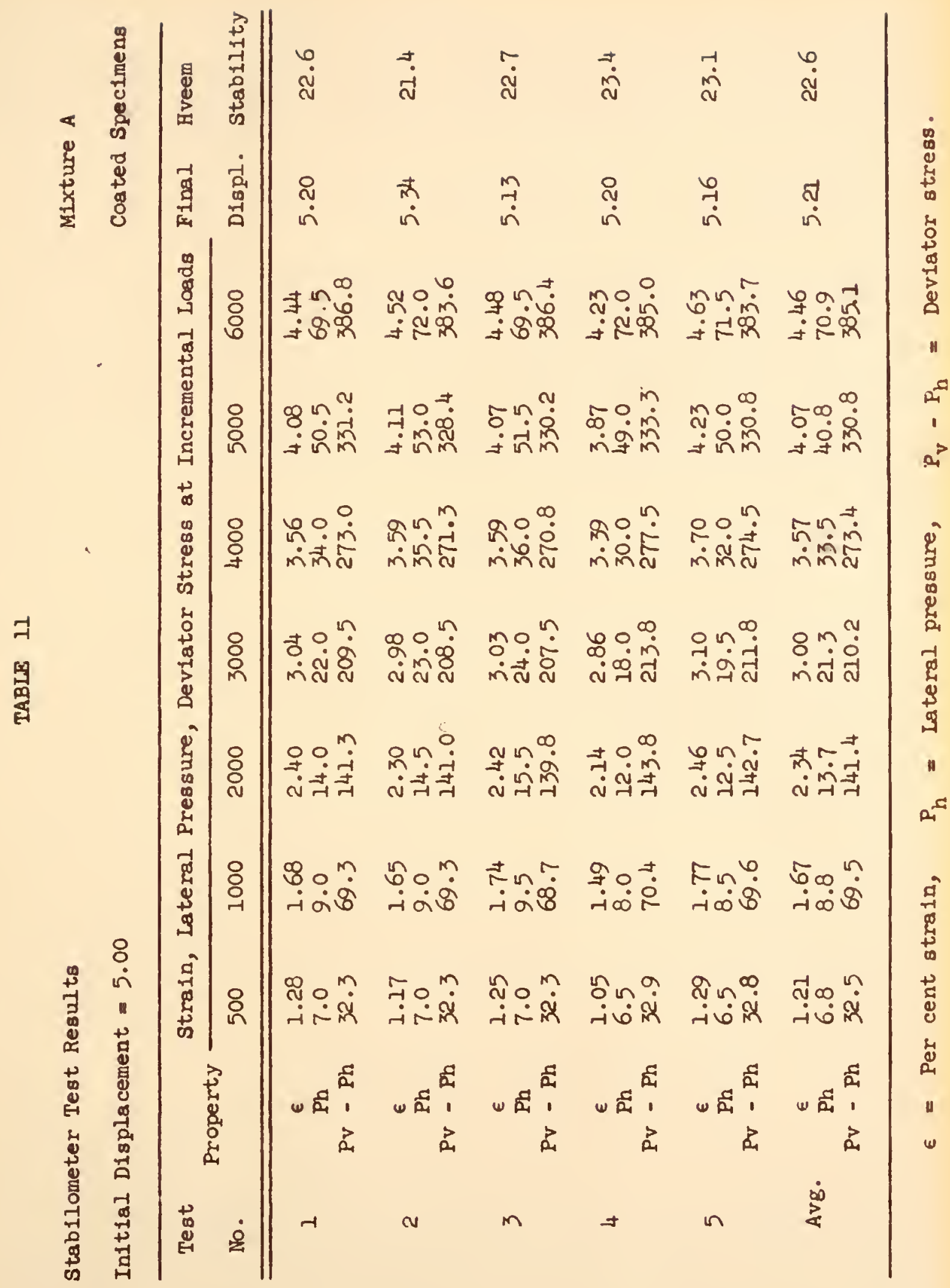




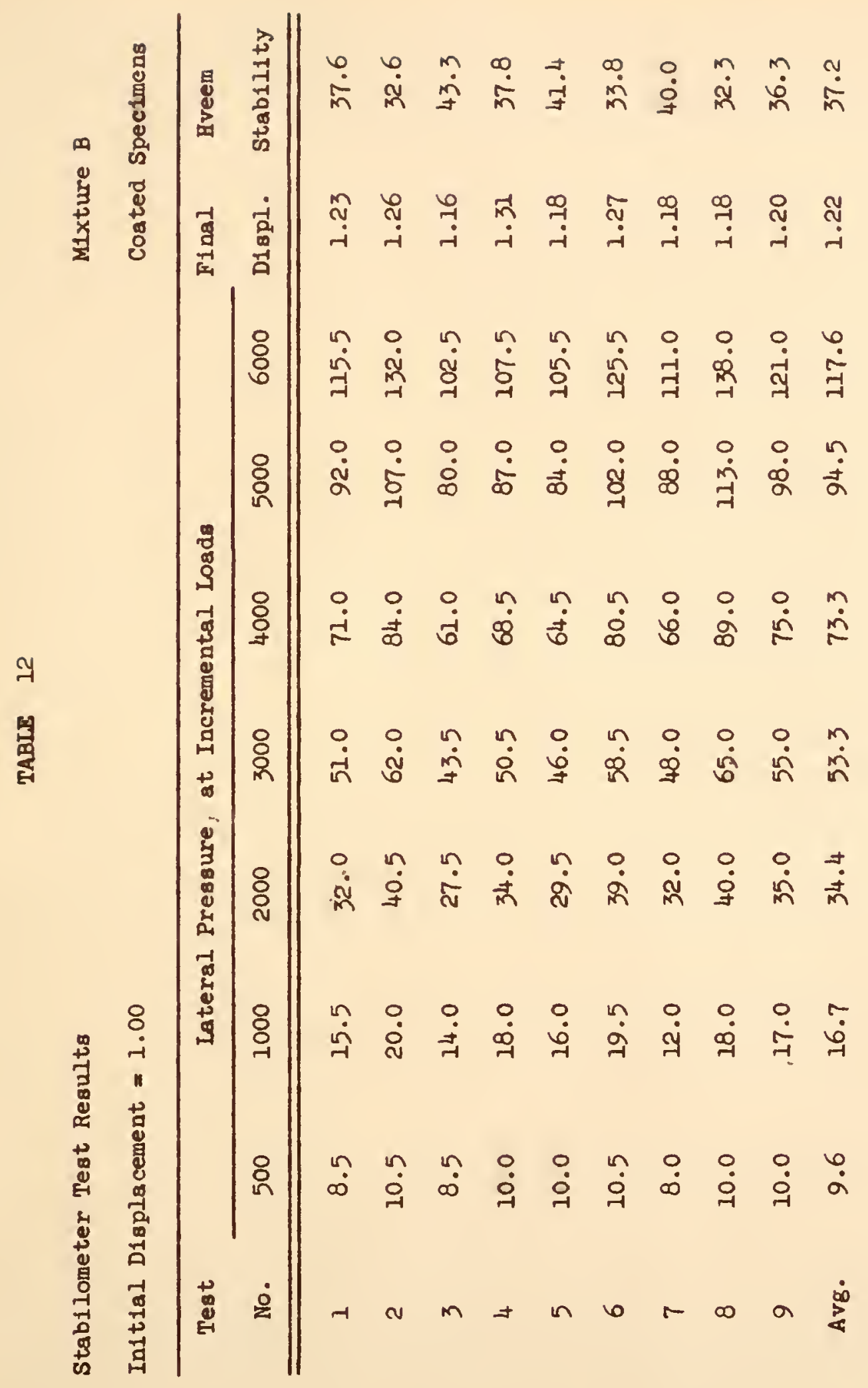




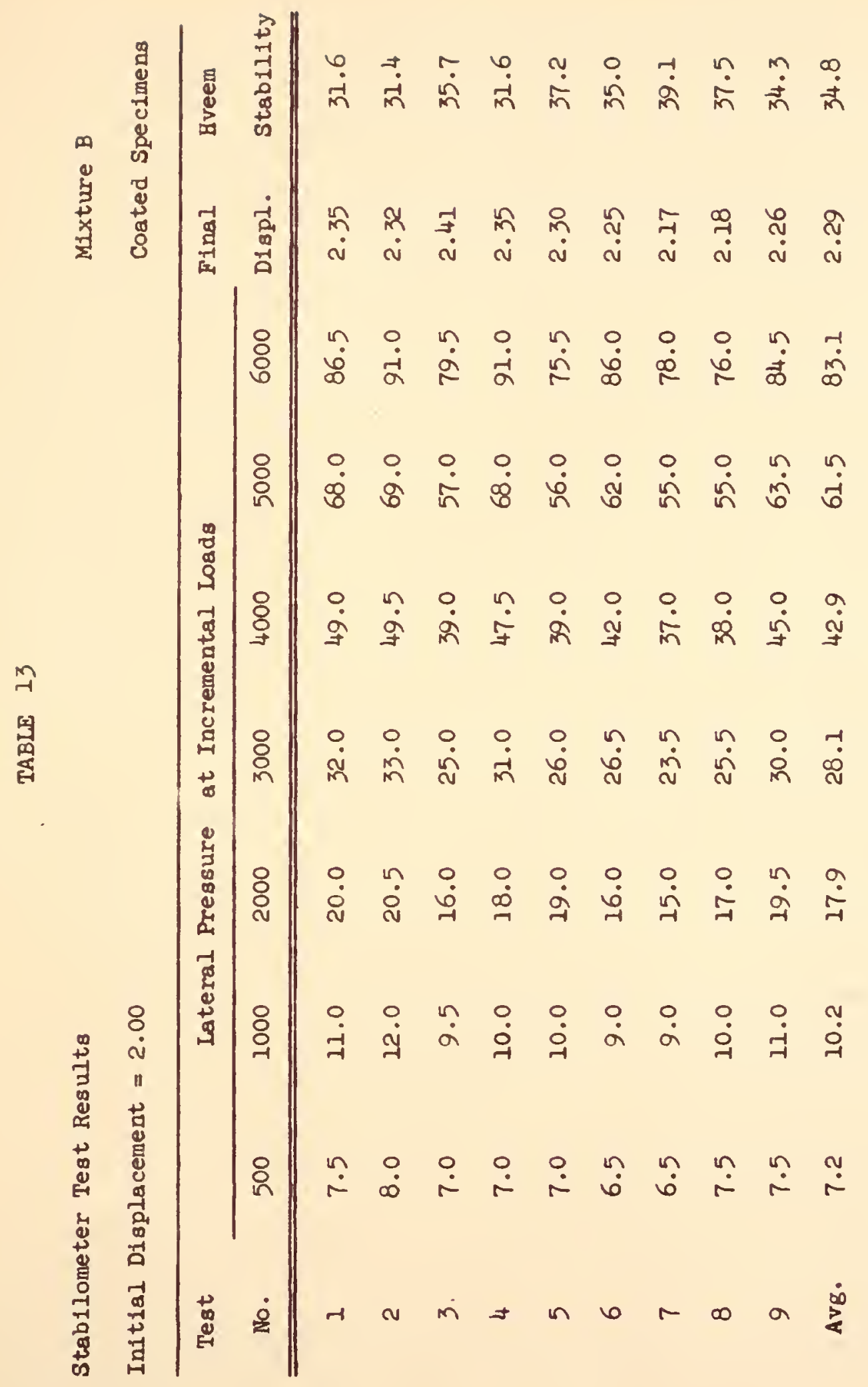




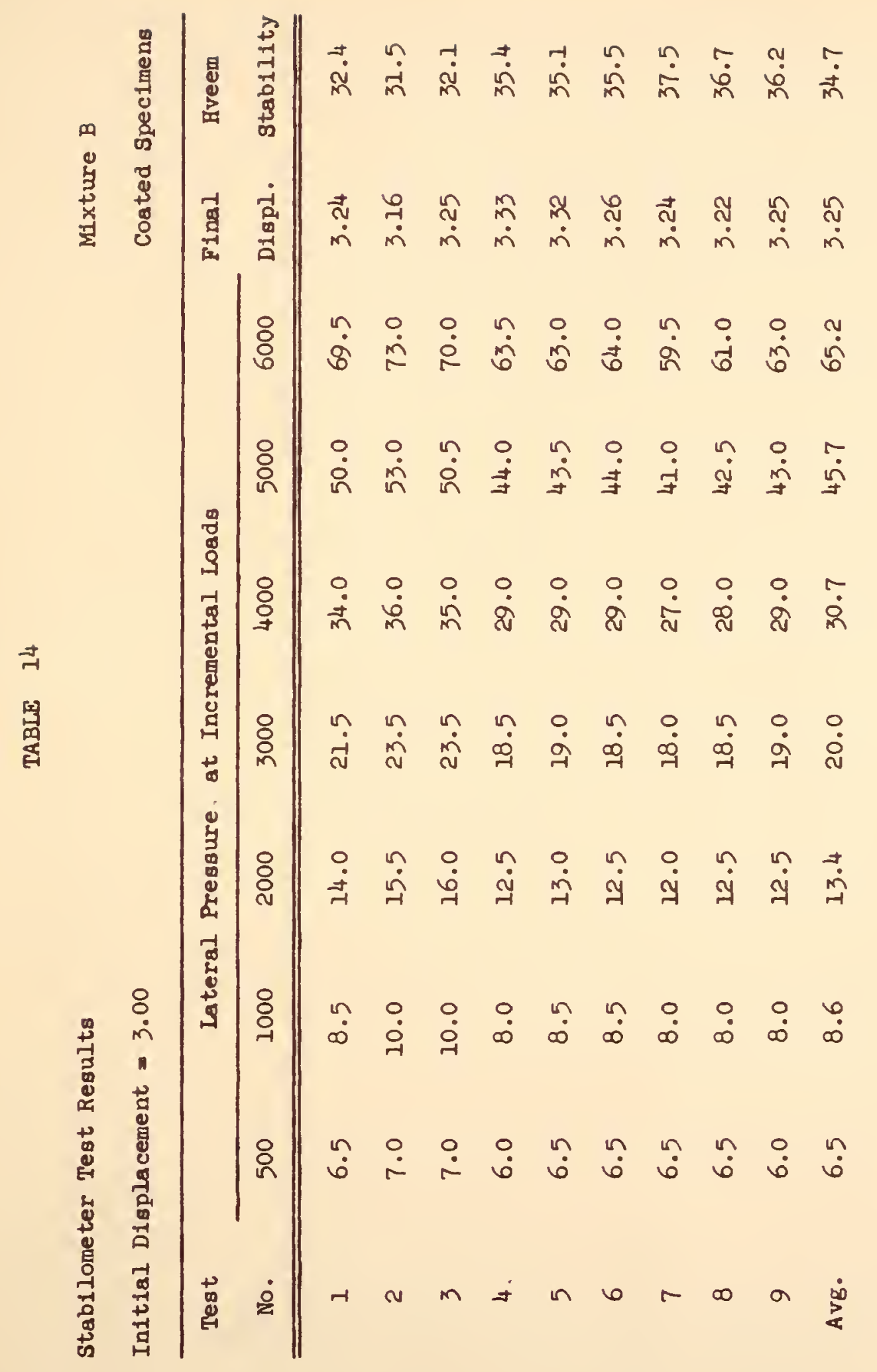




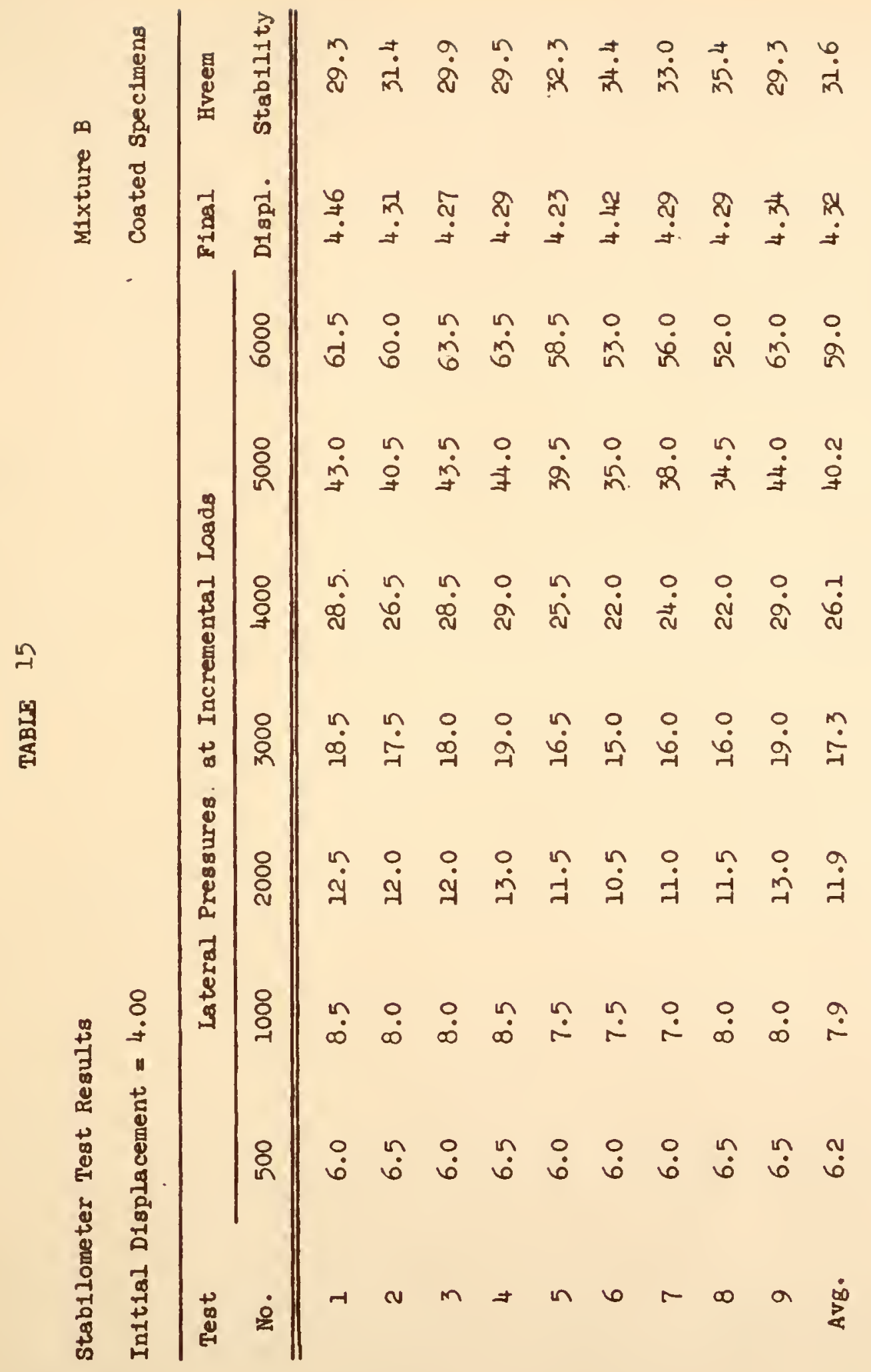




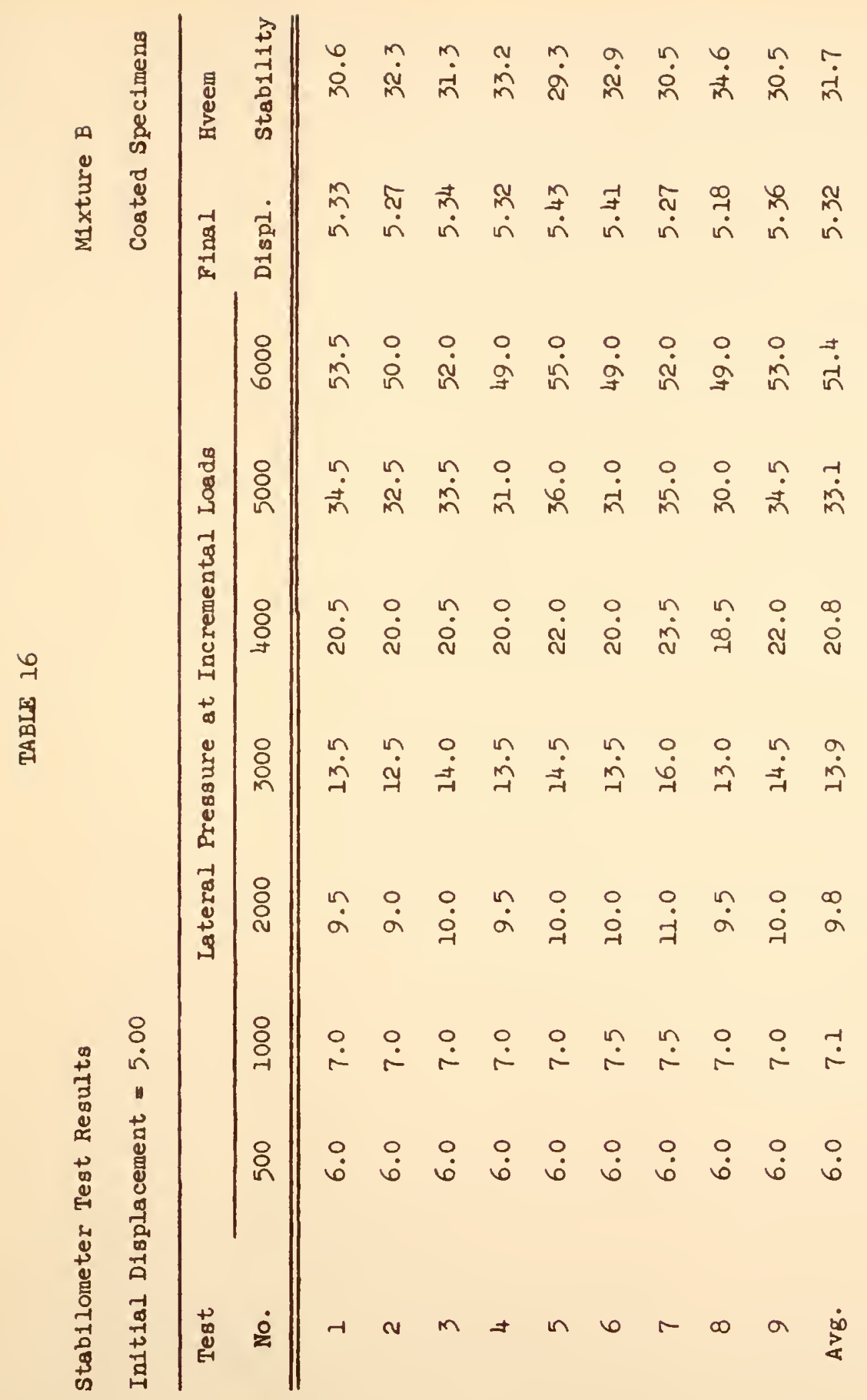




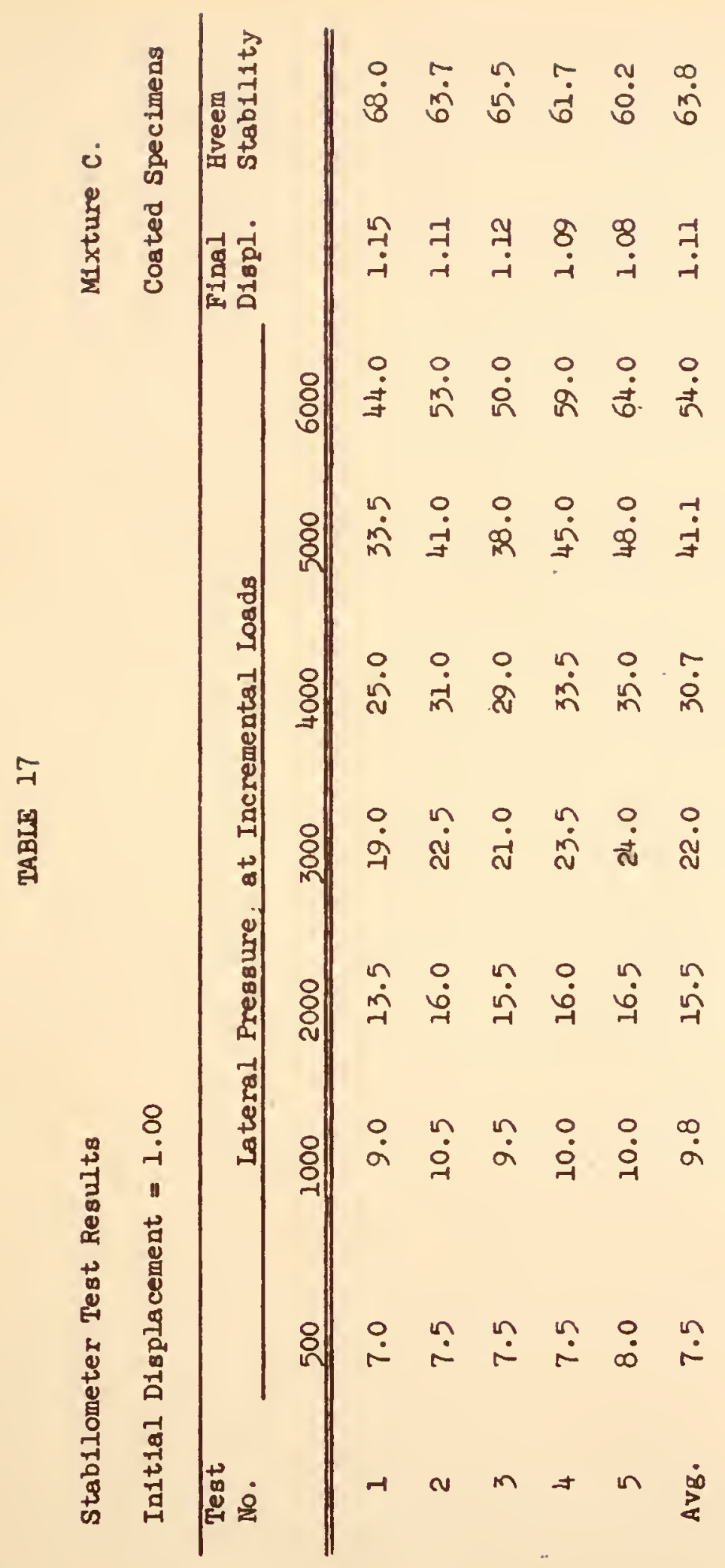




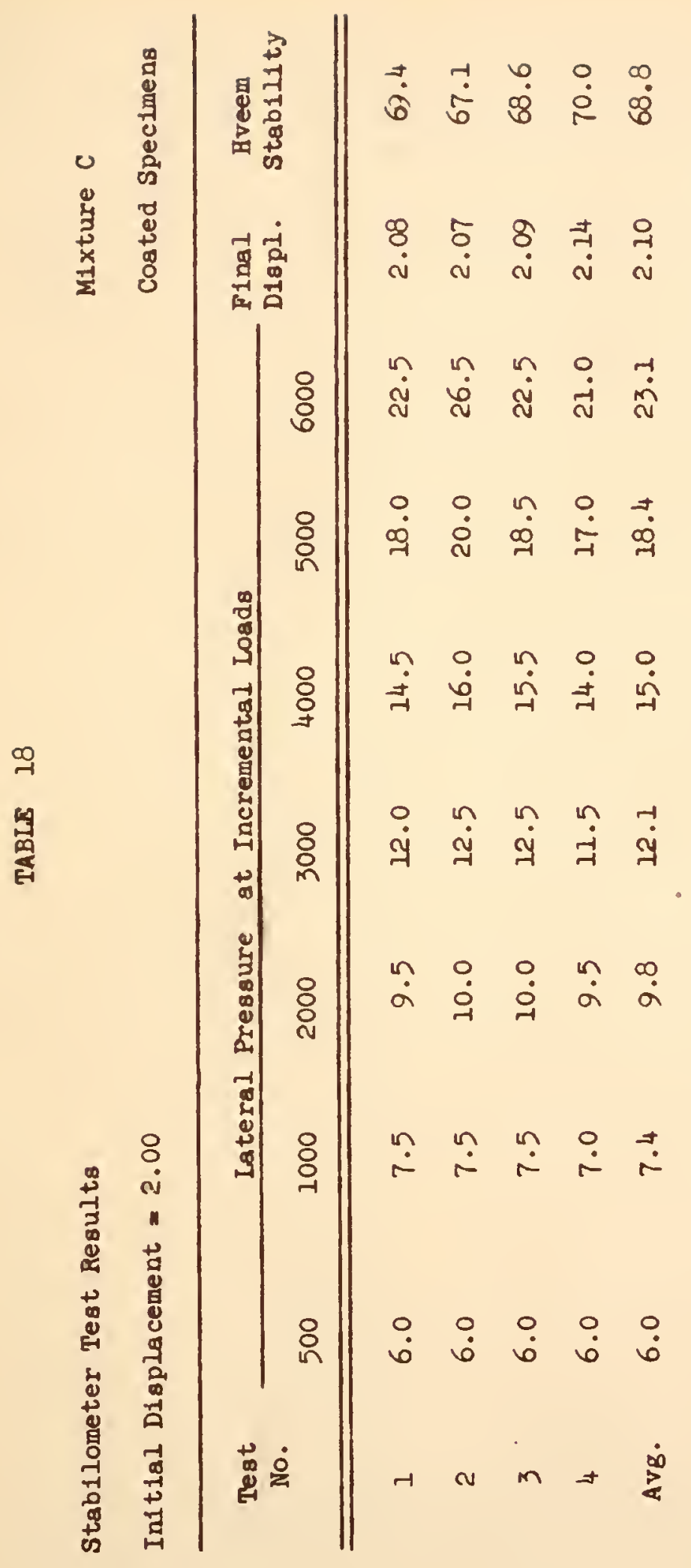




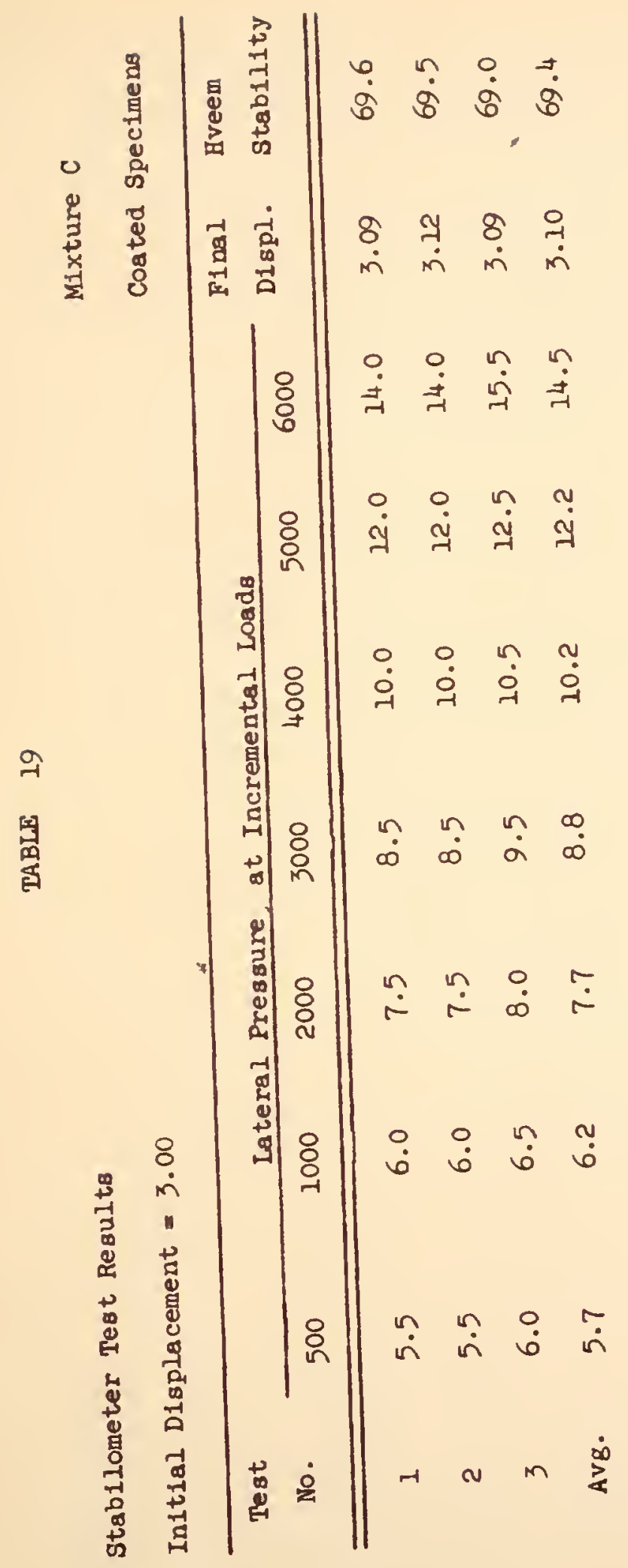




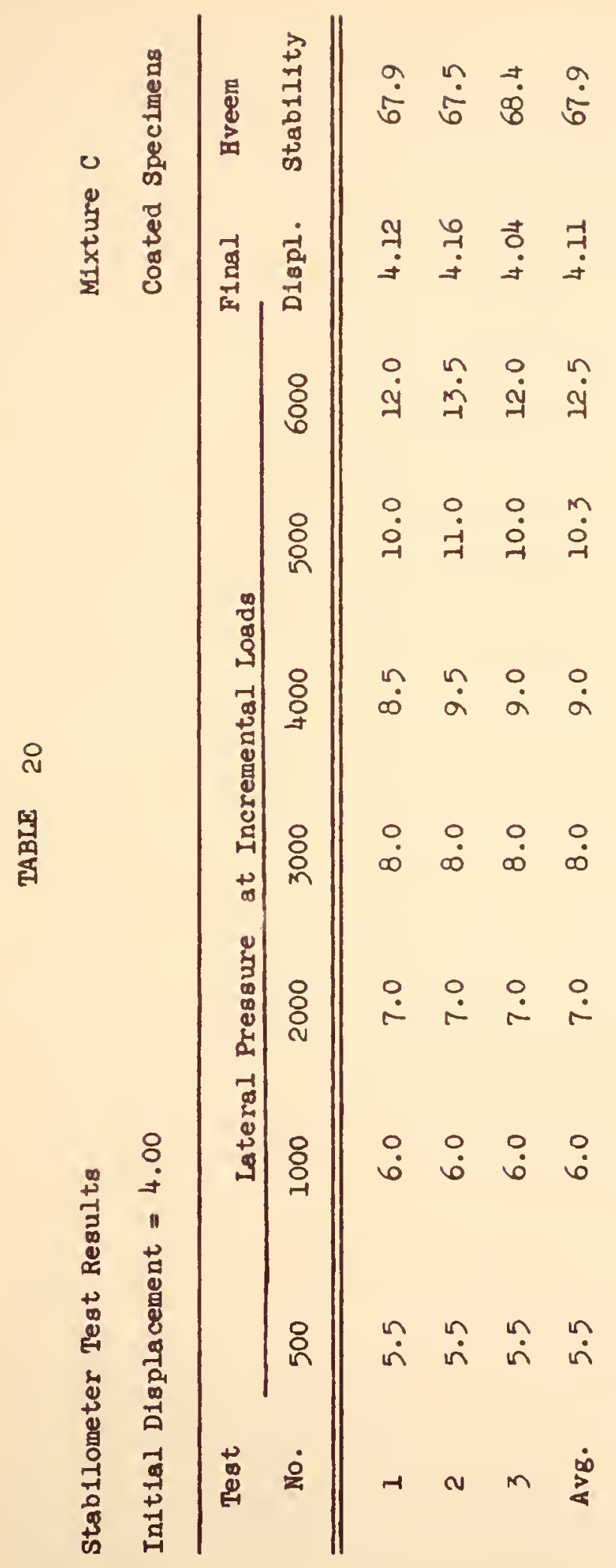




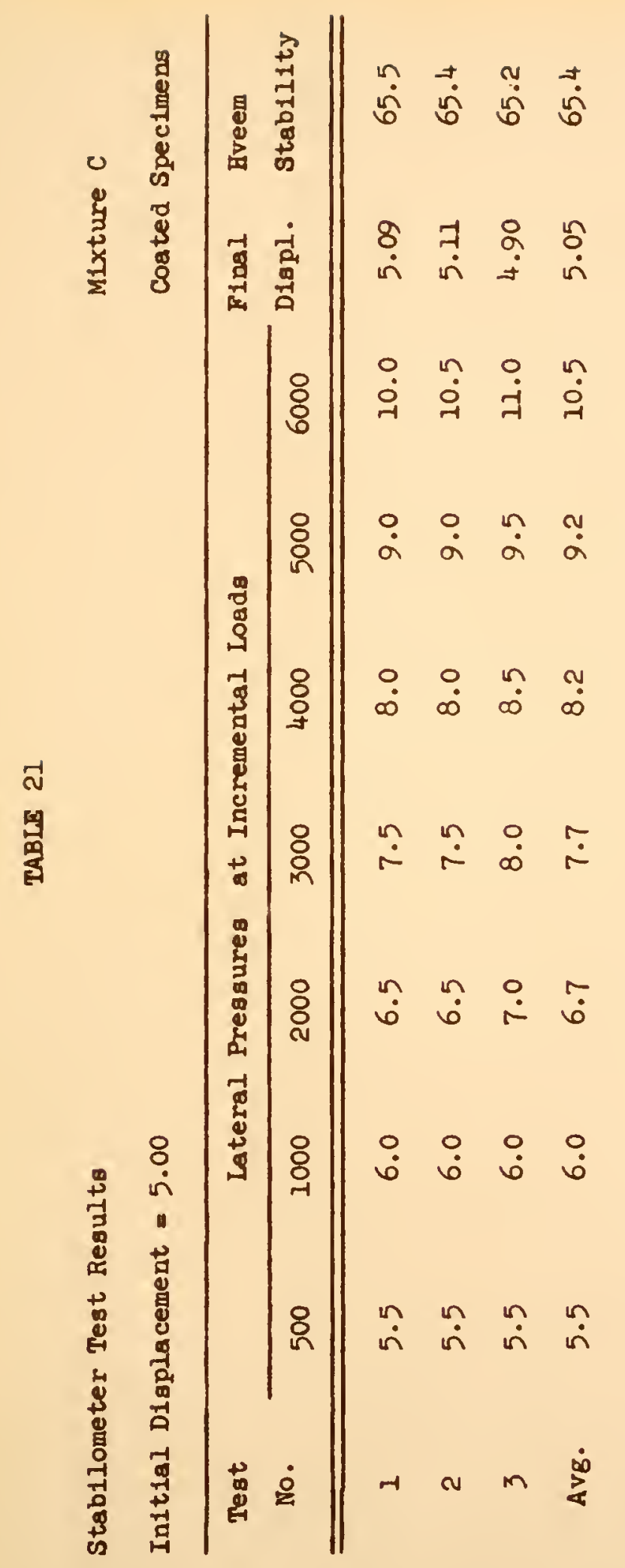




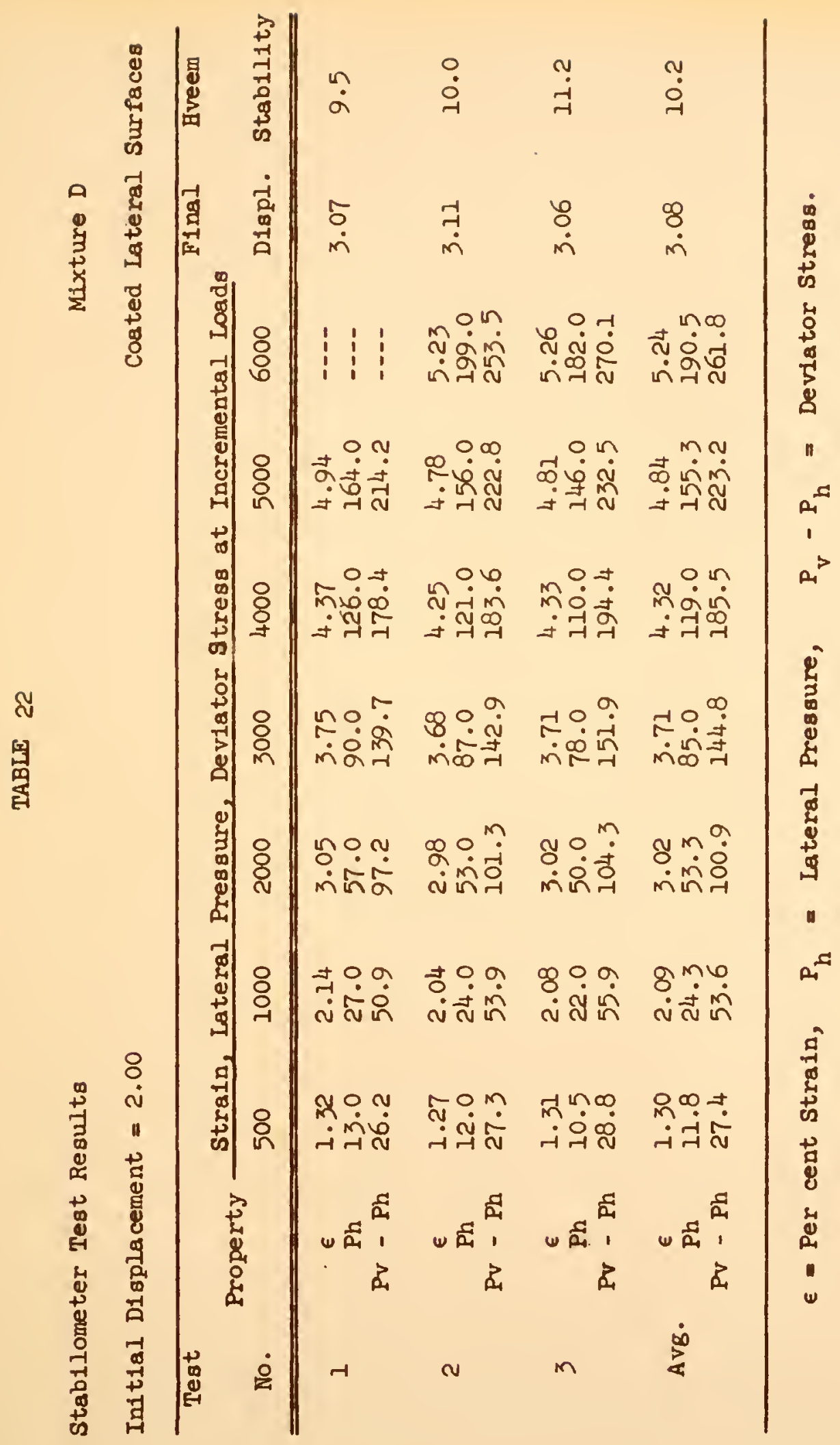




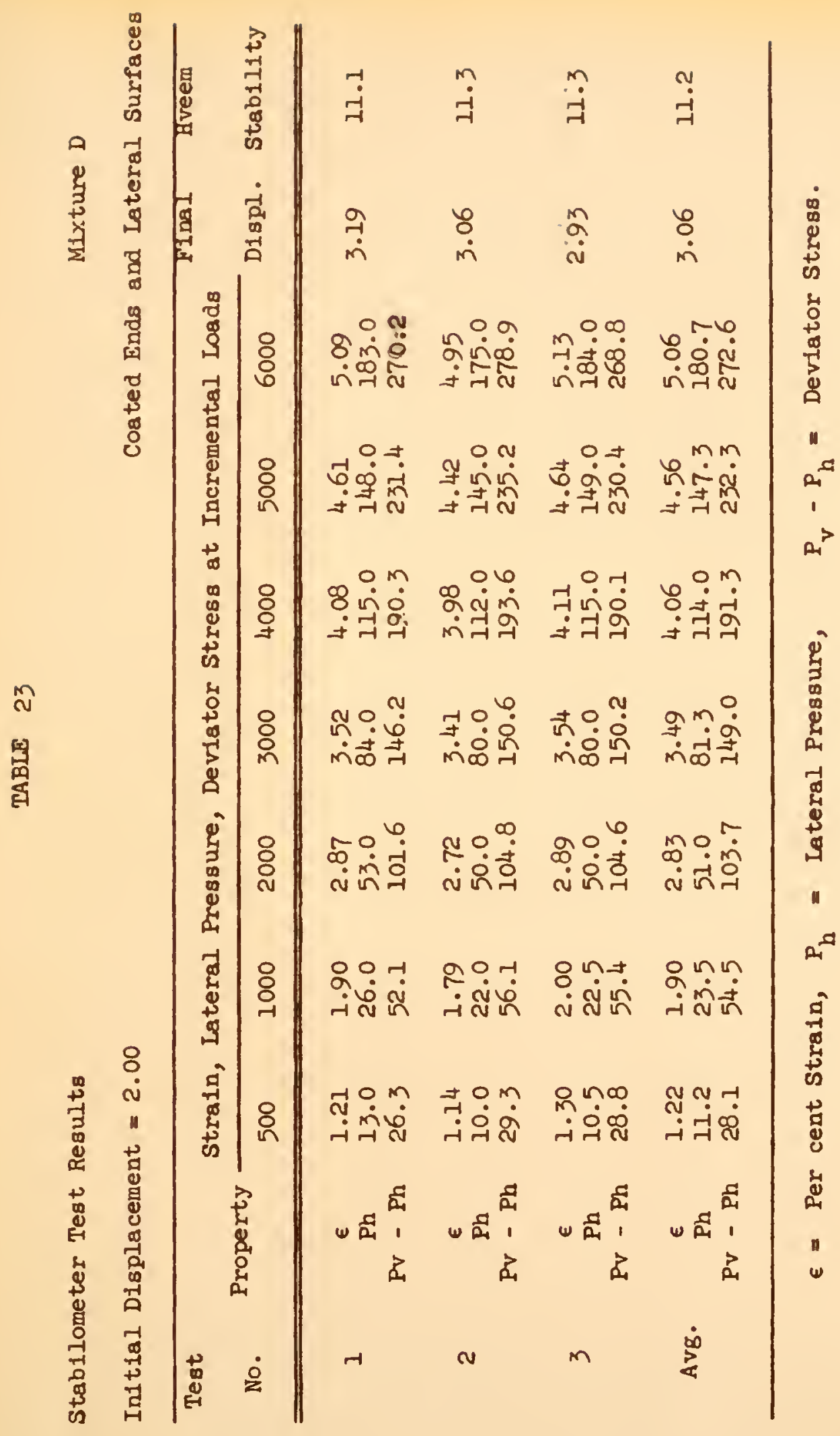


APPENDIX C

STATISTICAL COMPARISON OF MEAN STABILITY VALUES FOR SPECIMENS OF MIXTURE D, WITH AND WITHOUT COATED ENDS 


\section{APPENDIX C}

STATISTICAL COMPARISON OF MEAN STABILITY VAUUES FOR SPECIMENS OF MIXTURE D, WITE AND WITHOUT COATED ENDS

\section{Coated Ends}

$$
\begin{aligned}
& n_{1}=3 \\
& x_{1}=11.1,11.3,11.3 \\
& \bar{x}_{1}=11.233 \\
& s_{1}^{2}=0.013
\end{aligned}
$$

\section{Unaltered Ends}

$$
\begin{aligned}
& n_{2}=3 \\
& x_{2}=9.5,10.0,11.2 \\
& \bar{x}_{2}=10.233 \\
& s_{2}^{2}=0.774
\end{aligned}
$$

Testing for equality of variances,

$$
\begin{array}{ll}
\mathrm{H}_{0}: \sigma_{1}^{2}=\sigma_{2}^{2} & \alpha=.05 \\
\mathrm{H}_{1}: \sigma_{1}^{2}<\sigma_{2}^{2} & f_{1}=f_{2}=2 \\
\frac{s_{1}^{2}}{s_{2}^{2}}=59.538 & \\
F_{(.05,2,2)}=10.000<59.538 &
\end{array}
$$

Reject $H_{0}$ and conclude that $\sigma_{1}^{2}<\sigma_{2}^{2}$ at $5 \%$ level of significance.

Comparing mean stabllity values,

$$
\begin{aligned}
& \mathrm{B}_{0}: \mu_{1}=\mu_{2} \\
& \alpha=.05 \\
& \mathrm{H}_{1}: \mu_{1}>\mu_{2} \\
& f=\frac{\left(\frac{s_{1}^{2}}{n_{1}}+\frac{s_{2}^{2}}{n_{2}}\right)^{2}}{\left.\frac{s_{1}^{2}}{n_{1}}\right)^{2}+\left(\frac{s_{2}^{2}}{n_{1}+1}\right)^{2}}-2=2.13
\end{aligned}
$$




$$
\begin{aligned}
& t=\frac{\left(\bar{x}_{1}-\bar{x}_{2}\right)-\left(\mu_{1}-\mu_{2}\right)}{\sqrt{\sqrt{\frac{s_{1}^{2}}{n_{1}}+\frac{s_{2}^{2}}{n_{2}}}}}=1.99 \\
& t(.05,2.13)=2.43>1.99
\end{aligned}
$$

Accept $H_{0}$ and conclude that $\mu_{1}=\mu_{2}$ at $5 \%$ level of significance. 